\title{
Experimental Designs for Testing Differences in Survival Among Salmonid Populations
}

\section{Technical Report}

1993

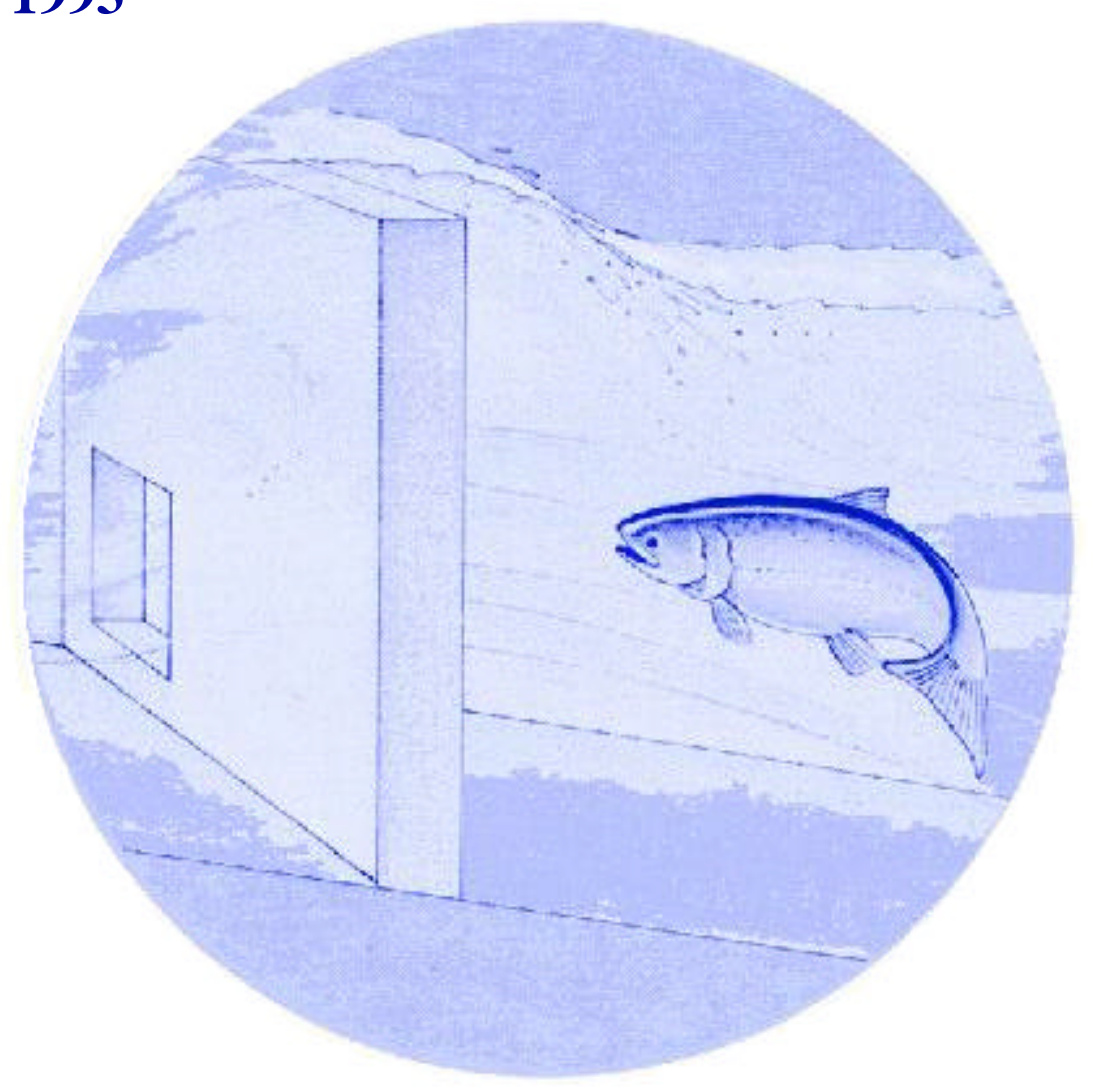

DOE/BP-00029-3

November 1994 
This Document should be cited as follows:

Busack, Craig, Annette Hoffman, Curt Knudsen, "Experimental Designs for Testing

Differences in Survival Among Salmonid Populations", Project No. 1985-06200, 82

electronic pages, (BPA Report DOE/BP-00029-3)

\author{
Bonneville Power Administration \\ P.O. Box 3621 \\ Portland, Oregon 97208
}

This report was funded by the Bonneville Power Administration (BPA), U.S. Department of Energy, as part of BPA's program to protect, mitigate, and enhance fish and wildlife affected by the development and operation of hydroelectric facilities on the Columbia River and its tributaries. The views in this report are the author's and do not necessarily represent the views of BPA. 


\title{
EXPERIMENTAL DESIGNS FOR TESTING DIFFERENCES IN SUR VIVAL AMONG SALMONID POPULATIONS
}

\author{
Prepared by: \\ Annette Hoffman \\ Associated Western Universities \\ and \\ Craig Busack \\ Curt Knudsen \\ Washington Department of Fisheries and Wildlife
}

Prepared for:

U. S. Department of Energy

Bonneville Power Administration

Environment, Fish and Wildlife

P.O. Box 3621

Portland, OR 97208-3621

Project Number 85-062

Contract Number DEAI79-93BP00029

November 1994 


\section{EXECUTIVE SUMMARY}

Testing differences in survival among salmonid populations is the primary objective of the Yakima Fisheries Project (YFP). Although this research was conducted to satisfy experimental needs of the YFP, the results are applicable to many fisheries studies with experimental objectives similar to those of the YFP. Implementation of the Yakima Fisheries Project (YFP) will include comparing the performance of spring chinook salmon raised under different treatments. In this report, performance was defined to reflect the harvest as well as the natural production objectives of the YFP and was measured by the number of successful fish. A successful fish was defined as one that either returned to the Yakima River basin to spawn or was recruited into a specified fishery.

We evaluated three alternative experimental designs for testing the effectiveness of a treatment to improve performance of spring chinook salmon. One of the designs is described in the Planning Status Report (PSR) (BPA 1993) of the YFP, and the other two are modifications of it. A key specification in the planning document for the YFP (BPA 1993), and which was used as a guideline to evaluate each design, was that a 50\% difference in survival between treatments should be detectable $90 \%$ of the time, i.e., with 90\% power. The simulation results showed that Design 3, described in the PSR (BPA 1993, Vol. 3 Chap. 6), yielded $90 \%$ power only under limited conditions. It performed the poorest because it could not account for all the sources of variation introduced by the physical layout of the acclimation ponds. The other two designs (Designs 1 and 2) could account for all the sources of variation and, therefore, were always more powerful. The difference between the other two designs was in how the fish were allocated. In Design 1 there were more ponds, and in Design 2 there were more fish per pond. The power assumption was met with Design 1 under the widest variety of conditions simulated. In particular, Design 1 yielded $90 \%$ power with sample sizes $66 \%$ smaller and with survival rates $33 \%$ smaller than those required by the other two designs. With a smaller sample size requirement, Design 1 is more likely to yield $90 \%$ power during the first few years when sample sizes are low. Likewise, with a smaller survival rate requirement, Design 1 will yield 90\% power in years when survival is low. Therefore, Design 1 was considered the most useful for the experimental objective of the YFP (BPA, 1993), and we recommend it over the other two designs.

Several factors independent of design also affected power and are applicable to fisheries studies other than the YFP. These factors included the number of smolts available for experimentation, smolt-adult survival rates, the number of treatments compared, and the sampling rate of the adult return. Power increased as the number of smolts available for experimentation increased, as the smolt:adult survival rate increased, as the sampling rate of the adult return increased, and as the number of treatments compared decreased. The relationships with survival and sampling rate were caused in part by the manner in which the data were simulated; that is, increases in the survival and sampling rate caused increases in the absolute difference in performance among treatments. As the absolute difference to be detected increased, the ease with which it was 
detected increased, and thus power increased. Because these relationships with survival and sampling rate depended on the simulation model, they should be applied only to those studies where the manner by which the data were simulated is thought to reflect reality. On the other hand, the relationships with the number of smolt and with the number of treatments are caused by sample size changes and are applicable to any study. 


\section{ACKNOWLEDGMENTS}

Support for this report came from the region's electrical ratepayers through the Bonneville Power Administration. We appreciate the input and direction received from Dr. Des Maynard (National Marine Fisheries Service), Dr. Lars Mobrand (Mobrand Biometrics) and Mr. Ron Costello (Northwest Water Resources Advisory Services). This report benefited from the technical review of Dr. John Thomas and from the editorial review of Nancy Peacock.. 


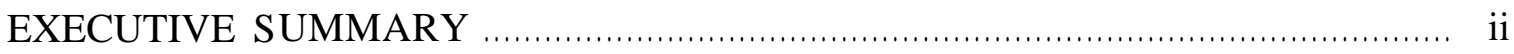

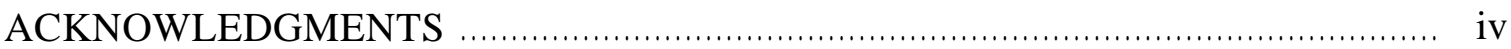

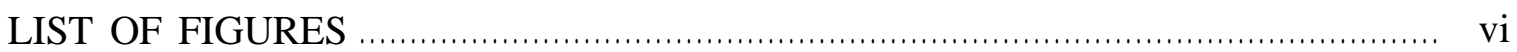

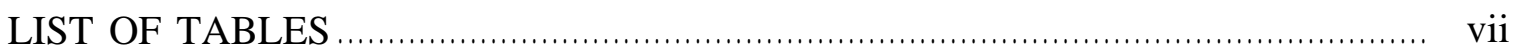

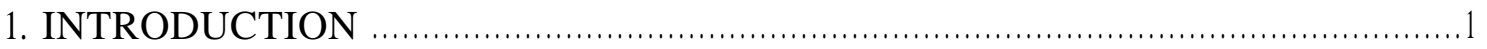

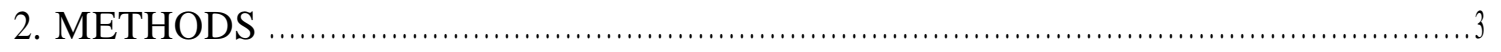

2.1 EXPERIMENTAL DESIGNS..........................................................................................

2.2 FACTORS From THE EXPERIMENTAL PROCEDURE CONSIDERED

TO HAVE EFFECTS ON SURVIVAL ..........................................................................5

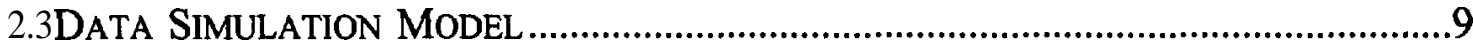

2.3.1 Factors Varied in the Simulations ................................................................. .11

2.3.2 Computational Details of the Simulations........................................................ 13

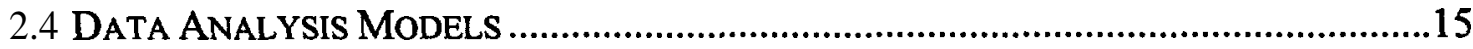

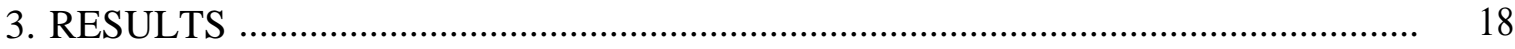

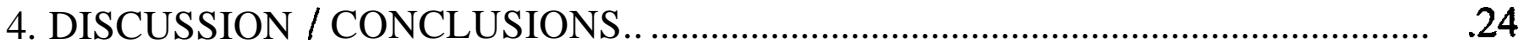

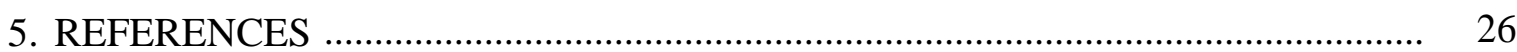

6. APPENDIX 1 - EQUIVALENCE BETWEEN AN INCREASE IN SCHOOL SIZE AND AN INCREASE IN THE MODELED BINOMIAL VARIANCE ................27

7. APPENDIX 2 - DETAILED SIMULATION RESULTS ................................... 28 


\section{List of Figures}

Figure 1. Yakima Fisheries Project location map (kindly furnished by CH2M Hill, Bellevue, Washington).

Figure 2. Schematic of the physical layout of experimental Design 1.

Figure 3. Schematic of the physical layout of experimental Design 2.

Figure 4. Schematic of the physical layout of experimental Design 3.

Figure 5. The major steps in the power analysis modeling process. 


\section{List of Tables}

Table 1. Description of either the values used or the random distribution from which values were drawn for the factors in the simulation.

Table 2. Power estimates for testing treatment effect at three different LNIT success rates.

Table 3. Power comparisons between Design 2 and Design 3.

Table 4. Experimental designs yielding $90 \%$ power. 


\section{INTRODUCTION}

The Yakima Fisheries Project (YFP) is a supplementation plan for enhancing salmon runs in the Yakima River basin (Figure 1). It is presumed that inadequate spawning and rearing habitat are limiting factors to population abundance of spring chinook salmon (Oncorhynchus tshawytscha). Therefore, the supplementation effort for spring chinook salmon is focused on introducing hatchery-raised smolts into the basin (BPA, 1993) to compensate for the lack of spawning habitat. However, based on empirical evidence in the Yakima basin (Fast et al. 1991, Pettit 1993), hatchery-reared salmon have survived poorly compared to wild salmon. Therefore, the YFP has proposed to alter the optimal conventional treatment (OCT), which is the state-of-the-art hatchery rearing method, to a new innovative treatment (NIT). The NIT is intended to produce hatchery fish that mimic wild fish and thereby to enhance their survival over that of OCT fish. A limited application of the NIT (LNIT) has also been proposed to reduce the cost of applying the new treatment, yet retain the benefits of increased survival. This research was conducted to test whether the uncertainty using the experimental design was within the limits specified by the Planning Status Report (PSR) (BPA 1993).

We directed the research effort in this report at analysis of a single year's experiment to ensure that the first year of experimentation will comply with project uncertainty specifications. The uncertainty associated with an outcome can be a Type I error (false positive, i.e., the treatment is concluded to be effective when in fact it is not) or a Type II error (false negative, i.e., the treatment is concluded to be ineffective when in fact it increases survival). The planning documents for the YFP (BPA, 1993) specify that neither the Type I nor the Type II error rates should exceed 10\%. The level of a Type I error is controlled by the significance level of the testing procedure. On the other hand, the Type II error rate is a function of uncontrollable factors such as the degree that the NIT treatment actually increases survival. Hence, the level of the Type II error rate is unknown for any one experiment. However, with simulation studies the unknown factors can be set to specified values, the experiment repeated many times, and the Type IT error rate estimated for those values. In this report the Type II error rate is measured by its opposite: power ${ }^{2}$. That is, when the Type II error rate is $10 \%$, power is $100 \%-10 \%=$ $90 \%$.

Experimental design can have a significant effect on power; some experimental designs yield a higher power than others under certain conditions. We evaluated the potential of three experimental designs on the basis of (1) whether the design could achieve the required power (BPA 1993), and (2) the range of conditions under which the power assumption could be met. One of the designs (denoted Design 3 ) has been described in the BPA( 1993) and the other two designs are variations of it. To estimate the potential of each design, we conducted computer simulations to investigate conditions under which the power assumption could be achieved.

\footnotetext{
${ }^{2}$ Power is the probability that a real difference is detected. It is the opposite of the Type II error.
} 


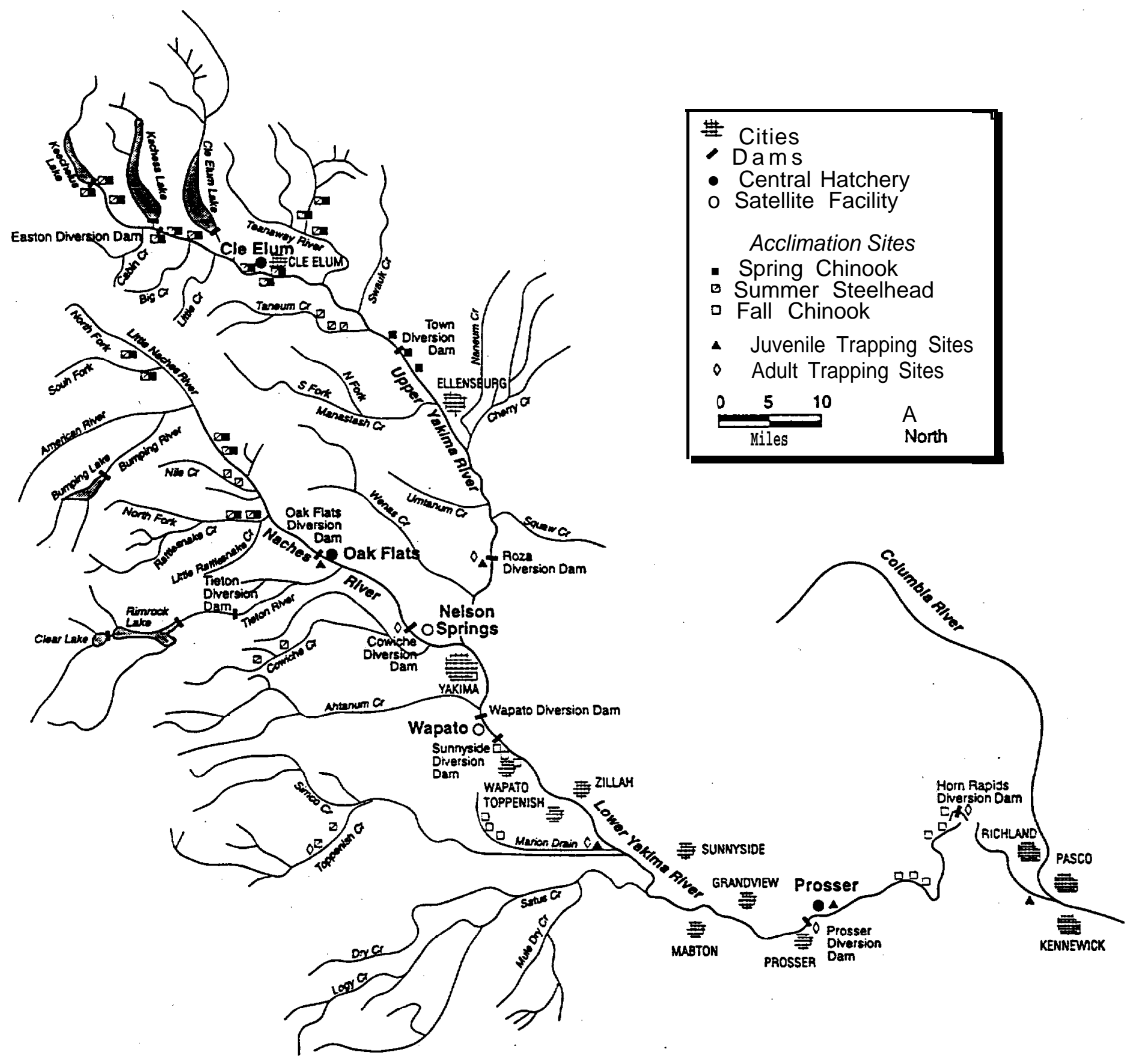

Figure 1. Yakima Fisheries Project location map (kindly furnished by CH2M Hill, Bellevue, Washington). 


\section{METHODS}

In this study, we estimated power using Monte Carlo simulations (Hammersley and Handscomb 1964). The simulations consisted of generating 5000 data sets under a prescribed set of conditions. Each data set represented the number of fish returning to the acclimation ponds from one broodyear over multiple return years and was tested for a significant treatment effect using an analysis of variance (ANOVA). The percentage of correct significant tests was the power estimate for those prescribed conditions. We repeated this procedure for many different sets of conditions to illustrate how much power varied and under which conditions the power assumption could be met with each experimental design.

We used the following notation in the data simulation and analysis models.

$$
\begin{aligned}
& \text { I } \quad=\text { number of geographic sites. } \\
& \mathrm{J}=\text { number of locales per site. } \\
& \mathrm{K}=\text { number of treatments. } \\
& \mathrm{N}=\text { number of smolts released per acclimation pond. } \\
& \mathrm{N}_{\mathrm{E}} \quad=\text { effective number of smolts released per acclimation pond } \\
& =\mathrm{N} / \text { (\#fish per school) } \text {. } \\
& \mathrm{Y}_{i j k}=\text { number of successful fish from the acclimation pond given treatment } k \\
& (k=1, \ldots, \mathrm{K}) \text { in localej }(j=1, \ldots, \mathrm{J}) \text {, at site } i(i=1, \ldots, \mathrm{I}) \text {. } \\
& \mathrm{P}_{i j k}=\text { proportion of successful fish from the acclimation pond given } \\
& \text { treatment } k(k=1, \ldots, \mathrm{K}) \text { in localej }(j=1, \ldots, \mathrm{J}) \text {, at site } i(i=1, \ldots, \mathrm{I}) \text {. } \\
& \mathrm{f}_{i j k}=\text { probability that a fish from the acclimation pond given treatment } k \\
& (k=1, \ldots, \mathrm{K}) \text { in localej }(j=1, \ldots, \mathrm{J}) \text {, at site } i(i=1, \ldots, \mathrm{I}) \text { is successful (i.e., is } \\
& \text { either recruited or returns to spawn) and is observed. } \\
& \mu \quad=\text { baseline smolt:adult success probability for an OCT fish. } \\
& \mathbf{s}_{i}=\text { product of environmental effects of geographic site } i(i=1, \ldots, \mathrm{I}-1) \text { and } \\
& \text { egg-take } i(i=1, \ldots, \mathrm{I}-1) \text { on success rate. The environmental effects } \\
& \text { represented in this term include differential predation rates, water } \\
& \text { quality, and water temperature. } \\
& 1_{j(i)}=\text { effects on success rate due to environmental differences among the } \\
& \text { locales within a site, i.e., effect of localej }(j=1, \ldots, \mathrm{J}-1) \text { nested within } \\
& \text { site } i(i=1, \ldots, \mathrm{I}) \text {. The effects represented in this term include differences } \\
& \text { among facilities, and differences in the microhabitat surrounding each } \\
& \text { locale. } \\
& \mathrm{t}_{k}=\text { effect of treatment } k(k=1, \ldots, \mathrm{K}-1) \text { on success rate. } \\
& \mathrm{r}=\text { probability that a successful fish will be observed. This term takes into } \\
& \text { account that not all successful fish will be observed. } \\
& \mathrm{e}_{i j k}=\text { error in estimating } \mathrm{Y}_{i j k} \text {. }
\end{aligned}
$$




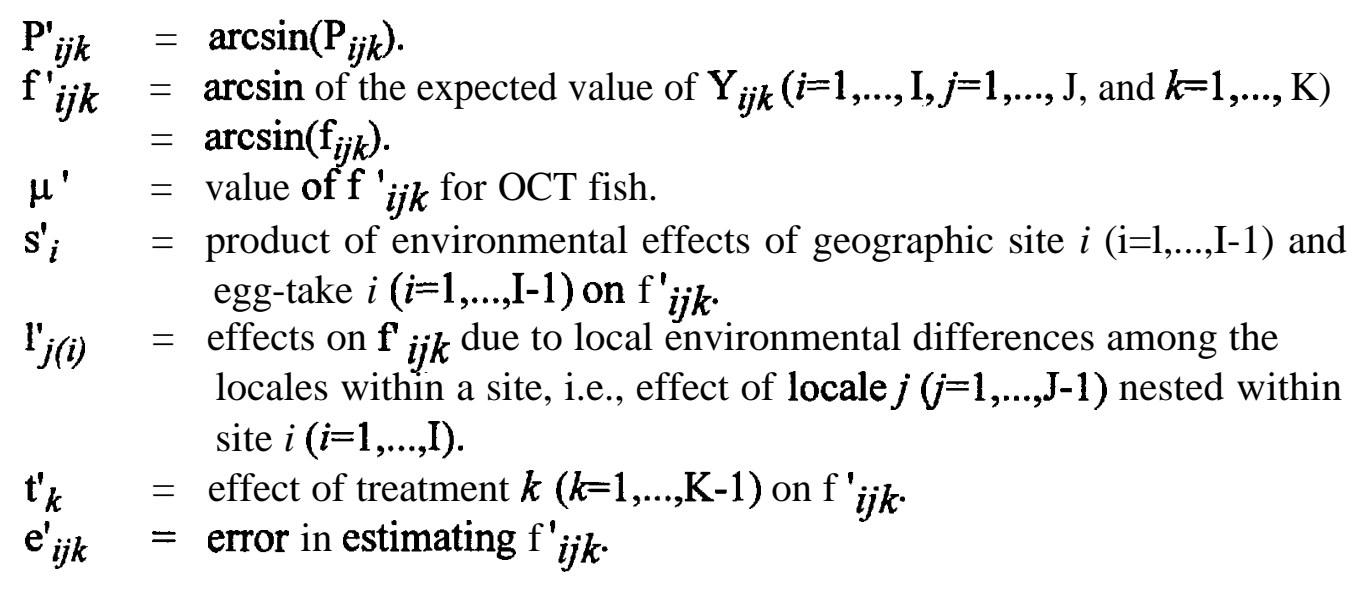

Definitions of several terms used throughout this report are given below.

Locale: A local area within a site. In the PSR (BPA 1993), the locales were specified to be separated by at least 1.61 river $\mathrm{km}$ and were referred to as ponds, because one pond was assigned to one locale. However, in the alternative designs more than one pond may be located at a locale. The 1.61 river $\mathrm{km}$. ( $\approx 1$ river mile) was thought to be enough distance to ensure that data among locales would be independent.

Site: A geographic region within the basin. In the PSR (BPA 1993), the sites were referred to as clusters. We have replaced the term "clusters" with "sites" to avoid confusion with the alternative models considered.

Successful Fish: By YFP standards, a successful fish is one that returns to spawn or is recruited into a specified fishery. This definition reflects the harvest as well as the natural production objectives of the YFP. A fish that returns to spawn can either (1) remain in the acclimation pond area as a precocious parr, (2) return to Roza Dam as a jack, (3) return to Roza Dam as an adult, or (4) return to the Yakima basin elsewhere as a stray.

Treatment Complement: A set of $\mathrm{K}$ acclimation ponds where each treatment is represented once. It is a full comparison of all the treatments. Generally, the $\mathrm{K}$ ponds in a complement are located in as close proximity to each other as the design allows.

\subsection{Experimental Designs}

We considered three experimental designs. For each, the procedure for rearing the 'fish and dividing them into acclimation ponds was the same. The designs differed in the number of treatment compliments per site or, if that number was the same, in the layout 
specifications of the acclimation ponds within a site. The number of sites was not fixed for any design. We conducted simulations with 3 or 5 sites to illustrate the power characteristics with a smaller-scale experiment. The number of treatment compliments and the physical layout of the acclimation ponds determined the potential sources of variation that could be accounted for.

\section{Design 1}

The first design specified three treatment complements per site. The three treatment complements within a site could be separated by 1.61 river km; however, the acclimation ponds within a treatment complement were located adjacent to one another (Figure 2). With the full complement of smolts $(1,125,000)$ the design specified 45 acclimation ponds and 25,000 smolts per pond. With this design, all the effects due to site, treatment, and locale could be accounted for.

\section{Design 2}

The second design allocated one treatment complement per site rather than three. All the acclimation ponds within a treatment complement were located adjacent to one another (Figure 3 ). The full complement of smolts $(1,125,000)$ was specified to be divided into 15 acclimation ponds with 75,000 smolts per pond. With this design, the effects due to site and treatment could be accounted for. Because of the adjacent placement of the ponds within a site, the locale effects were eliminated and did not need to be accounted for.

\section{Design 3}

The third design considered was that described in the PSR (BPA 1993) and specified one treatment complement per geographic site (Figure 4) as in Design 2. The acclimation ponds in each treatment complement were specified to be separated by 1.61 river $\mathrm{km}$. With the full complement of smolts $(1,125,000)$ the design specified 15 acclimation ponds and 75,000 smolts per pond. With this design, the effects due to site and treatment could be accounted for but the effect due to locale caused by separation of the ponds could not.

\subsection{Factors From the Experimental Procedure Considered to Have Effects on Survival}

In order to obtain realistic estimates of power, we attempted to simulate the data to reflect all the factors potentially affecting survival. We categorized the potential factors as (1) those due to treatment, (2) those due to the experimental procedure prior to acclimation, and (3) those due to location of the acclimation ponds. The effects in the first 

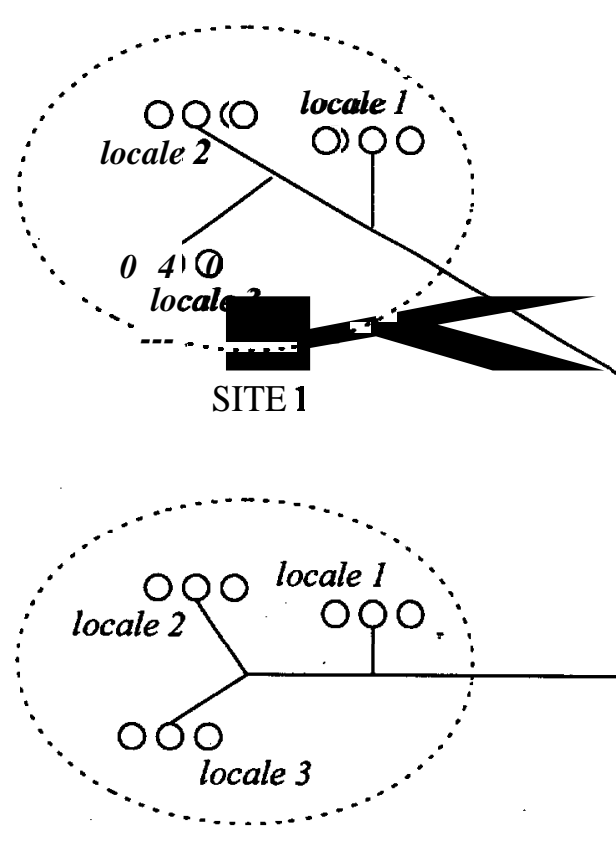

SITE 3

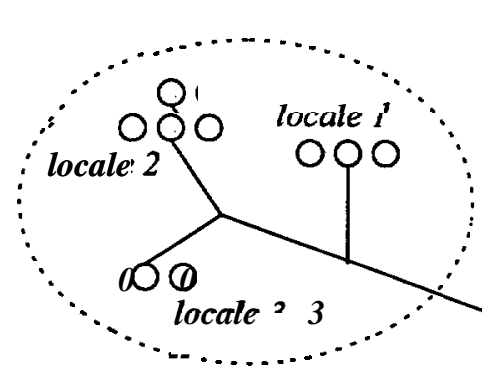

SITE 5

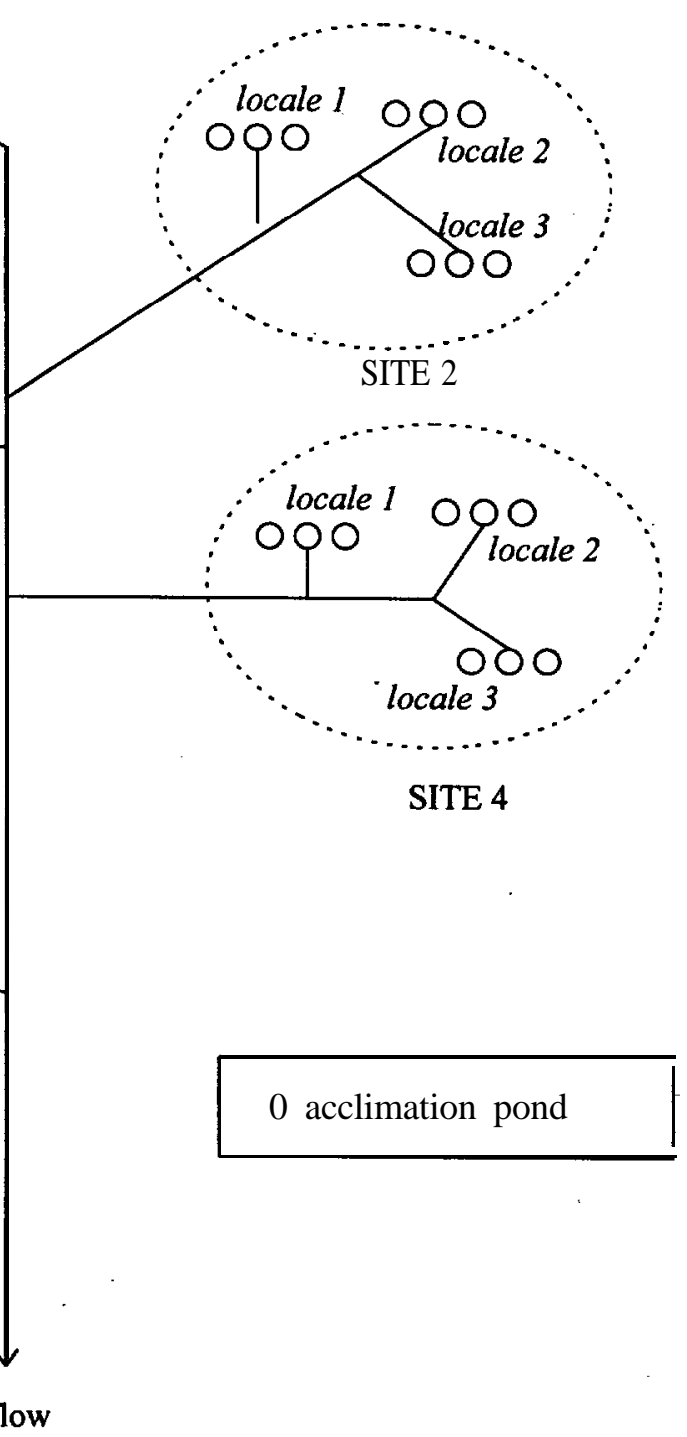

Figure 2. Schematic of the physical layout of experimental Design 1. At each site there are three locales, and locales within a site are separated by at least 1.61 river $\mathrm{km}$. In each locale there are three adjacent ponds representing a treatment complement (when there are three treatments). 


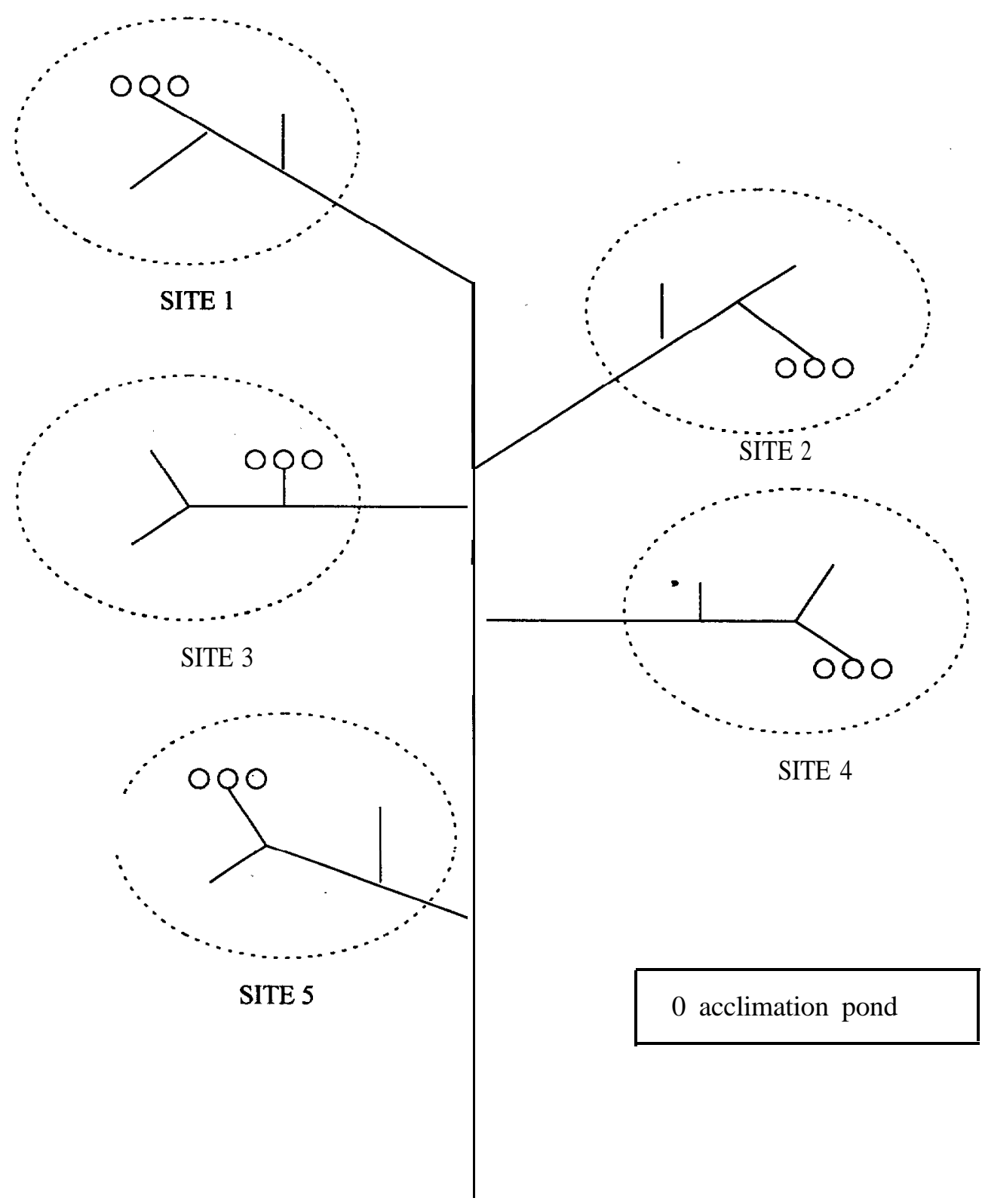

flow

Figure 3. Schematic of the physical layout of experimental Design 2. At each site the acclimation ponds are located adjacent to one another. 


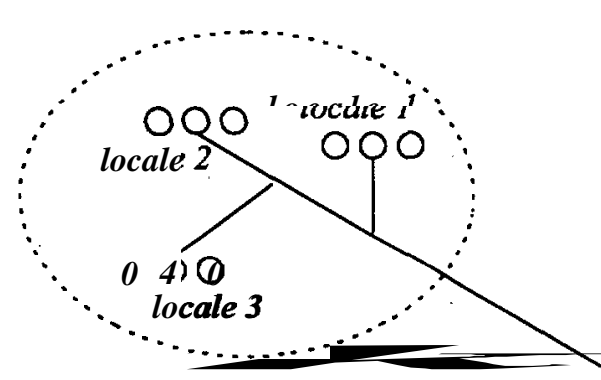

SITE 1
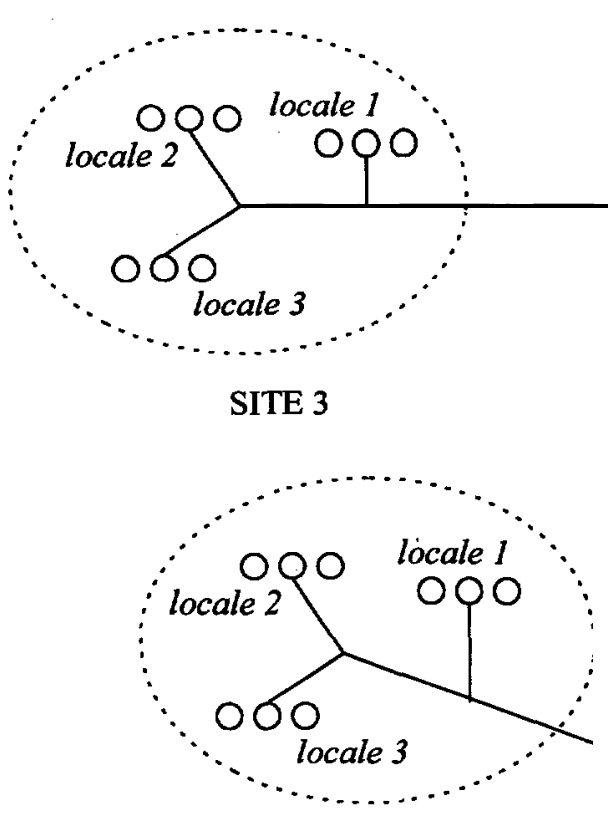

SITE 5

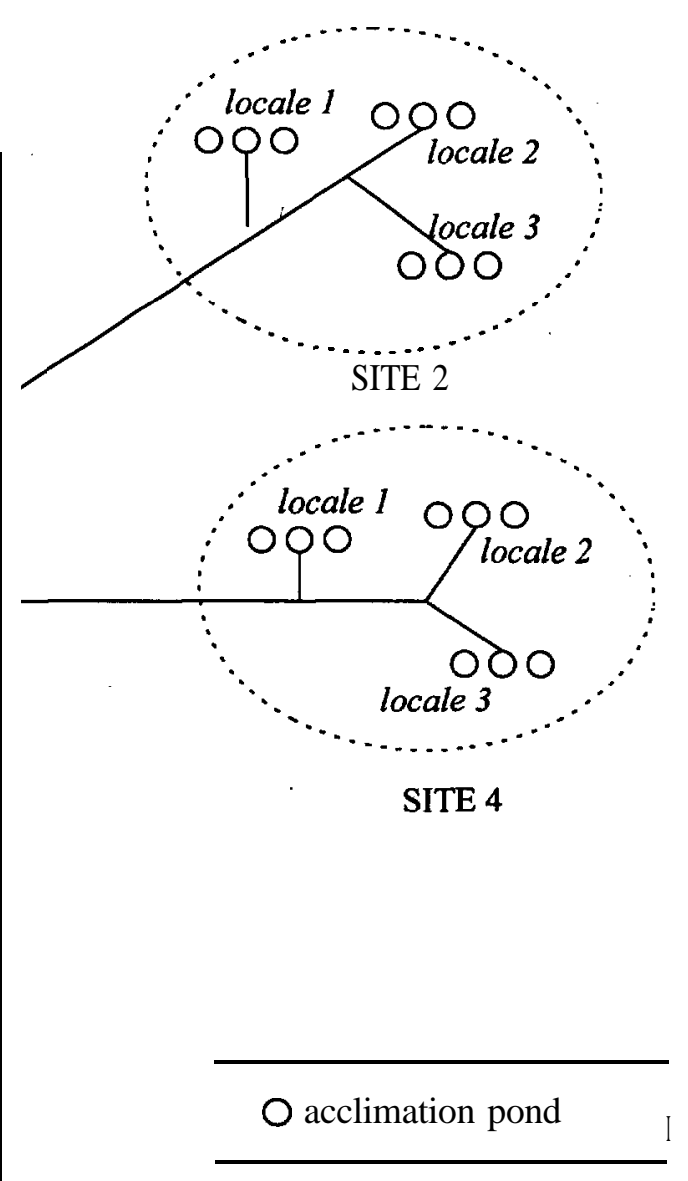

flow

Figure 2. Schematic of the physical layout of experimental Design 1. At each site there are three locales, and locales within a site are separated by at least 1.61 river $\mathrm{km}$. In each locale there are three adjacent ponds representing a treatment complement (when there are three treatments). 


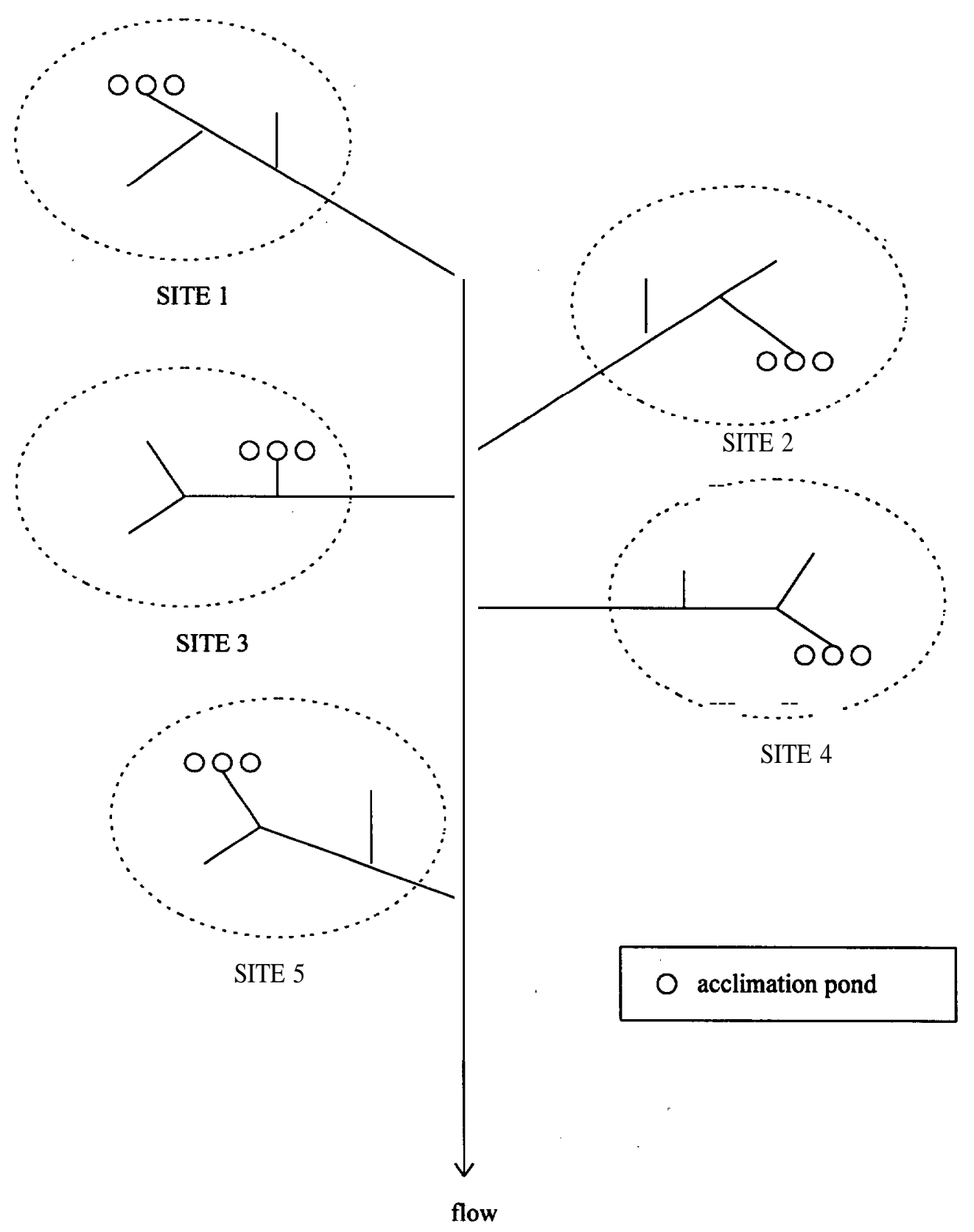

Figure 3. Schematic of the physical layout of experimental Design 2. At each site the acclimation ponds are located adjacent to one another. 


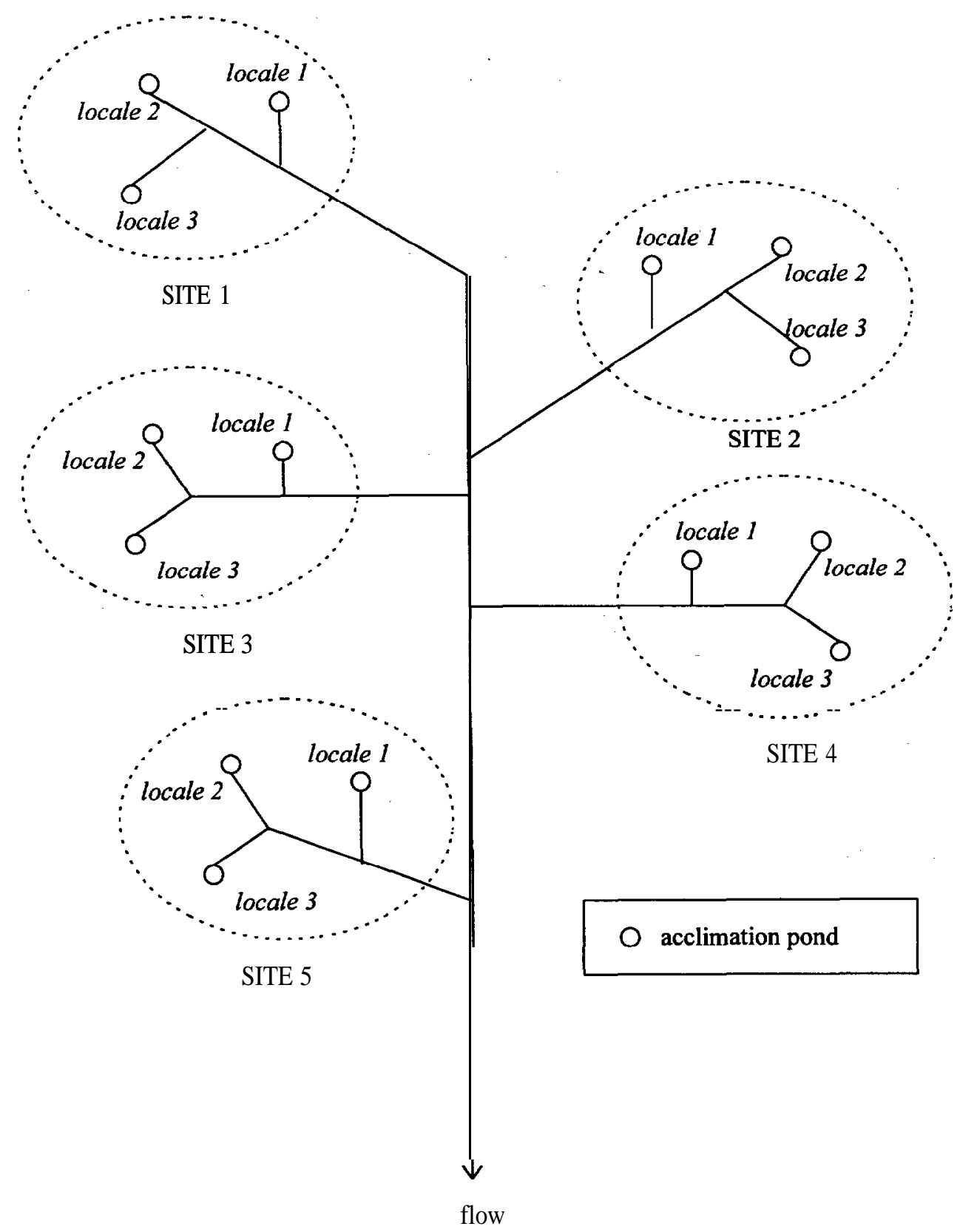

Figure 4. Schematic of the physical layout of experimental Design 3. At each site the acclimation ponds are separated by at least 1.61 river $\mathrm{km}$. 
and second categories were common to all designs, while the effects in the third category varied according to each design's specifications.

Treatment. The relative survival of the NIT fish was 150\% that of the OCT fish (BPA 1993).

Experimental Procedure. Prior to acclimation, the experimental procedure will consist of dividing the fish into groups and assigning treatments and acclimation ponds to each group. The process of dividing the fish will introduce potential sources of variation. According to the proposed procedure (Desmond Maynard, National Marine Fisheries Service, Seattle, pers. commun. 1993), broodstock will be collected at Roza Dam on the Yakima River (Figure 1). The season over which broodstock will be collected will be divided into egg-takes. A group of fish will be formed from the same egg-take to simplify the rearing procedure by having similarly aged fish in each acclimation pond.

The potential source of variation introduced by egg-take is a nuisance and could not be accounted for by Designs 2 or 3. However, the effect of egg-take can be confounded with site effects and thus eliminated from all the designs. That is, each eggtake will consist of the number of broodstock necessary to produce enough eggs for a site. Site effects will then be indistinguishable from egg-take effects. However, we also considered site effects to be nuisances and not quantities of interest. By confounding site and egg-take effects, we reduced the number of nuisance effects from two to one. The resulting nuisance effect, the product of site and egg-take effects, could be accounted for and therefore did not bias the test nor decrease the power.

Location. The physical layout of the acclimation ponds gave rise to potential location effects. Environmental differences among the different locations may cause differences in survival during early life history that, in turn, may be apparent in the overall survival and, therefore, in the success rate. Two kinds of potential location effects are: 1) site effects due to geographic variations within the basin and 2) effects due to local variations among the ponds within a site. The locale effects are nested within the sites, since the nature of the locale effects may differ from site to site.

\subsection{Data Simulation Model}

In simulating the data, we assumed that sources of variation not defined in Section 2.2 were insignificant, i.e., did not cause significant variations in survival. In particular, pond effects among adjacent ponds (on the same water source) were assumed insignificant. We also assumed that all the effects described in Section 2.2 were additive, i.e., there were no interactions among treatment, site/egg-take, and location.

In the simulated data, the number of successful fish (Y) from each acclimation pond was a binomial random variable. The sample size was the number of smolt released 
from each pond adjusted for a degree of schooling behavior. We determined the probability of success separately for each pond to reflect the applicable site, locale, and treatment effects. Fish within a school were assumed to behave as one unit. Therefore, the effective sample size was the sample size reduced proportionally by the school size. By decreasing the sample size, this adjustment increased the uncertainty in the proportion of successful fish (see Appendix 1). We simulated the data effectively as

$$
\mathrm{Y}_{i j k} \sim \text { Binomial\& } \mathrm{f}_{i j k} \text { ) }
$$

where the probability of success for a fish was calculated as either

$$
\begin{aligned}
& \mathrm{f}_{i j k}=\left[\mu+\mathrm{s}_{i}+1_{j(i)}\right]^{*}[\mathrm{X}(k=\mathrm{LNIT})+1.5 \mathrm{I}(k=\mathrm{NIT})]^{*} \mathrm{r} \text {, }
\end{aligned}
$$

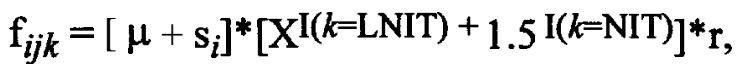

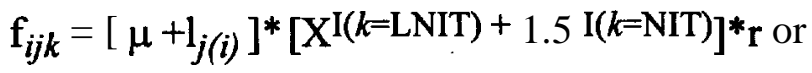

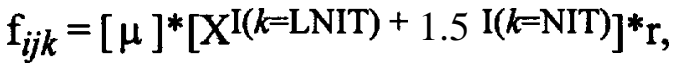

and where

$$
\mathrm{I}(\mathrm{A})=\left\{\begin{array}{l}
1 \text { if event } \mathrm{A} \text { is realized, and } \\
0 \text { otherwise }
\end{array}\right.
$$

The indicator function I(A) determined the treatment. For example, in Equation (1), when the treatment was OCT, then both $\mathrm{I}(\mathrm{k}=\mathrm{NIT})$ and $\mathrm{I}(\mathrm{k}=\mathrm{LNIT})$ are 0 and the probability of success was:

$$
\mathrm{f}_{i j(k=\mathrm{OCT})}=\left[\mu_{+} \mathrm{s}_{i}+1_{j(i)}\right]^{*} \mathrm{r} .
$$

When the treatment was LNIT, then $\mathrm{I}(\mathrm{k}=\mathrm{LNIT})=1, \mathrm{I}(\mathrm{k}=\mathrm{NIT})=0$, and the probability of success was:

$$
\mathrm{f}_{i j(k=\mathrm{LNIT})}=\left[\mu+\mathrm{s}_{i}+\mathrm{l}_{j(i)}\right]^{*}(\mathrm{X})^{*} \mathrm{r}
$$

where $\mathrm{X}$ was the multiplier indicating how much more successful the LNIT treatment was than the OCT treatment. When the treatment was NIT, then $\mathrm{I}(\mathrm{k}=\mathrm{LNIT})=0, \mathrm{I}(\mathrm{k}=\mathrm{NIT})$ $=1$, and the probability of success was:

$$
\mathrm{f}_{i j(k=\mathrm{NIT})}=\left[\mu+\mathrm{s}_{i}+1_{j(i)}\right]^{*}(1.5)^{*} \mathrm{r}
$$

which indicated that the NIT treatment is 1.5 times-as successful as the OCT treatment. Equation (1) reflected the treatment effects, site*eggtake effects, locale effects and the 
sampling rate, Equation (2) the treatment and site*eggtake effects, Equation (3) the treatment and locale effects, and Equation (4) only the treatment effects.

\subsubsection{Factors Varied in the Simulations}

The prescribed set of conditions for each simulation was determined by (1) the total number of fish available for experimentation, (2) the number of treatments compared, (3) the amount of environmental variation in success rate, (4) the average success rate, (5) the amount of schooling, and (6) the sampling rate of the successful fish (Table 1).

Table 1. Description of either the values used or the random distribution from which values were drawn from for the factors in the simulation.

\begin{tabular}{|c|c|}
\hline Factor Description & $\begin{array}{l}\text { Value or Random } \\
\text { Distribution Used }\end{array}$ \\
\hline 1) Number of Fish Available & $500 \mathrm{~K}-51 \mathrm{OK} ; 750 \mathrm{~K}-765 \mathrm{~K} ; 1,125 \mathrm{~K}$ \\
\hline 2) Number of Sites & $3 ; 5$ \\
\hline 3) Number of Treatments Compared & 2 (OCT, NIT); 3(OCT, LNIT, NIT) \\
\hline 4) Success Rate of OCT Fish $(\mu)$ & $0.001 ; 0.002 ; 0.003$ \\
\hline 5) Success Rate of LNIT Fish (X) & $1.0 ; 1.25 ; 1.5$ \\
\hline \multicolumn{2}{|l|}{ 6) Environmental Variation } \\
\hline Site Effects & 0 ; Uniform $(-0.003,0.003)$ \\
\hline Locale Effects & $0 ; 0.5 \mu * \mathrm{U}(-1,1) ; \mu * \mathrm{U}(-1,1)^{1}$ \\
\hline 7) School Size & 5 fish/school \\
\hline 8) Sampling Rate & $33 \% ; 67 \%$ \\
\hline
\end{tabular}

Total Number of Fish Available - We varied the total number of fish available for experimentation to accommodate the situation when a full complement of smolts would not be available. The number of treatment complements per site was kept constant, so reductions in the total number of fish available required a reduction in either the number of fish per pond, in the number of treatments, or in the number of sites. A fixed total number of fish could not always be divided evenly into the variable number of ponds presented for each design. Therefore, we give a range of total fish to show that relatively small adjustments were made to keep the number of fish per pond consistent in each design.

Number of Sites - We varied the number of sites to illustrate the power with a smaller experiment. The number of ponds per site remained constant, so the total number of ponds varied for each design depended on the number of sites. 
Number of Treatments Compared - In each simulation the OCT and NIT treatments were always represented. In some cases, the LNIT treatment was omitted and the number of fish reallocated to the other two treatments.

Success Rate of OCT Eish - The average success rate was always calculated relative to that of OCT fish. Because survival makes up a large portion of success, the values chosen for $\mu$ were considered to approximate the survival of OCT fish. The lowest value of $\mu$ was considered to be the worst-case scenario where a hatchery is at an approximate break-even point ${ }^{3}$ (Senn et al. 1984). This value (0.001) takes into account average fecundity of returning adults and typical survival rates for fish from conception to release from the hatchery. The highest value $(0.003)$ corresponds 'to $20 \%$ of the average survival of wild fish ${ }^{4}$ (Fast et al. 1991). All three values were considered comparable to survival rates calculated from data on hatchery fish in the Yakima River (Pettit 1993). The survival of fish given the LNIT treatment was considered to be the same as the NIT fish. The survival of fish given the NIT treatments were always $150 \%$ that of OCT fish.

Success Rate of LNIT Fish - In the simulations we set $\mathrm{X}$ to $1.0,1.25$, and 1.5. At $\mathrm{X}=1 . \mathrm{O}$ the LNIT success rate was equal to the OCT rate, at $\mathrm{X}=1.5$ the LNIT success rate was equal to the NIT rate, and at $\mathrm{X}=1.25$ LNIT success rate was equal to the average of the OCT and NIT rates (Equation (5)).

Environmental Variation - The environmental variations were specified by the values used for $\mathrm{s}_{i}(i=1, \ldots, \mathrm{I})$, and $\mathrm{l}_{j(i)} j(j=1, \ldots, \mathrm{J}) i(\mathrm{i}=1, \ldots, \mathrm{I})$. To emulate natural fluctuations in success among different locations and among different years, the values of $\left\{\mathbf{s}_{i}\right.$ and $\left.\mathbf{l}_{j(i)}\right\}$ were drawn randomly from uniform distributions. The site*egg-take effects $\left\{s_{i}\right\}$ were allowed to be as large as the maximum OCT baseline survival rate considered (0.003). The locale effects were on the order of $50 \%$ of the OCT survival rate. Effects of this magnitude translated into a range of 0 to 113 fish, or $75 \%$ of the differences expected between the NIT ponds and the OCT ponds, and were considered to be reasonable.

School Size - A school size of size 5 was considered to be reasonable based on results in Welch and Ishida (1993). Thus, the effective sample size was then 5 times smaller than the actual number of smolts released.

\footnotetext{
${ }^{3}$ The break-even point was determined from parameter values in Table 2, Chapter 9 of Senn et al. (1984): a 1.5: 1 male to female ratio, a 20\% spawning mortality, 5000 eggs/female, and 65\% survival from egg to release. These values correspond to 3.125 returning adults per spawning female. Each spawning female produces an estimated 5000 eggs from which $(5000)(0.65)=3250$ smolts that migrate. Thus the smolt:adult survival needed to replace the population is $3.125 / 3250 \cong 0.001$.

${ }^{4}$ Yakama Indian Nation biologists have determined that survival from smolt to adult return to Prosser Dam (Figure 1) is about 0.03 (Fast et al. 1991). They have also estimated that $50 \%$ of the smolts are lost before they reach Prosser Dam. Therefore, the estimated wild smolt survival from the acclimation areas to adult return to Prosser Dam is estimated to be 0.015 , or $20 \%$ of 0.003 .
} 
Sampling Rate - The values used for the sampling rate (p) were considered to be representative of sampling rates possible at different locations, including Roza Dam and on the spawning grounds.

The first set of computer simulations were used to identify plausible values for each factor. A value was considered implausible if it caused the success rate to be outside the range $(0,1)$, if power in that range was always less that $90 \%$, or if practical considerations precluded its use, (e.g., it was not considered reasonable for the sampling rate of successful fish to be $100 \%$ ). The second set of simulations was used to show that the site effects did not affect the power. In each of the analytical models, the site effects were accounted for and, therefore, were not expected to have detrimental effects on power. The third set of simulations was used to show that the locale effects were detrimental to power for Design 3 (Table 2) but not for Design 1. The locale effects did not exist for Design 2 and, therefore, caused no problems for that design. The last and most comprehensive set of simulations gave estimates of power that were matched to the project's specifications and resulted in our recommendations.

\subsubsection{Computational Details of the Simulations}

The simulation programs were coded in FORTRAN 77, compiled with the Lahey F77-EM/32 compiler (Lahey Computer Systems, Inc., Incline Village, Nevada), and run on a 386 personal computer. All the sampling routines in the programs were directly from or based on functions found in Press et al. (1986). Simple binomial sampling was done via the BNLDEV function.

Binomial sampling with inflated variance for simulated schooling was done using a normal approximation to the binomial. Briefly, if $X$-Binomial $(n, p)$, then $X$ is approximately $N(n p, n p q)$ if $n p q>5$ (Rosner 1986), where $q=1-p$. For school size $M$, the number of surviving adults was simulated by sampling a Normal(np,Mnpq) distribution using function GASDEV. Pseudorandom numbers required for these two functions were supplied by function RAN1 . Both the binomial and normal approximation sampling functions were tested extensively before inclusion in the simulation programs. This overall procedure is illustrated in Figure 5.

The analysis programs used original randomized-block ANOVA subroutines based on the formulations in Sokal and Rohlf (1981). The subroutines were tested on the data presented in Sokal and Rohlf (198 1) before inclusion in the simulation programs. Final testing of the simulation programs was done by setting the NIT survival rate to the OCT rate (i.e., simulating data under the null hypothesis of no treatment effect) and verifying that power was equal to a for both the 0.05 and 0.10 levels of significance. 


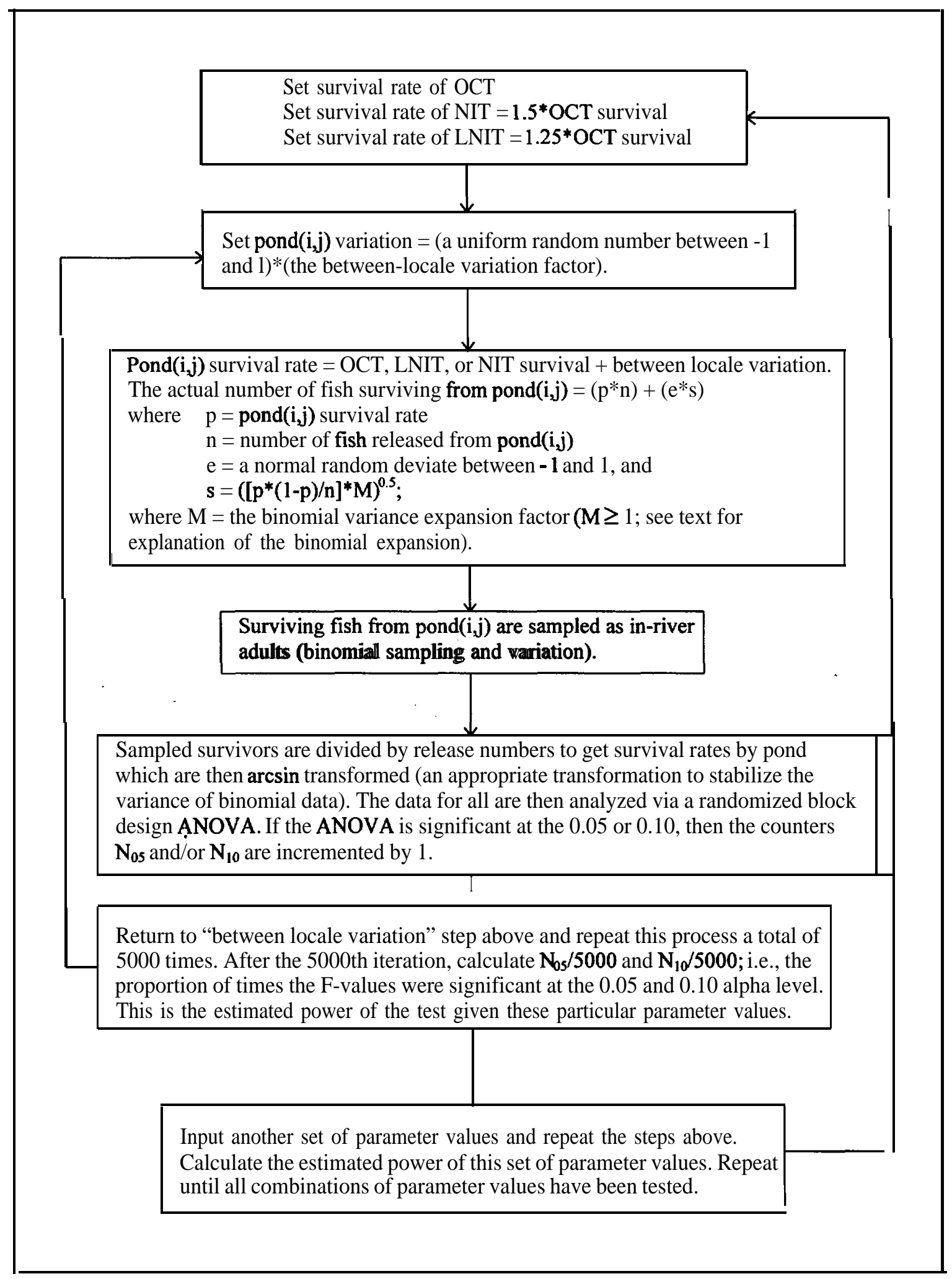

Figure 5. The major steps in the power analysis modeling process. 


\subsection{Data Analysis Models}

We based the ANOVA analysis performed on each simulated data set on the model:

$$
\mathrm{P}_{i j k}=\mathrm{f}_{i j k}+\mathrm{e}_{i j k}
$$

where $\mathrm{f}_{i j k}$ depended on the design and the number of effects simulated (Equations (1) through (4)). For Designs 2 and 3,

$$
\mathrm{f}_{i j k}=\left[\mu+\mathrm{s}_{i}\right]^{*}[\mathrm{X}(k=\mathrm{LNIT})+1.5 \mathrm{I}(k=\mathrm{NIT})]^{*} \mathrm{r},
$$

but for Design 1,

$$
\mathrm{f}_{i j k}=\left[\mu+\mathrm{s}_{i}+1_{j(i)}\right]^{*}\left[\mathrm{X}^{\mathrm{I}(k=\mathrm{LNIT})+1.5 \mathrm{I}(k=\mathrm{NIT})}\right]^{*} \mathrm{r}
$$

The difference was inclusion of the locale effects in Equation (4). The errors $\left\{\mathbf{e}_{i j k}\right\}$ were assumed to be independent and,

$$
\mathrm{e}_{i j k} \sim \operatorname{Normal}\left(0, \sigma^{2}\right)
$$

for all $\mathrm{i}(i=1, \ldots, \mathrm{I}), \mathrm{j}(j=1, \ldots, \mathrm{J})$, and $\mathrm{k},(k=1, \ldots, \mathrm{K})$.

Constant error variance assumption. An assumption made with this model (Equation (2)) was that the variances of the errors $\left\{\mathbf{e}_{i j k}\right\}$ were constant. However, the variance of $\mathbf{e}_{i j k}$ is equal to the variance of the observation $\left\{\mathrm{P}_{i j k}\right\}$ which is a function of its expected value $\left\{\mathrm{f}_{i j k}\right\}$ because $\mathrm{Y}_{i j k}$ is a binomial random variable. Since the expected value varied from acclimation pond to acclimation pond, the assumption of constant error variance could not be met. In fact, the variation in variance was on the order of the difference in number of expected returning fish (between treatment and control ponds) and ranged from as few as 75 fish $(=75,000 * 0.001 * 0.999)$ to more than 224 fish $(=75,000 * 0.003 * 0.997)$. To stabilize the variance of a proportion, an arcsin transformation was used (Hogg and Craig 1978: 217):

$$
\mathrm{P}^{\prime}=[\arcsin (\sqrt{P})]^{2}
$$

Since $\arcsin (\mathrm{x}) \cong \mathrm{x}$, when $\mathrm{x}$ is small (as can be seen by the trigonometric series expansion of arcsin in Beyer 1984:298), $\mathrm{P}^{\prime} \cong \mathrm{P}$. This fact is useful when interpreting the results of the transformed ANOVA model. The transformed ANOVA model was

$$
\mathrm{P}_{i j k}^{\prime}=\mathrm{N}[\arcsin (\sqrt{P})]^{\mathrm{a}}=\mathrm{f}^{\prime}{ }_{i j k}+\mathrm{e}^{\prime}{ }_{i j k}
$$

where 


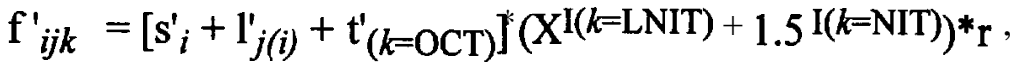

$$
\begin{aligned}
& \mathrm{f}^{\prime} i j k=\left[\mathrm{s}_{i}^{\prime}+\mathrm{t}_{(k=\mathrm{OCT})}\right]^{k}\left(\mathrm{X}^{\mathrm{I}(k=\mathrm{LNIT})+1.5 \mathrm{I}(k=\mathrm{NIT}))^{*} \mathrm{r}},\right.
\end{aligned}
$$

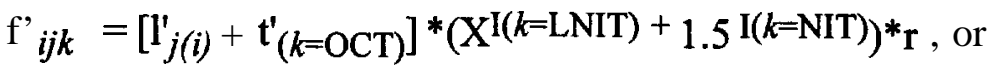

$$
\begin{aligned}
& \mathrm{f}^{\prime}{ }_{i j k}=\left[\mathrm{t}^{\prime}(k=\mathrm{OCT})\right]^{*}\left(\mathrm{X}^{\mathrm{I}(k=\mathrm{LNIT})+1.5 \mathrm{I}(k=\mathrm{NIT})}\right){ }^{*} \mathrm{r},
\end{aligned}
$$

and where the errors $\left\{\mathrm{e}^{\prime}{ }_{i j k}\right\}$ were independent and distributed as

$$
\mathrm{e}_{i j k}^{\prime} \sim \operatorname{Normal}\left(0, \sigma^{2}\right)
$$

for all i $(i=1, \ldots, \mathrm{I}), \mathrm{j}(j=1, \ldots, \mathrm{J})$, and $\mathrm{k},(k=1, \ldots, \mathrm{K})$. With this model, the error variance was constant.

Normality of error assumption. With the transformation, the errors were also approximately normal since the errors on $\left\{\mathrm{P}^{\prime}{ }_{i j k}\right\}$ were approximately normal (Bickel and Doksum 1977: 133-135).

The test statistic for a treatment effect for Designs 1 and 2 was

$$
\mathrm{F}_{\mathrm{K}-1,(1-1)(\mathrm{K}-1)}=\frac{I \sum_{k}\left(\bar{P}_{k}-\bar{P}\right)^{2} /(K-1)}{\sum_{i, k}\left(P_{i k}-\bar{P}_{i}-\bar{P}_{k}+\bar{P}\right)^{2} /[(I-1)(K-1)} .
$$

This test statistic treated the sites as replicate trials. Note that locale effects did not enter Equation (6). On the other hand, the F-test for Design 1 was calculated by

$$
\mathrm{F}_{\mathrm{K}-1,(-1-1)(\mathrm{I}-1)(\mathrm{K}-1)}=\frac{I J \sum_{k}\left(\bar{P}_{k}-\bar{P}\right)^{2} /(K-1)}{\sum_{i, j, k}\left(P_{i j k}-\bar{P}_{i j}-\bar{P}_{i k}-\bar{P}_{j k}+\bar{P}_{i}+\bar{P}_{j}+\bar{P}_{k}-\bar{P}\right)^{2} /[(I-1)(J-1)(K-1)]} .
$$

In most of the simulations, the site*egg-take effects were not modeled into the data because the size of these effects did not affect power. In these instances, the F-test statistic reduced to

$$
\mathrm{F}_{\mathrm{K}-1, \mathrm{U}(\mathrm{K}-\mathrm{l})}=\frac{I J \sum_{k}\left(\bar{Y}_{k}-\bar{Y}\right)^{2} /(K-1)}{\sum_{i, j, k}\left(Y_{j j k}-\bar{Y}_{k}\right)^{2} /[I J(K-1)]} .
$$


Power was estimated by the proportion of F-statistics calculated from the 5000 data sets whose value exceeded the critical value for an $F_{\mathbf{d}_{1}, \mathbf{d}_{2}}$ random variable with $\mathrm{d}$, and $\mathbf{d}_{2}$ degrees of freedom. The significance level was set at $\alpha=0.10$ (BPA 1993). 


\section{RESULTS}

In the first set of simulations, we compared the power of detecting a treatment effect for different levels of LNIT success rate (Table 2). The results showed that the power was least when the LNIT success rate was set to the average of the OCT and NIT success rates. Therefore, to be conservative, we set the LNIT success rate to be the average $(\mathrm{X}=1.25)$ for the remainder of the simulations.

Table 2. Power estimates for testing treatment effect at three different LNIT success rates. The sampling rate was set at $33 \%$ and locale effects were set at $100 \%$ of the OCT success rate.

\begin{tabular}{cccc}
\hline & \multicolumn{3}{c}{ Power for LNIT Success Rate Equal To: } \\
\cline { 2 - 4 } OCT Success Rate & OCT & Mean [OCT,NIT] & NIT \\
$(\mathrm{X}=1.0)$ & $(\mathrm{X}-=1.25)$ & $(\mathrm{X}=1.5)$ \\
\hline 0.003 & $62 \%$ & $53 \%$ & $64 \%$ \\
0.001 & $45 \%$ & $37 \%$ & $46 \%$ \\
\hline
\end{tabular}

The second set of simulations compared the power between Designs 2 and 3 (Table 3). Design 2 outperformed Design 3 in all cases. However, the degree to which Design 2 was more powerful was dependent on the size of the locale effects. With no locale effect, Designs 2 and 3 were statistically identical and, therefore, equally powerful. As the locale effect increased, the power of Design 2 increased over that of Design 3 (Table 3). This relationship was due to the differences in physical layout of the acclimation ponds between the two designs. Design 2 ponds are not separated by 1.61 river $\mathrm{km}$ within a treatment complement, so the locale effects did not exist. In contrast, Design 3 locales were randomly assigned to the treatments, so any effects due to locale differences were random effects. As a random effect, locale acted to increase the error variance in the model without biasing the error mean square. To see this, recall that the data were simulated with success probability described in Equation (1), but analyzed with Equation (2). Since Equation (2) did not include a locale effect $\left(l_{j(i)}\right)$, this term became part of the error. The new error was

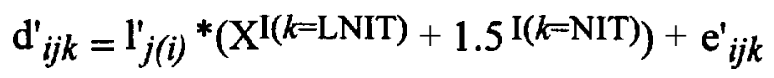

where

$$
\begin{aligned}
\mathrm{E}\left(\mathrm{d}_{i j k}^{\prime}\right) & =\left(\mathrm{X}^{\mathrm{I}(k=\mathrm{LNIT})+1.5 \mathrm{I}(k=\mathrm{NIT})}\right) \mathrm{E}\left(\mathrm{l}_{j(i)}^{\prime}\right)+\mathrm{E}\left(\mathrm{e}_{i j k}^{\prime}\right) \\
& =0,
\end{aligned}
$$

and

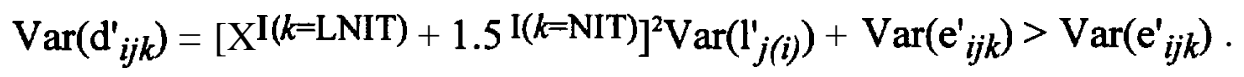




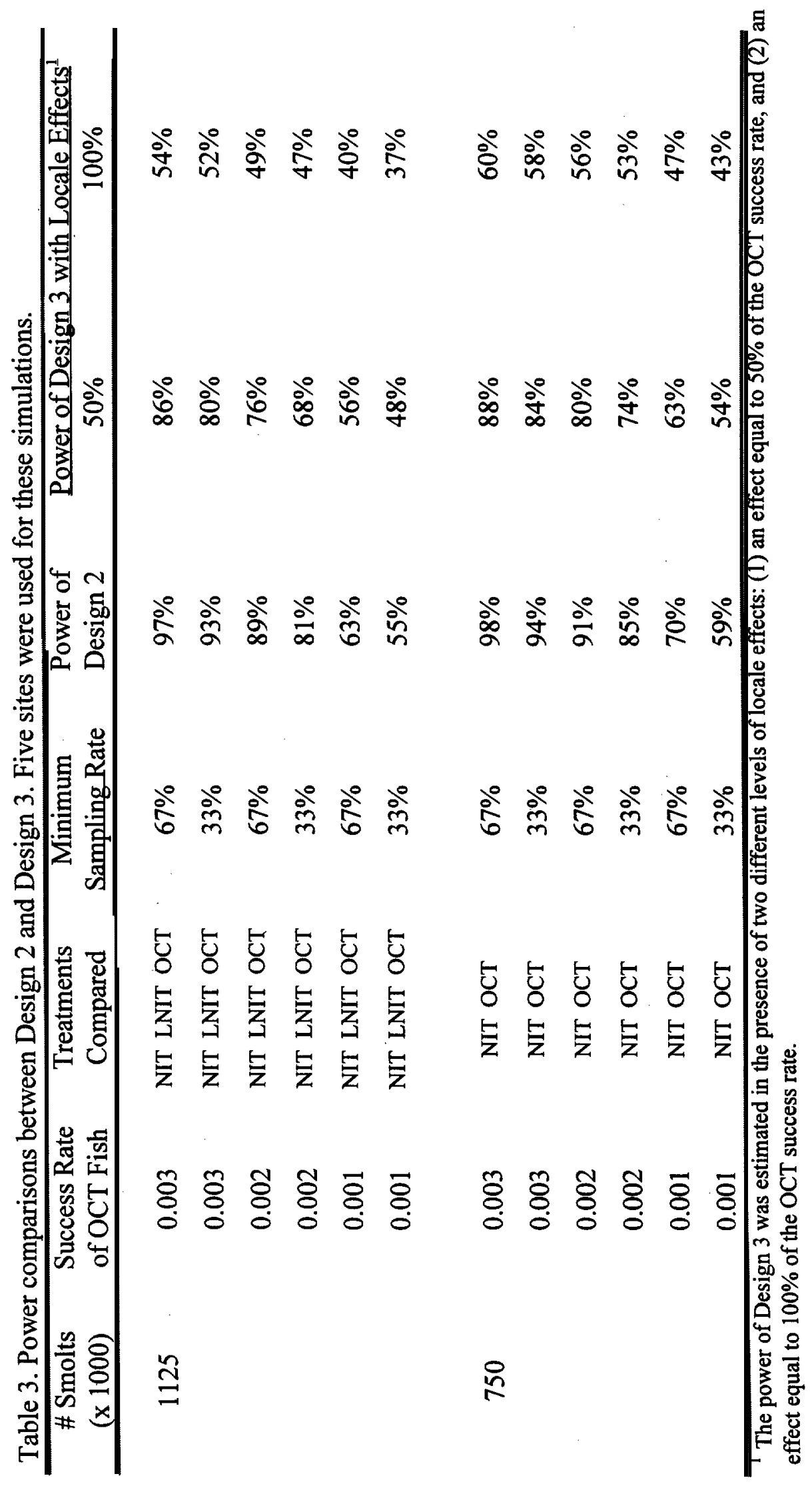


Since power is inversely related to the error variance (Neter et al. 1985: 547-549), the power of Design 3 (with error variance $\operatorname{Var}\left(\mathrm{d}^{\prime}{ }_{i j k}\right)$ ) was always less than that of Design 2 (with error variance $\operatorname{Var}\left(\mathrm{e}_{i j k}^{\prime}\right)$ ) whenever locale effects exist. Because the true degree of locale effect is an unknown, we prefer Design 2 over Design 3 to maximize the chances of achieving $90 \%$ power.

The rest of the simulations that compared Designs 2 and 3 are presented in Appendix 2. We present results where at least $90 \%$ power of detecting differences among treatments was achieved in Table 4 . Table 4 can be used in several different ways depending on whether the most important consideration is fish availability, the anticipated survival rate of OCT fish, the number of treatments to be compared, the maximum sampling rate achievable, or the maximum number of sites available. To use the table, one should prioritize the above considerations and then choose the appropriate design accordingly. For example, suppose the primary concern is fish availability (at 780,000 smolts), the secondary concern is the number of sites at which acclimation ponds can be built (only three sites can be developed in the near future), and the tertiary concern is the sampling rate achievable (33\%). Table 4 specifies that either Design 1 or Design 2 can be used with only 780,000 smolts. However, if only three sites can be developed, then Design 2 no longer meets the power criterion and Design 1 must be used. Table 4 indicates that under the conditions of 780,000 smolts and three sites, the power criterion can be met with a sampling rate of $33 \%$ if the survival of OCT fish is at least 0.003 although a sampling rate of $67 \%$ is required if the survival of OCT fish is less than 0.003 but greater than 0.002 . Therefore, if the sampling rate is limited to $33 \%$, the power criterion would be achievable only during those years in which the survival of OCT fish was at least 0.003 . It can be seen that some combinations do not achieve a $90 \%$ power, e.g., a three treatment experiment with 780,000 smolts.

The power of an ANOVA was affected by three general factors:

(1) size of the treatment effect,

(2) sample size, and

(3) size of the error variance (Neter et al. 1985).

In this study the sample size had two dimensions: number of fish per pond, and number of replicates (treatment complements). Increases in both the number of fish and the number of replicates increased power (Appendix 2). These three general factors manifested themselves in different ways, creating some specific relationships in this study (see Appendix 2). Some of the specific factors can be manipulated (e.g., sampling rate) whereas others cannot (e.g., locale effects). Adjusting the level of those factors that can be manipulated can compensate somewhat for the impacts of the factors that cannot be controlled. The factors that can and cannot be controlled are discussed below. 
Table 4. Experimental designs yielding $90 \%$ power. The simulations assumed an average school size of 5 fish throughout the life history.

\begin{tabular}{|c|c|c|c|c|c|c|c|}
\hline \multirow[b]{2}{*}{$\begin{array}{l}\text { \# Smolts } \\
(\mathrm{x} \mathrm{1000)}\end{array}$} & \multirow[b]{2}{*}{$\begin{array}{l}\text { Success Rate } \\
\text { of OCT Fish }\end{array}$} & \multirow[b]{2}{*}{$\begin{array}{l}\text { Treatments } \\
\text { Compared } \\
\end{array}$} & \multirow[b]{2}{*}{$\begin{array}{c}\text { Minimum } \\
\text { Sampling Rate } \\
\end{array}$} & \multicolumn{4}{|c|}{ Facilities } \\
\hline & & & & \# Sites & \# Ponds/Site & $\begin{array}{c}\text { \# Fish/Pond } \\
\text { (x 1000) }\end{array}$ & Design \\
\hline \multirow[t]{4}{*}{1125} & 0.002 & NIT LNIT OCT & $67 \%$ & 5 & 9 & 25 & 1 \\
\hline & 0.002 & NIT OCT & $33 \%$ & 3 & 6 & 62.5 & 1 \\
\hline & 0.003 & NIT LNIT OCT & $33 \%$ & 5 & 9 & 25 & 1 \\
\hline & 0.003 & NIT LNIT OCT & $33 \%$ & 5 & 3 & 75 & 2 \\
\hline \multirow[t]{5}{*}{$750-765$} & 0.002 & NIT OCT & $67 \%$ & 3 & 6 & 42 & 1 \\
\hline & 0.002 & NIT OCT & $33 \%$ & 5 & 6 & 25 & 1 \\
\hline & 0.003 & NIT OCT & $33 \%$ & 5 & 6 & 25 & 1 \\
\hline & 0.003 & NIT OCT & $33 \%$ & 5 & 2 & 75 & 2 \\
\hline & 0.003 & NIT OCT & $33 \%$ & 3 & 6 & 42 & 1 \\
\hline \multirow[t]{2}{*}{$500-510$} & 0.003 & NIT OCT & $67 \%$ & 3 & 6 & 28 & 1 \\
\hline & 0.003 & NIT OCT & $33 \%$ & 5 & 6 & 17 & 1 \\
\hline
\end{tabular}


Specific Relationships for Factors That Cannot be Manipulated

Power increased with OCT success rate. This relationship relates to the size of the treatment effect. The absolute difference in survival rates between NIT and OCT fish was $0.5^{*}$ (OCT survival rate) because the NIT survival rate was always assumed to be $150 \%$ the OCT survival rate. Therefore, the difference increased with the OCT survival rate and, consequently, so did the power.

For any design, power was increased by reducing the number of treatments to two.

This relationship relates to the sample size. Reducing the number of treatments increased the number of fish per pond for the remaining treatments.

Specific Relationships for Factors That Can be Manipulated

Locale effects decreased power. This relationship relates to the size of the error variance for Design 3 only (Design 1 accounted for locale effects and Design 2 eliminated locale effects). The level of locale effects cannot be manipulated, but they can be eliminated by locating the ponds within a treatment complement in a close proximity to one another as possible. Every reasonable effort should be made to minimize the differences among ponds within a complement .

Power increased as the number_of fish_per_nondincrease\& This relationship relates to the sample size (a). Given a fixed design, increases in the number of fish per pond by increasing the total number of experimental fish increased power. Such an increase reduced the uncertainty in the success rate estimated per pond and, therefore, increased the efficiency of comparing treatment ponds.

Power increased as the number of treatment comblements increased. This relationship relates to sample size (b). With a fixed total number of smolts, there is a tradeoff between increasing the number of fish per pond and increasing the number of treatment complements; if one is increased, the other is decreased. However, for a fixed total number of smolts, a greater increase in power was achieved by increasing the number of treatment complements rather than by increasing the number of smolts per pond. This result is evident from the superiority of Design 1 over Design 2.

Design 1 specified three times the number of treatment complements as Design 2 and one-third the number of fish per pond.

Power increased with sampling rate of successful fish. This relationship relates to the size of the treatment effect. The absolute difference in success rate between NIT and OCT fish was also directly related to the sampling rate $(\mathrm{p})$ : 


$$
\begin{aligned}
\mathrm{f}_{i j(k=N I T)-\mathrm{f}_{i j(k=O C T)}} & =\left[\mu+\mathrm{s}_{i}\right]^{*}\left[1.5^{\mathrm{I}(k=\mathrm{NIT})}\right]^{*} \mathrm{p}-\left[\mu+\mathrm{s}_{i}\right]^{*} \mathrm{p} \\
& =0.5^{*}\left[\mu+\mathrm{s}_{i}\right]^{*} \mathrm{p}
\end{aligned}
$$

As $p$ increased, the difference in apparent success rate was larger which increased the power. 


\section{DISCUSSION AND CONCLUSIONS}

A key assumption in the PSR (BPA 1993) is that the spring chinook salmon experiment should detect a $50 \%$ increase in survival caused by the NIT treatment compared to the OCT treatment at least $90 \%$ of the time. This assumption was used to evaluate three experimental designs. Design 3, proposed in the PSR (BPA 1993) required a $1.61 \mathrm{~km}$ separation of the acclimation ponds within a treatment. This separation introduced a locale effect that could not be accounted for with that design. Since treatments would be randomly allocated to the different locales, locale was a random effect. Therefore, the inability to account for locale effect did not bias the model, but did increase the amount of error variance and therefore decreased the power. A modification to this design (Design 2) eliminated the $1.61 \mathrm{~km}$ separation and thereby eliminated effects due to locale. For this reason, the error variance for Design 2 was always less than for Design 3; consequently, Design 2 was more powerful.

Although Design 2 was more powerful than Design 3, Design 2 could meet the power requirement only under a limited range of conditions. For example, $90 \%$ power was achieved with Design 2 only when OCT survival was high (0.003) and when the total number of smolts available for experimentation was greater than 750,000. The success rate limitation indicates that only in "good" years (years of high survival) will the power criterion be met with Design 2. Since the number of smolts available for the first years of implementation (before the runs have been reestablished) is expected to be significantly less than the full complement of 1,125,000 smolts, the power criterion cannot be met with Design 2. On the other hand, Design 1 proved to yield the highest power under the widest range of conditions. Based on our results, the preference among the three designs is

\begin{tabular}{cc}
\hline Design & $\begin{array}{c}\text { Preference for YFP } \\
\text { Objectives }\end{array}$ \\
\hline 1 & 1 \\
2 & 2 \\
3 & 3 \\
\hline
\end{tabular}

where preference indicates how likely a design can be used to meet the YFP experimentation objective for spring chinook salmon.

Any fisheries study designed to test for differences in survival or performance (as described here) may also benefit from the results described in this report. The general relationships described between power and the four factors (number of fish available, number of treatments to be compared, success rate of the control method, and sampling rate of survivors) can be used to adapt an experiment to increase power and conduct a more effective study. However, some of the results depended on the method used in simulating the data. Those results may not apply to studies for which the simulated data 
are not realistic. For example, consider a study where the factors are likely to reflect those given in Table 1 but where the success of the treatment method does not increase proportionally with that of the control method (OCT). The difference in success may remain constant regardless of the level of success of the control. In this case, the relationships between power and the success rate of the control method and between power and the sampling rate are not applicable. Alternatively, if the success of the treatment is expected to increase proportionally to that of the control method, then all the results are herein applicable. 


\section{REFERENCES}

Beyer, W.H. (ed.). 1984. CRC Standard Mathematical Tables 27th Edition. CRC Press, Inc., Boca Raton, Florida.

Bickel, P.J., and K.A. Doksum. 1977. Mathematical Statistics Basic Ideas and Selected Topics. Holden-Day, Inc., Oakland, California.

BPA. 1993. Planning Status Report 1993, Yakima/Klickitat Fisheries Project. Vols. 1-8. Bonneville Power Administration, Portland, Oregon.

Fast, D., J. Hubble, M. Kohn, and B. Watson. 1991. Yakima River spring chinook salmon enhancement study, Final Report 1991 to the Bonneville Power Administration, Contract DE-A179-83BP39461.

Hammersley, J.M., and D.C. Handscomb. 1964. Monte Carlo Methods. Methuen, London.

Hogg, R.V., and A.T. Craig. 1978. Introduction to Mathematical Statistics Fourth Edition. Macmillan Publ. Co., Inc., New York.

Neter, J., W. Wasserman, and M.H. Kutner. 1985. Applied Linear Statistical Models Regression, Analysis of Variance, 'and Experimental Designs Second Edition. Richard D. Irwin, Inc., Homewood Illinois.

Pettit, R. 1993. Escapement estimates for spring chinook in Washington tributaries above Bonneville Dam, 1970- 1992. Washington Department of Fisheries, Columbia River Laboratory Progress Report 93-4, Battle Ground, Washington.

Press, W.H., B.P. Flannery, S.A. Teukolsky, and W.T. Vetterling. 1986. Numerical Recipes The Art of Scientific Computing. Cambridge Univ. Press, New York.

Rosner, B. 1986. Fundamentals of Biostatistics, 2nd ed. Duxbury Press, Boston.

Senn, H., J. Mack, and L. Rothfus. 1984. Compendium of Low-Cost Pacific Salmon and Steelhead Trout Production Facilities and Practices in the Pacific Northwest. Report to the Bonneville Power Administration, Contract DE-AC7983BP12745.S

Sokal, R.R., and F.J. Rohlf. 198 1. Biometry, 2nd ed. W.H. Freeman, San Francisco.

Welch, D.W., and Y. Ishida. 1993. On the statistical distribution of salmon in the sea; application of the negative binomial distribution, and the influence of sampling effort. Can. J. Fish. Aquat. Sci. 50:1029-1038. 


\section{APPENDIX 1 - Equivalence between an increase in school size and an increase in the modeled binomial variance.}

Fish are not typically independent units but travel together in schools which encounter common rearing environments, prey and predator densities, and oceanographic conditions. Therefore, the fates of fish within a school are positively correlated. When schooling occurs, the variance in the success rates is greater than the binomial variance based on independence of fish success. A variance inflation factor was used to model the consequences of fish schooling. This appendix demonstrates the equivalence between inflation of the binomial variance and increasing the school size of the experimental releases.

Let

$\mathrm{N}=$ number of fish from a single pond,

$\mathrm{p}=$ probability that a fish from that pond is successful, and

$\mathrm{X}=$ number of surviving fish from a single pond.

Then,

$\mathrm{X} \sim \operatorname{Binomial}(\mathrm{N}, \mathrm{p})$, and

$\operatorname{Var}(\mathrm{X} / \mathrm{N})=\mathrm{pq} / \mathrm{N}$, where $\mathrm{q}=1-\mathrm{p}$.

If the fish school, then consider each school to be an independent unit and each fish within a school to suffer the same fate. Then, let

$$
\begin{aligned}
& \mathrm{a}=\text { number of fish/school, } \\
& \mathrm{M}=\text { number of schools from a single pond }=\mathrm{N} / \alpha, \\
& \mathrm{p}=\text { probability that a schools from that pond is successful, and } \\
& \mathrm{Y}=\text { number of successful schools. }
\end{aligned}
$$

Then

$$
\begin{aligned}
& \mathrm{Y} \sim \operatorname{Binomial}(\mathrm{M}, \mathrm{p}) \\
& \begin{aligned}
\operatorname{Var}(\mathrm{Y} / \mathrm{M}) & =\mathrm{pq} / \mathrm{M} \\
& =\mathrm{pq} \alpha / \mathrm{N} \\
& =\alpha \operatorname{Var}(\mathrm{X} / \mathrm{N}) .
\end{aligned}
\end{aligned}
$$

Thus, a school size of $\boldsymbol{\alpha}$ fish/school is equivalent to decreasing the sample size $\mathrm{N}$ by a factor of $\alpha$ to $M$. 


\section{APPENDIX 2 - Detailed Simulation Results}

The main text of this report presents a distillation of the simulation results, focusing on specific survival and sampling rates, and school size. A much broader array of parameter values was simulated and the results are presented here. Most of the simulations involving fewer than 500,000 total fish have been excluded, as well as those that are virtually redundant (i.e., a simulation involving 675,000 fish was excluded if a run of 750,000 fish was also done).

The simulations are grouped by model and model version. The numerical designation of each model version indicates the specific details of the model configuration. For example, version 1.53 is model 1 with 5 sites and 3 treatments. Version 1.52 is the same, but with only 2 treatments. Corresponding 3-site versions of model 1 are designated 1.33 and 1.32, respectively. Otherwise, data headings should be self-explanatory. Note that power results are presented for a levels of 0.05 as well as 0.10 .

Model 3 results presented here include locale variation at the $25 \%$ and $50 \%$ levels only, although a few simulations at $100 \%$ were done for Table 2. Although models 2 and 3 differed in physical layout a great deal, in terms of the simulations, the only difference between them was level of the locale effect. Locale effects did not exist in model 2 and were therefore equal to 0 . Power for any model 2 version is equivalent to the power of the corresponding model 3 version with locale effect set to 0 . For example, if locale effect in model 3.52 could be eliminated, the design would be exactly as powerful as model 2.52 . 


\section{Model 1 Simulations}

Model 1.53: 5 sites, 3 treatment complements per site, and 3 treatments yielding a total of 45 ponds; 25,000 fish/pond; 1,125,000 smolts.

\begin{tabular}{|c|c|c|c|c|}
\hline OCT Survival & Sampling Rate & School size & Power for $\alpha=.10^{T}$ & Power for $\alpha=.05$ \\
\hline 0.001 & 0.33 & 10 & 0.39 & 0.27 \\
\hline 0.001 & 0.33 & 5 & 0.59 & 0.46 \\
\hline 0.001 & 0.33 & 2 & 0.84 & 0.74 \\
\hline 0.001 & 0.67 & 10 & 0.42 & 0.30 \\
\hline 0.001 & 0.67 & 5 & 0.68 & 0.56 \\
\hline 0.001 & 0.67 & 2 & 0.96 & 0.91 \\
\hline 0.001 & 1.00 & 10 & 0.44 & 0.30 \\
\hline 0.001 & 1.00 & 5 & 0.71 & 0.58 \\
\hline 0.001 & 1.00 & 2 & 0.98 & 0.96 \\
\hline 0.002 & 0.33 & 10 & 0.65 & 0.52 \\
\hline 0.002 & 0.33 & 5 & 0.88 & 0.79 \\
\hline 0.002 & 0.33 & 2 & 0.99 & 0.96 \\
\hline 0.002 & 0.67 & 10 & 0.69 & 0.57 \\
\hline 0.002 & 0.67 & 5 & 0.94 & 0.87 \\
\hline 0.002 & 0.67 & 2 & 1.00 & 1.00 \\
\hline 0.002 & 1.00 & 10 & 0.71 & 0.57 \\
\hline 0.002 & 1.00 & 5 & 0.96 & 0.91 \\
\hline 0.002 & 1.00 & 2 & 1.00 & 1.00 \\
\hline 0.003 & 0.33 & 10 & 0.81 & 0.70 \\
\hline 0.003 & 0.33 & 5 & 0.97 & 0.93 \\
\hline 0.003 & 0.33 & 2 & 1.00 & 1.00 \\
\hline 0.003 & 0.67 & 10 & 0.86 & 0.77 \\
\hline 0.003 & 0.67 & 5 & 0.99 & 0.97 \\
\hline 0.003 & 0.67 & 2 & 1.00 & 1.00 \\
\hline 0.003 & 1.00 & 10 & 0.88 & 0.81 \\
\hline 0.003 & 1.00 & 5 & 0.99 & 0.98 \\
\hline 0.003 & 1.00 & 2 & 1.00 & 1.00 \\
\hline
\end{tabular}

The significance level at which the test was conducted is given by $\boldsymbol{\alpha}$. 
Model 1.53: 5 sites, 3 treatment complements per site, and 3 treatments yielding a total of 45 ponds; 17,000 fish/pond; 765,000 smolts.

\begin{tabular}{|c|c|c|c|c|}
\hline OCT Survival & Sampling Rate & School Size & Power for $\alpha=.10^{1}$ & Power for $\alpha=.05^{1}$ \\
\hline 0.001 & 0.33 & 10 & 0.29 & 0.19 \\
\hline 0.001 & 0.33 & 5 & 0.45 & 0.31 \\
\hline 0.001 & 0.33 & 2 & 0.66 & 0.53 \\
\hline 0.001 & 0.67 & 10 & 0.32 & 0.21 \\
\hline 0.001 & 0.67 & 5 & 0.52 & 0.38 \\
\hline 0.001 & 0.67 & 2 & 0.86 & 0.76 \\
\hline 0.001 & 1.00 & 10 & 0.33 & 0.22 \\
\hline 0.001 & 1.00 & 5 & 0.54 & 0.41 \\
\hline 0.001 & 1.00 & 2 & 0.91 & 0.84 \\
\hline 0.002 & 0.33 & 10 & 0.50 & 0.37 \\
\hline 0.002 & 0.33 & 5 & 0.71 & 0.59 \\
\hline 0.002 & 0.33 & 2 & 0.93 & 0.87 \\
\hline 0.002 & 0.67 & 10 & 0.54 & 0.40 \\
\hline 0.002 & 0.67 & 5 & 0.81 & 0.70 \\
\hline 0.002 & 0.67 & 2 & 0.99 & 0.98 \\
\hline 0.002 & 1.00 & 10 & 0.55 & 0.42 \\
\hline 0.002 & 1.00 & 5 & 0.84 & 0.74 \\
\hline 0.002 & 1.00 & 2 & 1.00 & 0.99 \\
\hline 0.003 & 0.33 & 10 & 0.65 & 0.51 \\
\hline 0.003 & 0.33 & 5 & 0.87 & 0.79 \\
\hline 0.003 & 0.33 & 2 & 0.99 & 0.96 \\
\hline 0.003 & 0.67 & 10 & 0.71 & 0.58 \\
\hline 0.003 & 0.67 & 5 & 0.94 & 0.89 \\
\hline 0.003 & 0.67 & 2 & 1.00 & 1.00 \\
\hline 0.003 & 1.00 & 10 & 0.72 & 0.60 \\
\hline 0.003 & 1.00 & 5 & 0.98 & 0.91 \\
\hline 0.003 & 1.00 & 2 & 1.00 & 1.00 \\
\hline
\end{tabular}

$\mathbf{T}$ The significance level at which the test was conducted is given by $\alpha$. 
Model 1.52: 5 sites, 3 treatment complements per site, and 2 treatments yielding a total of 30 ponds; 37,500 fish/pond; $1,125,000$ smolts.

\begin{tabular}{|c|c|c|c|c|}
\hline OCT Survival & Sampling Rate & School Size & Power for $\alpha=.10^{T}$ & Power for $\alpha=.05^{\mathrm{T}}$ \\
\hline 0.001 & 0.33 & 10 & 0.62 & 0.49 \\
\hline 0.001 & 0.33 & 5 & 0.84 & 0.72 \\
\hline 0.001 & 0.33 & 2 & 0.97 & 0.93 \\
\hline 0.001 & 0.67 & 10 & 0.65 & 0.52 \\
\hline 0.001 & 0.67 & 5 & 0.90 & 0.82 \\
\hline 0.001 & 0.67 & 2 & 1.00 & 0.99 \\
\hline 0.001 & 1.00 & 10 & 0.67 & 0.54 \\
\hline 0.001 & 1.00 & 5 & 0.93 & 0.86 \\
\hline 0.001 & 1.00 & 2 & 1.00 & 1.00 \\
\hline 0.002 & 0.33 & 10 & 0.87 & 0.79 \\
\hline 0.002 & 0.33 & 5 & 0.98 & 0.96 \\
\hline 0.002 & 0.33 & 2 & 1.00 & 1.00 \\
\hline 0.002 & 0.67 & 10 & 0.91 & 0.83 \\
\hline 0.002 & 0.67 & 5 & 1.00 & 0.98 \\
\hline 0.002 & 0.67 & 2 & 1.00 & 1.00 \\
\hline 0.002 & 1.00 & 10 & 0.92 & 0.85 \\
\hline 0.002 & 1.00 & 5 & 1.00 & 0.99 \\
\hline 0.002 & 1.00 & 2 & 1.00 & 1.00 \\
\hline 0.003 & 0.33 & 10 & 0.97 & 0.93 \\
\hline 0.003 & 0.33 & 5 & 1.00 & 0.99 \\
\hline 0.003 & 0.33 & 2 & 1.00 & 1.00 \\
\hline 0.003 & 0.67 & 10 & 0.98 & 0.96 \\
\hline 0.003 & 0.67 & 5 & 1.00 & 1.00 \\
\hline 0.003 & 0.67 & 2 & 1.00 & 1.00 \\
\hline 0.003 & 1.00 & 10 & 0.98 & 0.96 \\
\hline 0.003 & 1.00 & 5 & 1.00 & 1.00 \\
\hline 0.003 & 1.00 & 2 & 1.00 & 1.00 \\
\hline
\end{tabular}

The significance level at which the test was conducted is given by $\boldsymbol{\alpha}$. 
Model 1.52: 5 sites, 3 treatment complements per site, and 2 treatments yielding a total of 30 ponds; 25,000 fish/pond; 750,000 smolts.

\begin{tabular}{|c|c|c|c|c|}
\hline OCT Survival & Sampling Rate & School Size & Power for $\alpha=.10^{1}$ & Power for $\alpha=.05^{1}$ \\
\hline 0.001 & 0.33 & 10 & 0.46 & 0.32 \\
\hline 0.001 & 0.33 & 5 & 0.68 & 0.54 \\
\hline 0.001 & 0.33 & 2 & 0.89 & 0.80 \\
\hline 0.001 & 0.67 & 10 & 0.50 & 0.36 \\
\hline 0.001 & 0.67 & 5 & 0.75 & 0.63 \\
\hline 0.001 & 0.67 & 2 & 0.97 & 0.93 \\
\hline 0.001 & 1.00 & 10 & 0.52 & 0.38 \\
\hline 0.001 & 1.00 & 5 & 0.80 & 0.68 \\
\hline 0.001 & 1.00 & 2 & 0.99 & 0.97 \\
\hline 0.002 & 0.33 & 10 & 0.74 & 0.61 \\
\hline 0.002 & 0.33 & 5 & 0.92 & 0.85 \\
\hline 0.002 & 0.33 & 2 & 0.99 & 0.98 \\
\hline 0.002 & 0.67 & 10 & 0.77 & 0.66 \\
\hline 0.002 & 0.67 & 5 & 0.96 & 0.92 \\
\hline 0.002 & 0.67 & 2 & 1.00 & 1.00 \\
\hline 0.002 & 1.00 & 10 & 0.78 & 0.67 \\
\hline 0.002 & 1.00 & 5 & 0.97 & 0.94 \\
\hline 0.002 & 1.00 & 2 & 1.00 & 1.00 \\
\hline 0.003 & 0.33 & 10 & 0.88 & 0.80 \\
\hline 0.003 & 0.33 & 5 & 0.99 & 0.96 \\
\hline 0.003 & 0.33 & 2 & 1.00 & 1.00 \\
\hline 0.003 & 0.67 & 10 & 0.91 & 0.84 \\
\hline 0.003 & 0.67 & 5 & 1.00 & 0.98 \\
\hline 0.003 & 0.67 & 2 & 1.00 & 1.00 \\
\hline 0.003 & 1.00 & 10 & 0.93 & 0.86 \\
\hline 0.003 & 1.00 & 5 & 1.00 & 0.99 \\
\hline 0.003 & 1.00 & 2 & 1.00 & 1.00 \\
\hline
\end{tabular}

The significance level at which the test was conducted is given by a. 
Model 1.52: 5 sites, 3 treatment complements per site, and 2 treatments yielding a total of 30 ponds; 17,000 fish/pond; 5 10,000 smolts.

\begin{tabular}{|c|c|c|c|c|}
\hline OCT Survival & Sampling Rate & School Size & Power for $\alpha=.10^{T}$ & Power for $\alpha=.05$ \\
\hline 0.001 & 0.33 & 10 & 0.37 & 0.25 \\
\hline 0.001 & 0.33 & 5 & 0.53 & 0.40 \\
\hline 0.001 & 0.33 & 2 & 0.77 & 0.65 \\
\hline 0.001 & 0.67 & 10 & 0.38 & 0.26 \\
\hline 0.001 & 0.67 & 5 & 0.61 & 0.47 \\
\hline 0.001 & 0.67 & 2 & 0.90 & 0.82 \\
\hline 0.001 & 1.00 & 10 & 0.40 & 0.28 \\
\hline 0.001 & 1.00 & 5 & 0.64 & 0.50 \\
\hline 0.001 & 1.00 & 2 & 0.94 & 0.89 \\
\hline 0.002 & 0.33 & 1 & 0.57 & 0.43 \\
\hline 0.002 & 0.33 & 5 & 0.80 & 0.68 \\
\hline 0.002 & 0.33 & 2 & 0.96 & 0.91 \\
\hline 0.002 & 0.67 & 10 & 0.62 & 0.48 \\
\hline 0.002 & 0.67 & 5 & 0.87 & 0.77 \\
\hline 0.002 & 0.67 & 2 & 1.00 & 0.99 \\
\hline 0.002 & 1.00 & 10 & 0.64 & 0.50 \\
\hline 0.002 & 1.00 & 5 & 0.90 & 0.82 \\
\hline 0.002 & 1.00 & 2 & 1.00 & 1.00 \\
\hline 0.003 & 0.33 & 10 & 0.74 & 0.62 \\
\hline 0.003 & 0.33 & 5 & 0.92 & 0.85 \\
\hline 0.003 & 0.33 & 2 & 0.99 & 0.98 \\
\hline 0.003 & 0.67 & 10 & 0.77 & 0.66 \\
\hline 0.003 & 0.67 & 5 & 0.97 & 0.93 \\
\hline 0.003 & 0.67 & 2 & 1.00 & 1.00 \\
\hline 0.003 & 1.00 & 10 & 0.80 & 0.70 \\
\hline 0.003 & 1.00 & 5 & 0.97 & 0.94 \\
\hline 0.003 & 1.00 & 2 & 1.00 & 1.00 \\
\hline
\end{tabular}


Model 1.33 : 3 sites, 3 treatment complements per site, and 3 treatments yielding a total of 27 ponds; 25,000 fish/pond; 675,000 smolts.

\begin{tabular}{|c|c|c|c|c|}
\hline OCT Survival & Sampling Rate & School Size & Power for $\alpha=.10^{T}$ & Power for $\alpha=.05^{1}$ \\
\hline 0.001 & 0.33 & 10 & 0.27 & 0.17 \\
\hline 0.001 & 0.33 & 5 & 0.40 & 0.27 \\
\hline 0.001 & 0.33 & 2 & 0.61 & 0.47 \\
\hline 0.001 & 0.67 & 10 & 0.29 & 0.19 \\
\hline 0.001 & 0.67 & 5 & 0.47 & 0.33 \\
\hline 0.001 & 0.67 & 2 & 0.80 & 0.68 \\
\hline 0.001 & 1.00 & 10 & 0.30 & 0.19 \\
\hline 0.001 & 1.00 & 5 & 0.50 & 0.36 \\
\hline 0.001 & 1.00 & 2 & 0.87 & 0.78 \\
\hline 0.002 & 0.33 & 10 & 0.43 & 0.30 \\
\hline 0.002 & 0.33 & 5 & 0.67 & 0.52 \\
\hline 0.002 & 0.33 & 2 & 0.87 & 0.78 \\
\hline 0.002 & 0.67 & 10 & 0.49 & 0.35 \\
\hline 0.002 & 0.67 & 5 & 0.75 & 0.61 \\
\hline 0.002 & 0.67 & 2 & 0.98 & 0.94 \\
\hline 0.002 & 1.00 & 10 & 0.50 & 0.35 \\
\hline 0.002 & 1.00 & 5 & 0.78 & 0.66 \\
\hline 0.002 & 1.00 & 2 & 0.99 & 0.98 \\
\hline 0.003 & 0.33 & 10 & 0.61 & 0.46 \\
\hline 0.003 & 0.33 & 5 & 0.82 & 0.70 \\
\hline 0.003 & 0.33 & 2 & 0.96 & 0.93 \\
\hline 0.003 & 0.67 & 10 & 0.65 & 0.52 \\
\hline 0.003 & 0.67 & 5 & 0.89 & 0.81 \\
\hline 0.003 & 0.67 & 2 & 1.00 & 0.99 \\
\hline 0.003 & 1.00 & 10 & 0.67 & 0.53 \\
\hline 0.003 & 1.00 & 5 & 0.93 & 0.86 \\
\hline 0.003 & 1.00 & 2 & 1.00 & 1.00 \\
\hline
\end{tabular}

$\mathbf{T}$ The significance level at which the test was conducted is given by $\mathbf{a}$. 
Model 1.33: 3 sites, 3 treatment complements per site, and 3 treatments yielding a total of 27 ponds; 17,000 fish/pond; 459,000 smolts.

\begin{tabular}{|c|c|c|c|c|}
\hline OCT Survival & Sampling Rate & School Size & Power for $\alpha=.10^{1}$ & Power for $\alpha=.05^{1}$ \\
\hline 0.001 & 0.33 & 10 & 0.21 & 0.12 \\
\hline 0.001 & 0.33 & 5 & 0.30 & 0.19 \\
\hline 0.001 & 0.33 & 2 & 0.47 & 0.33 \\
\hline 0.001 & 0.67 & 10 & 0.23 & 0.14 \\
\hline 0.001 & 0.67 & 5 & 0.34 & 0.23 \\
\hline 0.001 & 0.67 & 2 & 0.64 & 0.49 \\
\hline 0.001 & 1.00 & 10 & 0.23 & 0.14 \\
\hline 0.001 & 1.00 & 5 & 0.36 & 0.24 \\
\hline 0.001 & 1.00 & 2 & 0.71 & 0.58 \\
\hline 0.002 & 0.33 & 10 & 0.33 & 0.21 \\
\hline 0.002 & 0.33 & 5 & 0.49 & 0.35 \\
\hline 0.002 & 0.33 & 2 & 0.74 & 0.60 \\
\hline 0.002 & 0.67 & 10 & 0.37 & 0.24 \\
\hline 0.002 & 0.67 & 5 & 0.57 & 0.43 \\
\hline 0.002 & 0.67 & 2 & 0.90 & 0.82 \\
\hline 0.002 & 1.00 & 10 & 0.36 & 0.24 \\
\hline 0.002 & 1.00 & 5 & 0.61 & 0.47 \\
\hline 0.002 & 1.00 & 2 & 0.96 & 0.90 \\
\hline 0.003 & 0.33 & 10 & 0.45 & 0.31 \\
\hline 0.003 & 0.33 & 5 & 0.66 & 0.52 \\
\hline 0.003 & 0.33 & 2 & 0.89 & 0.80 \\
\hline 0.003 & 0.67 & 10 & 0.50 & 0.35 \\
\hline 0.003 & 0.67 & 5 & 0.75 & 0.63 \\
\hline 0.003 & 0.67 & 2 & 0.98 & 0.95 \\
\hline 0.003 & 1.00 & 10 & 0.52 & 0.38 \\
\hline 0.003 & 1.00 & 5 & 0.79 & 0.67 \\
\hline 0.003 & 1.00 & 2 & 0.99 & 0.98 \\
\hline
\end{tabular}

The significance level at which the test was conducted is given by a. 
Model 1.32: 3 sites, 3 treatment complements per site, and 2 treatments yielding a total of 18 ponds; 62,500 fish/pond; $1,125,000$ smolts.

\begin{tabular}{|c|c|c|c|c|}
\hline OCT Survival & Sampling Rate & School Size & Power for $\alpha=.10^{T}$ & Power for $\alpha=.05^{1}$ \\
\hline 0.001 & 0.33 & 10 & 0.62 & 0.47 \\
\hline 0.001 & 0.33 & 5 & 0.82 & 0.69 \\
\hline 0.001 & 0.33 & 2 & 0.95 & 0.90 \\
\hline 0.001 & 0.67 & 10 & 0.65 & 0.50 \\
\hline 0.001 & 0.67 & 5 & 0.89 & 0.79 \\
\hline 0.001 & 0.67 & 2 & 1.00 & 0.98 \\
\hline 0.001 & 1.00 & 10 & 0.67 & 0.52 \\
\hline 0.001 & 1.00 & 5 & 0.91 & 0.82 \\
\hline 0.001 & 1.00 & 2 & 1.00 & 0.99 \\
\hline 0.002 & 0.33 & 10 & 0.86 & 0.76 \\
\hline 0.002 & 0.33 & 5 & 0.98 & 0.94 \\
\hline 0.002 & 0.33 & 2 & 1.00 & 1.00 \\
\hline 0.002 & 0.67 & 10 & 0.90 & 0.80 \\
\hline 0.002 & 0.67 & 5 & 0.99 & 0.97 \\
\hline 0.002 & 0.67 & 2 & 1.00 & 1.00 \\
\hline 0.002 & 1.00 & 10 & 0.92 & 0.83 \\
\hline 0.002 & 1.00 & 5 & 1.00 & 0.99 \\
\hline 0.002 & 1.00 & 2 & 1.00 & 1.00 \\
\hline 0.003 & 0.33 & 10 & 0.95 & 0.90 \\
\hline 0.003 & 0.33 & 5 & 1.00 & 0.99 \\
\hline 0.003 & 0.33 & 2 & 1.00 & 1.00 \\
\hline 0.003 & 0.67 & 10 & 0.97 & 0.93 \\
\hline 0.003 & 0.67 & 5 & 1.00 & 1.00 \\
\hline 0.003 & 0.67 & 2 & 1.00 & 1.00 \\
\hline 0.003 & 1.00 & 10 & 0.98 & 0.95 \\
\hline 0.003 & 1.00 & 5 & 1.00 & 1.00 \\
\hline 0.003 & 1.00 & 2 & 1.00 & 1.00 \\
\hline
\end{tabular}

The significance level at which the test was conducted is given by a. 
Model 1.32: 3 sites, 3 treatment complements per site, and 2 treatments yielding a total of 18 ponds; 41,667 fish/pond; 750,000 smolts.

\begin{tabular}{|c|c|c|c|c|}
\hline OCT Survival & Sampling Rate & School Size & Power for $\alpha=.10^{T}$ & Power for $\alpha=.05^{1}$ \\
\hline 0.001 & 0.33 & 10 & 0.46 & 0.32 \\
\hline 0.001 & 0.33 & 5 & 0.66 & 0.51 \\
\hline 0.001 & 0.33 & 2 & 0.87 & 0.75 \\
\hline 0.001 & 0.67 & 10 & 0.50 & 0.35 \\
\hline 0.001 & 0.67 & ‘5 & 0.76 & 0.62 \\
\hline 0.001 & 0.67 & 2 & 0.96 & 0.92 \\
\hline 0.001 & 1.00 & 10 & 0.51 & 0.36 \\
\hline 0.001 & 1.00 & 5 & 0.78 & 0.65 \\
\hline 0.001 & 1.00 & 2 & 0.99 & 0.96 \\
\hline 0.002 & 0.33 & 10 & 0.73 & 0.59 \\
\hline 0.002 & 0.33 & 5 & 0.90 & 0.81 \\
\hline 0.002 & 0.33 & 2 & 0.99 & 0.97 \\
\hline 0.002 & 0.67 & 10 & 0.77 & 0.62 \\
\hline 0.002 & 0.67 & 5 & 0.96 & 0.89 \\
\hline 0.002 & 0.67 & 2 & 1.00 & 1.00 \\
\hline 0.002 & 1.00 & 10 & 0.78 & 0.65 \\
\hline 0.002 & 1.00 & 5 & 0.97 & 0.92 \\
\hline 0.002 & 1.00 & 2 & 1.00 & 1.00 \\
\hline 0.003 & 0.33 & 10 & 0.87 & 0.76 \\
\hline 0.003 & 0.33 & 5 & 0.97 & 0.93 \\
\hline 0.003 & 0.33 & 2 & 1.00 & 1.00 \\
\hline 0.003 & 0.67 & 10 & 0.90 & 0.82 \\
\hline 0.003 & 0.67 & 5 & 0.99 & 0.97 \\
\hline 0.003 & 0.67 & 2 & 1.00 & 1.00 \\
\hline 0.003 & 1.00 & 10 & 0.91 & 0.83 \\
\hline 0.003 & 1.00 & 5 & 1.00 & 0.98 \\
\hline 0.003 & 1.00 & 2 & 1.00 & 1.00 \\
\hline
\end{tabular}

The significance level at which the test was conducted is given by $\mathbf{a}$. 
Model 1.32: 3 sites, 3 treatment complements per site, and 2 treatments yielding a total of 18 ponds; 27,778 fish/pond; 500,000 smolts.

\begin{tabular}{|c|c|c|c|c|}
\hline OCT Survival & Sampling Rate & School Size & Power for $\alpha=.10^{1}$ & Power for $\alpha=.05^{1}$ \\
\hline 0.001 & 0.33 & 10 & 0.33 & 0.21 \\
\hline 0.001 & 0.33 & 5 & 0.52 & 0.37 \\
\hline 0.001 & 0.33 & 2 & 0.73 & 0.59 \\
\hline 0.001 & 0.67 & 10 & 0.37 & 0.24 \\
\hline 0.001 & 0.67 & 5 & 0.59 & 0.43 \\
\hline 0.001 & 0.67 & 2 & 0.89 & 0.78 \\
\hline 0.001 & 1.00 & 10 & 0.38 & 0.25 \\
\hline 0.001 & 1.00 & 5 & 0.63 & 0.47 \\
\hline 0.001 & 1.00 & 2 & 0.94 & 0.86 \\
\hline 0.002 & 0.33 & 10 & 0.57 & 0.41 \\
\hline 0.002 & 0.33 & 5 & 0.78 & 0.64 \\
\hline 0.002 & 0.33 & 2 & 0.94 & 0.87 \\
\hline 0.002 & 0.67 & 10 & 0.60 & 0.46 \\
\hline 0.002 & 0.67 & 5 & 0.85 & 0.74 \\
\hline 0.002 & 0.67 & 2 & 0.99 & 0.97 \\
\hline 0.002 & 1.00 & 10 & 0.62 & 0.47 \\
\hline 0.002 & I .00 & 5 & 0.88 & 0.77 \\
\hline 0.002 & 1.00 & 2 & 1.00 & 0.99 \\
\hline 0.003 & 0.33 & 10 & 0.72 & 0.58 \\
\hline 0.003 & 0.33 & 5 & 0.90 & 0.81 \\
\hline 0.003 & 0.33 & 2 & 0.99 & 0.97 \\
\hline 0.003 & 0.67 & 10 & 0.77 & 0.63 \\
\hline 0.003 & 0.67 & 5 & 0.95 & 0.89 \\
\hline 0.003 & 0.67 & 2 & 1.00 & 1.00 \\
\hline 0.003 & 1.00 & 10 & 0.79 & 0.65 \\
\hline 0.003 & 1.00 & 5 & 0.96 & 0.92 \\
\hline 0.003 & 1.00 & 2 & 1.00 & 1.00 \\
\hline
\end{tabular}

The significance level at which the test was conducted is given by a. 


\section{Model 2 Simulations}

Model 2.53: 5 sites, 1 treatment complement per site, and 3 treatments yielding a total of 15 ponds; 75,000 fish/pond; $1,125,000$ smolts.

\begin{tabular}{|c|c|c|c|c|}
\hline OCT Survival & Sampling Rate & School Size & Power for $\alpha=.10^{1}$ & Power for $\alpha=.05$ \\
\hline 0.001 & 0.33 & 10 & 0.37 & 0.23 \\
\hline 0.001 & 0.33 & 5 & 0.54 & 0.38 \\
\hline 0.001 & 0.33 & 2 & 0.77 & 0.63 \\
\hline 0.001 & 0.67 & 10 & 0.40 & 0.26 \\
\hline 0.001 & 0.67 & 5 & 0.62 & 0.47 \\
\hline 0.001 & 0.67 & 2. & 0.91 & 0.83 \\
\hline 0.001 & 1.00 & 10 & 0.42 & 0.28 \\
\hline 0.001 & 1.00 & 5 & 0.66 & 0.50 \\
\hline 0.001 & 1.00 & 2 & 0.96 & 0.89 \\
\hline 0.002 & 0.33 & 10 & 0.59 & 0.43 \\
\hline 0.002 & 0.33 & 5 & 0.81 & 0 . \\
\hline 0.002 & 0.33 & 2 & 0.96 & 0.90 \\
\hline 0.002 & 0.67 & 10 & 0.66 & 0.50 \\
\hline 0.002 & 0.67 & 5 & 0.88 & 0.77 \\
\hline 0.002 & 0.67 & 2 & 1.00 & 0.99 \\
\hline 0.002 & 1.00 & 10 & 0.66 & 0.51 \\
\hline 0.002 & 1.00 & 5 & 0.92 & 0.83 \\
\hline 0.002 & 1.00 & 2 & 1.00 & $\begin{array}{ll}0 & 0\end{array}$ \\
\hline 0.003 & 0.33 & 10 & 0.77 & 0.62 \\
\hline 0.003 & 0.33 & 5 & 0.93 & 0.84 \\
\hline 0.003 & 0.33 & 2 & 0.99 & 0.98 \\
\hline 0.003 & 0.67 & 10 & 0.81 & 0.67 \\
\hline 0.003 & 0.67 & 5 & 0.97 & 0.93 \\
\hline 0.003 & 0.67 & 2 & 1.00 & 1.00 \\
\hline 0.003 & 1.00 & 10 & 0.83 & 0.70 \\
\hline 0.003 & 1.00 & 5 & 0.98 & 0.95 \\
\hline 0.003 & 1.00 & 2 & 1.00 & 1.00 \\
\hline
\end{tabular}

The significance level at which the test was conducted is given by a. 
Model 2.53: 5 sites, 1 treatment complement per site, and 3 treatments yielding a total of 15 ponds; 50,000 fish/pond; 750,000 smolts.

\begin{tabular}{ccccc}
\hline OCT Survival Sampling Rate & School Size & Power & for $\boldsymbol{\alpha}=\mathbf{. 1 0}^{\mathbf{1}}$ & ${\text { Power for } \boldsymbol{\alpha}=\mathbf{. 0 5}^{\mathbf{1}}}$ \\
\hline & & & & \\
0.001 & 0.33 & 10 & 0.28 & 0.17 \\
0.001 & 0.33 & 5 & 0.40 & 0.26 \\
0.001 & 0.33 & 2 & 0.58 & 0.41 \\
0.001 & 0.67 & 10 & 0.29 & 0.17 \\
$\mathbf{0 . 0 0 1}$ & 0.67 & 5 & 0.48 & 0.33 \\
0.001 & 0.67 & 2 & 0.78 & 0.63 \\
0.001 & 1.00 & 10 & 0.30 & 0.18 \\
0.001 & 1.00 & 5 & 0.51 & 0.36 \\
0.001 & 1.00 & 2 & 0.85 & 0.73 \\
0.002 & 0.33 & 10 & 0.45 & 0.30 \\
0.002 & 0.33 & 5 & 0.66 & 0.49 \\
0.002 & 0.33 & 2 & 0.85 & 0.73 \\
0.002 & 0.67 & 10 & 0.50 & 0.34 \\
0.002 & 0.67 & 5 & 0.74 & 0.59 \\
0.002 & 0.67 & 2 & 0.97 & 0.91 \\
0.002 & 1.00 & 10 & 0.51 & 0.36 \\
0.002 & 1.00 & 5 & 0.78 & 0.63 \\
0.002 & 1.00 & 2 & 0.99 & 0.96 \\
0.003 & 0.33 & 10 & 0.59 & 0.44 \\
0.003 & 0.33 & 5 & 0.82 & 0.69 \\
0.003 & 0.33 & 2 & 0.96 & 0.90 \\
0.003 & 0.67 & 10 & 0.65 & 0.49 \\
0.003 & 0.67 & 5 & 0.89 & 0.79 \\
0.003 & 0.67 & 2 & 1.00 & 0.98 \\
0.003 & 1.00 & 10 & 0.67 & 0.52 \\
$\mathbf{0 . 0 0 3}$ & 1.00 & 5 & 0.91 & 0.81 \\
0.003 & 1.00 & 2 & 1.00 & 1.00 \\
\hline
\end{tabular}

The significance level at which the test was conducted is given by a. 
Model 2.52: 5 sites, 1 treatment complement per site, and 2 treatments yielding a total of 10 ponds; 112,500 fish/pond; $1,125,000$ smolts.

\begin{tabular}{lcccc}
\hline OCT Survival & Sampling Rate & School Size & Power for $\boldsymbol{\alpha}=\mathbf{. 1 0}^{\mathbf{T}}$ & ${\text { Power for } \boldsymbol{\alpha}=\mathbf{. 0 5}^{\mathbf{T}}}$ \\
\hline & & & & \\
0.001 & 0.33 & 10 & 0.54 & 0.37 \\
0.001 & 0.33 & 5 & 0.74 & 0.56 \\
0.001 & 0.33 & 2 & 0.91 & 0.79 \\
0.001 & $\mathbf{0 . 6 7}$ & 10 & 0.59 & 0.41 \\
0.001 & 0.67 & 5 & 0.84 & 0.68 \\
0.001 & 0.67 & 2 & 0.99 & 0.94 \\
0.001 & 1.00 & 10 & 0.62 & 0.44 \\
0.001 & 1.00 & 5 & 0.86 & 0.71 \\
0.001 & 1.00 & 2 & 0.99 & 0.97 \\
0.002 & 0.33 & 10 & 0.80 & 0.63 \\
0.002 & 0.33 & 5 & 0.95 & 0.84 \\
0.002 & 0.33 & 2 & 1.00 & 0.97 \\
0.002 & 0.67 & 10 & 0.85 & 0.70 \\
0.002 & 0.67 & 5 & 0.98. & 0.92 \\
0.002 & 0.67 & 2 & 1.00 & 1.00 \\
0.002 & 1.00 & 10 & 0.87 & 0.72 \\
0.002 & 1.00 & 5 & 0.99 & 0.94 \\
0.002 & 1.00 & 2 & 1.00 & $\mathbf{1 . 0 0}$ \\
0.003 & 0.33 & 10 & 0.92 & 0.80 \\
0.003 & 0.33 & 5 & 0.99 & 0.95 \\
0.003 & 0.33 & 2 & 1.00 & 1.00 \\
0.003 & 0.67 & 10 & 0.94 & 0.86 \\
0.003 & 0.67 & 5 & 1.00 & 0.98 \\
0.003 & 0.67 & 2 & 1.00 & 1.00 \\
0.003 & 1.00 & 10 & 0.95 & 0.87 \\
0.003 & 1.00 & 5 & 1.00 & 0.99 \\
0.003 & 1.00 & 2 & 1.00 & 1.00 \\
\hline
\end{tabular}

The significance level at which the test was conducted is given by a. 
Model 2.52: 5 sites, 1 treatment complement per site, and 2 treatments yielding a total of 10 ponds; 75,000 fish/pond; 750,000 smolts.

\begin{tabular}{lcccc}
\hline OCT Survival Sampling Rate & School Size & Power for $\boldsymbol{\alpha}=\mathbf{. 1 0}^{\mathbf{I}}$ & ${\text { Power for } \boldsymbol{\alpha}=\mathbf{. 0 5}^{\mathbf{I}}}$ \\
\hline & & & & \\
0.001 & 0.33 & 10 & 0.42 & 0.26 \\
0.001 & 0.33 & 5 & 0.60 & 0.43 \\
0.001 & 0.33 & 2 & 0.80 & 0.63 \\
0.001 & 0.67 & $\mathbf{1 0}$ & 0.44 & 0.29 \\
0.001 & 0.67 & 5 & 0.69 & 0.50 \\
0.001 & 0.67 & 2 & 0.93 & 0.82 \\
0.001 & 1.00 & 10 & 0.49 & 0.33 \\
0.001 & 1.00 & 5 & 0.72 & 0.54 \\
0.001 & 1.00 & 2 & 0.97 & 0.88 \\
0.002 & 0.33 & 10 & 0.66 & 0.47 \\
0.002 & 0.33 & 5 & 0.85 & 0.69 \\
0.002 & 0.33 & 2 & 0.97 & 0.89 \\
0.002 & 0.67 & 10 & 0.70 & 0.52 \\
0.002 & 0.67 & 5 & 0.90 & 0.78 \\
0.002 & 0.67 & 2 & 1.00 & 0.98 \\
0.002 & 1.00 & 10 & 0.72 & 0.54 \\
0.002 & 1.00 & 5 & 0.93 & 0.82 \\
0.002 & 1.00 & 2 & 1.00 & 0.99 \\
0.003 & 0.33 & 10 & 0.80 & 0.63 \\
0.003 & 0.33 & 5 & 0.95 & 0.84 \\
0.003 & 0.33 & 2 & 0.99 & 0.97 \\
0.003 & 0.67 & 10 & 0.85 & 0.69 \\
0.003 & 0.67 & 5 & 0.98 & 0.92 \\
0.003 & 0.67 & 2 & 1.00 & 1.00 \\
0.003 & 1.00 & 10 & 0.87 & 0.71 \\
0.003 & 1.00 & 5 & 0.99 & 0.94 \\
0.003 & 1.00 & 2 & 1.00 & 1.00 \\
\hline
\end{tabular}

${ }^{\top}$ The significance level at which the test was conducted is given by a. 
Model 2.52: 5 sites, 1 treatment complement per site, and 2 treatments yielding a total of 10 ponds; 50,000 fish/pond; 500,000 smolts.

\begin{tabular}{|c|c|c|c|c|}
\hline OCT Survival & Sampling Rate & School Size & Power for $\alpha=.10^{T}$ & Power for $\alpha=.05^{1}$ \\
\hline 0.001 & 0.33 & 10 & 0.31 & 0.18 \\
\hline 0.001 & 0.33 & 5 & 0.45 & 0.30 \\
\hline 0.001 & 0.33 & 2 & 0.66 & 0.47 \\
\hline 0.001 & 0.67 & 10 & 0.35 & 0.21 \\
\hline 0.001 & 0.67 & 5 & 0.53 & 0.36 \\
\hline 0.001 & 0.67 & 2 & 0.83 & 0.67 \\
\hline 0.001 & 1.00 & 10 & 0.35 & 0.22 \\
\hline 0.001 & 1.00 & 5 & 0.56 & 0.38 \\
\hline 0.001 & 1.00 & 2 & 0.89 & 0.75 \\
\hline 0.002 & 0.33 & 10 & 0.51 & 0.34 \\
\hline 0.002 & 0.33 & 5 & 0.71 & 0.52 \\
\hline 0.002 & 0.33 & 2 & 0.89 & 0.76 \\
\hline 0.002 & 0.67 & 10 & 0.55 & 0.37 \\
\hline 0.002 & 0.67 & 5 & 0.79 & 0.62 \\
\hline 0.002 & 0.67 & 2 & 0.97 & 0.91 \\
\hline 0.002 & 1.00 & 10 & 0.58 & 0.39 \\
\hline 0.002 & 1.00 & 5 & 0.82 & 0.66 \\
\hline 0.002 & 1.00 & 2 & 0.99 & 0.95 \\
\hline 0.004 & 0.33 & 10 & 0.65 & 0.47 \\
\hline 0.003 & 0.33 & 5 & 0.84 & 0.68 \\
\hline 0.003 & 0.33 & 2 & 0.97 & 0.89 \\
\hline 0.003 & 0.67 & 10 & 0.70 & 0.52 \\
\hline 0.003 & 0.67 & 5 & 0.91 & 0.79 \\
\hline 0.003 & 0.67 & 2 & 1.00 & 0.98 \\
\hline 0.003 & 1.00 & 10 & 0.72 & 0.54 \\
\hline 0.003 & 1.00 & 5 & 0.93 & 0.81 \\
\hline 0.003 & 1.00 & 2 & 1.00 & 0.99 \\
\hline
\end{tabular}

The significance level at which the test was conducted is given by a. 
Model 2.33: 3 sites, 1 treatment complement per site, and 3 treatments yielding a total of 9 ponds; 75,000 fish/pond; 675,000 smolts.

\begin{tabular}{ccccc}
\hline OCT Survival & Sampling Rate & School Size & Power for $\boldsymbol{\alpha = . 1 0}$ & Power for $\boldsymbol{\alpha = . . 0 5}^{\mathbf{l}}$ \\
\hline & & & & \\
0.001 & 0.33 & 10 & 0.23 & 0.13 \\
0.001 & 0.33 & 5 & 0.31 & 0.18 \\
0.001 & 0.33 & 2 & 0.45 & 0.28 \\
0.001 & 0.67 & 10 & 0.23 & 0.13 \\
0.001 & 0.67 & 5 & 0.37 & 0.22 \\
0.001 & 0.67 & 2 & 0.63 & 0.45 \\
0.001 & 1.00 & $\mathbf{1 0}$ & 0.26 & 0.14 \\
0.001 & 1.00 & 5 & 0.38 & 0.23 \\
0.001 & 1.00 & 2 & 0.72 & 0.52 \\
0.002 & 0.33 & 10 & 0.34 & 0.19 \\
0.002 & 0.33 & 5 & 0.50 & 0.32 \\
0.002 & 0.33 & 2 & 0.71 & 0.52 \\
0.002 & 0.67 & 10 & 0.39 & 0.23 \\
0.002 & 0.67 & 5 & 0.60 & 0.40 \\
0.002 & 0.67 & 2 & 0.88 & 0.72 \\
0.002 & 1.00 & 10 & 0.38 & 0.23 \\
0.002 & 1.00 & 5 & 0.64 & 0.44 \\
0.002 & 1.00 & 2 & 0.93 & 0.81 \\
0.003 & 0.33 & 10 & 0.46 & 0.30 \\
0.003 & 0.33 & 5 & 0.66 & 0.46 \\
0.003 & 0.33 & 2 & 0.85 & 0.66 \\
0.003 & 0.67 & 10 & 0.51 & 0.34 \\
0.003 & 0.67 & 5 & 0.75 & 0.57 \\
0.003 & 0.67 & 2 & 0.96 & 0.87 \\
0.003 & 1.00 & 10 & 0.52 & 0.34 \\
0.003 & 1.00 & 5 & 0.78 & 0.59 \\
0.003 & 1.00 & 2 & 0.99 & 0.93 \\
\hline
\end{tabular}

${ }^{\top}$ The significance level at which the test was conducted is given by a. 
Model 2.33: 3 sites, 1 treatment complement per site, and 3 treatments yielding a total of 9 ponds; 50,000 fish/pond; 450,000 smolts.

\begin{tabular}{|c|c|c|c|c|}
\hline OCT Survival & Sampling Rate & School Size & Power for $\alpha=.10^{1}$ & Power for $\alpha=.05^{1}$ \\
\hline 0.001 & 0.33 & 10 & 0.18 & 0.10 \\
\hline 0.001 & 0.33 & 5 & 0.24 & 0.13 \\
\hline 0.001 & 0.33 & 2 & 0.35 & 0.21 \\
\hline 0.001 & 0.67 & 10 & 0.19 & 0.10 \\
\hline 0.001 & 0.67 & 5 & 0.28 & 0.17 \\
\hline 0.001 & 0.67 & 2 & 0.48 & 0.31 \\
\hline 0.001 & 1.00 & 10 & 0.19 & 0.10 \\
\hline 0.001 & 1.00 & 5 & 0.31 & 0.18 \\
\hline 0.001 & 1.00 & 2 & 0.56 & 0.38 \\
\hline 0.002 & 0.33 & 10 & 0.27 & 0.15 \\
\hline 0.002 & 0.33 & 5 & 0.37 & 0.22 \\
\hline 0.002 & 0.33 & 2 & 0.57 & 0.38 \\
\hline 0.002 & 0.67 & 10 & 0.29 & 0.17 \\
\hline 0.002 & 0.67 & 5 & 0.44 & 0.27 \\
\hline 0.002 & 0.67 & 2 & 0.73 & 0.54 \\
\hline 0.002 & 1.00 & 10 & 0.29 & 0.17 \\
\hline 0.002 & 1.00 & 5 & 0.48 & 0.31 \\
\hline 0.002 & 1.00 & 2 & 0.81 & 0.63 \\
\hline 0.003 & 0.33 & 10 & 0.33 & 0.20 \\
\hline 0.003 & 0.33 & 5 & 0.51 & 0.32 \\
\hline 0.003 & 0.33 & 2 & 0.71 & 0.51 \\
\hline 0.003 & 0.67 & 10 & 0.38 & 0.23 \\
\hline 0.003 & 0.67 & 5 & 0.59 & 0.40 \\
\hline 0.003 & 0.67 & 2 & 0.88 & 0.72 \\
\hline 0.003 & 1.00 & 10 & 0.40 & 0.25 \\
\hline 0.003 & 1.00 & 5 & 0.63 & 0.43 \\
\hline 0.003 & 1.00 & 2 & 0.93 & 0.81 \\
\hline
\end{tabular}

The significance level at which the test was conducted is given by a. 
Model 2.32: 3 sites, 1 treatment complement per site, and 2 treatments yielding a total of 6 ponds; 187,500 fish/pond; $1,125,000$ smolts.

\begin{tabular}{lcccc}
\hline OCT Survival & Sampling Rate & School Size & Power for $\boldsymbol{\alpha}=\mathbf{. 1 0}^{\mathbf{1}}$ & ${\text { Power for } \boldsymbol{\alpha}=\mathbf{. 0 5}^{\mathbf{1}}}$ \\
\hline & & & & \\
0.001 & 0.33 & 10 & 0.43 & 0.24 \\
0.001 & 0.33 & 5 & 0.58 & 0.35 \\
0.001 & 0.33 & 2 & 0.76 & 0.52 \\
0.001 & 0.67 & 10 & 0.46 & 0.27 \\
0.001 & 0.67 & 5 & 0.66 & 0.43 \\
0.001 & 0.67 & 2 & 0.89 & 0.67 \\
0.001 & 1.00 & 10 & 0.47 & 0.28 \\
0.001 & 1.00 & 5 & 0.69 & 0.44 \\
0.001 & 1.00 & 2 & 0.94 & 0.76 \\
0.002 & 0.33 & 10 & 0.63 & 0.39 \\
0.002 & 0.33 & 5 & 0.81 & 0.57 \\
0.002 & 0.33 & 2 & 0.94 & 0.76 \\
0.002 & 0.67 & 10 & 0.67 & 0.43 \\
0.002 & 0.67 & 5 & 0.87 & 0.65 \\
0.002 & 0.67 & 2 & 0.99 & 0.90 \\
0.002 & 1.00 & 10 & 0.68 & 0.45 \\
0.002 & 1.00 & 5 & 0.90 & 0.69 \\
0.002 & 1.00 & 2 & 1.00 & 0.94 \\
0.003 & 0.33 & 10 & 0.76 & 0.52 \\
0.003 & 0.33 & 5 & 0.91 & 0.70 \\
0.003 & 0.33 & 2 & 0.98 & 0.88 \\
0.003 & 0.67 & 10 & 0.81 & 0.57 \\
0.003 & 0.67 & 5 & 0.95 & 0.80 \\
0.003 & 0.67 & 2 & 1.00 & 0.97 \\
0.003 & 1.00 & 10 & 0.82 & 0.82 \\
0.003 & 1.00 & 5 & 0.96 & 0.98 \\
0.003 & 1.00 & 2 & 1.00 & \\
\hline
\end{tabular}

The significance level at which the test was conducted is given by $\boldsymbol{\alpha}$. 
Model 2.32: 3 sites, 1 treatment complement per site, and 2 treatments yielding a total of 6 ponds; 125,000 fish/pond; 750,000 smolts.

\begin{tabular}{lcccc}
\hline OCT Survival Sampling Rate & School Size & Power for $\boldsymbol{\alpha}=\mathbf{. 1 0}^{\mathbf{T}}$ & ${\text { Power for } \boldsymbol{\alpha}_{\mathbf{. 0 5}}}^{\mathbf{T}}$ \\
\hline & & & & \\
0.001 & 0.33 & 10 & 0.33 & 0.18 \\
0.001 & 0.33 & 5 & 0.45 & 0.27 \\
0.001 & 0.33 & 2 & 0.64 & 0.40 \\
0.001 & 0.67 & 10 & 0.36 & 0.20 \\
0.001 & 0.67 & 5 & 0.53 & 0.31 \\
0.001 & 0.67 & 2 & 0.79 & 0.55 \\
0.001 & 1.00 & 10 & 0.37 & 0.20 \\
0.001 & 1.00 & 5 & 0.56 & 0.35 \\
0.001 & 1.00 & 2 & 0.86 & 0.63 \\
$\mathbf{0 . 0 0 2}$ & 0.33 & 10 & 0.50 & 0.29 \\
0.002 & 0.33 & 5 & 0.68 & 0.44 \\
0.002 & 0.33 & 2 & 0.85 & 0.63 \\
0.002 & 0.67 & 10 & 0.55 & 0.32 \\
0.002 & 0.67 & 5 & 0.76 & 0.51 \\
0.002 & 0.67 & 2 & 0.95 & 0.78 \\
0.002 & 1.00 & 10 & 0.56 & 0.35 \\
0.002 & 1.00 & 5 & 0.79 & 0.55 \\
0.002 & 1.00 & 2 & 0.98 & 0.85 \\
0.003 & 0.33 & 10 & 0.63 & 0.41 \\
0.003 & 0.33 & 5 & 0.80 & 0.57 \\
0.003 & 0.33 & 2 & 0.94 & 0.76 \\
0.003 & 0.67 & 10 & 0.68 & 0.44 \\
0.003 & 0.67 & 5 & 0.88 & 0.66 \\
0.003 & 0.67 & 2 & 0.99 & 0.90 \\
0.003 & 1.00 & 10 & 0.70 & 0.45 \\
0.003 & 1.00 & 5 & 0.89 & 0.68 \\
0.003 & 1.00 & 2 & 1.00 & 0.94 \\
\hline
\end{tabular}

${ }^{\mathrm{T}}$ The significance level at which the test was conducted is given by $\mathrm{a}$. 
Model 2.32: 3 sites, 1 treatment complement per site, and 2 treatments yielding a total of 6 ponds; 112,500 fish/pond; 675,000 smolts.

\begin{tabular}{lcccc}
\hline OCT Survival Sampling Rate & School Size & Power for $\boldsymbol{\alpha}=\mathbf{. 1 0}^{\mathbf{T}}$ & ${\text { Power for } \boldsymbol{\alpha}=\mathbf{. 0 5}^{\mathbf{1}}}$ \\
\hline & & & & \\
0.001 & 0.33 & 10 & 0.29 & 0.15 \\
0.001 & 0.33 & 5 & 0.43 & 0.25 \\
0.001 & 0.33 & 2 & 0.60 & 0.37 \\
0.001 & 0.67 & 10 & 0.33 & 0.18 \\
0.001 & 0.67 & 5 & 0.50 & 0.30 \\
0.001 & 0.67 & 2 & 0.75 & 0.51 \\
0.001 & 1.00 & 10 & 0.34 & 0.19 \\
0.001 & 1.00 & 5 & 0.52 & 0.31 \\
0.001 & 1.00 & 2 & 0.83 & 0.60 \\
0.002 & 0.33 & 10 & 0.48 & 0.28 \\
0.002 & 0.33 & 5 & 0.64 & 0.41 \\
0.002 & 0.33 & 2 & 0.82 & 0.58 \\
0.002 & 0.67 & 10 & 0.51 & 0.30 \\
0.002 & 0.67 & 5 & 0.72 & 0.47 \\
0.002 & 0.67 & 2 & 0.93 & 0.74 \\
0.002 & 1.00 & 10 & 0.53 & 0.32 \\
0.002 & 1.00 & 5 & 0.75 & 0.52 \\
0.002 & 1.00 & 2 & 0.97 & 0.82 \\
0.003 & 0.33 & 10 & 0.60 & 0.38 \\
0.003 & 0.33 & 5 & 0.77 & 0.53 \\
0.003 & 0.33 & 2 & 0.92 & 0.73 \\
0.003 & 0.67 & 10 & 0.64 & 0.40 \\
0.003 & 0.67 & 5 & 0.85 & 0.62 \\
0.003 & 0.67 & 2 & 0.98 & 0.87 \\
0.003 & $\mathbf{1 . 0 0}$ & 10 & 0.66 & 0.42 \\
0.003 & $\mathbf{1 . 0 0}$ & 5 & 0.87 & 0.66 \\
0.003 & 1.00 & 2 & $\mathbf{1 . 0 0}$ & 0.92 \\
\hline
\end{tabular}

$\mathbf{T}$ The significance level at which the test was conducted is given by $\boldsymbol{\alpha}$. 
Model 2.32: 3 sites, 1 treatment complement per site, and 2 treatments yielding a total of 6 ponds; 83,333 fish/pond; 500,000 smolts.

\begin{tabular}{|c|c|c|c|c|}
\hline OCT Survival & Sampling Rate & School Size & Power for $\alpha=.10^{T}$ & Power for $\alpha=.05^{\top}$ \\
\hline 0.001 & 0.33 & 10 & 0.25 & 0.13 \\
\hline 0.001 & 0.33 & 5 & 0.36 & 0.20 \\
\hline 0.001 & 0.33 & 2 & 0.50 & 0.30 \\
\hline 0.001 & 0.67 & 10 & 0.29 & 0.16 \\
\hline 0.001 & 0.67 & 5 & 0.41 & 0.24 \\
\hline 0.001 & 0.67 & 2 & 0.65 & 0.42 \\
\hline 0.001 & 1.00 & 10 & 0.29 & 0.16 \\
\hline 0.001 & 1.00 & 5 & 0.43 & 0.25 \\
\hline 0.001 & 1.00 & 2 & 0.72 & 0.48 \\
\hline 0.002 & 0.33 & 10 & 0.39 & 0.22 \\
\hline 0.002 & 0.33 & 5 & 0.55 & 0.33 \\
\hline 0.002 & 0.33 & 2 & 0.73 & 0.48 \\
\hline 0.002 & 0.67 & 10 & 0.43 & 0.24 \\
\hline 0.002 & 0.67 & 5 & 0.63 & 0.40 \\
\hline 0.002 & 0.67 & 2 & 0.87 & 0.65 \\
\hline 0.002 & 1.00 & 10 & 0.44 & 0.26 \\
\hline 0.002 & 1.00 & 5 & 0.66 & 0.42 \\
\hline 0.002 & 1.00 & 2 & 0.92 & 0.72 \\
\hline 0.003 & 0.33 & 10 & 0.51 & 0.30 \\
\hline 0.003 & 0.33 & 5 & 0.66 & 0.43 \\
\hline 0.003 & 0.33 & 2 & 0.85 & 0.61 \\
\hline 0.003 & 0.67 & 10 & 0.54 & 0.33 \\
\hline 0.003 & 0.67 & 5 & 0.76 & 0.52 \\
\hline 0.003 & 0.67 & 2 & 0.95 & 0.79 \\
\hline 0.003 & 1.00 & 10 & 0.56 & 0.35 \\
\hline 0.003 & 1.00 & 5 & 0.79 & 0.54 \\
\hline 0.003 & 1.00 & 2 & 0.98 & 0.85 \\
\hline
\end{tabular}

The significance level at which the test was conducted is given by $\boldsymbol{\alpha}$. 


\section{Model 3 Simulations}

Model 3.53 with Locale Effects $=0.25: 5$ sites, 1 treatment complement per site, and 3 treatments yielding a total of 15 ponds; 75,000 fish/pond; 1,125,000 smolts.

\begin{tabular}{lcccc}
\hline OCT Survival & Sampling Rate & School Size & Power for $\boldsymbol{\alpha}_{\mathbf{. 1 0}}^{\mathbf{1}}$ & ${\text { Power for } \boldsymbol{\alpha}=\mathbf{. 0 5}^{\mathbf{1}}}$ \\
\hline & & & & \\
0.001 & 0.33 & 10 & 0.36 & 0.24 \\
0.001 & 0.33 & 5 & 0.53 & 0.37 \\
0.001 & 0.33 & 2 & 0.75 & 0.60 \\
0.001 & 0.67 & 10 & 0.39 & 0.25 \\
0.001 & 0.67 & 5 & 0.62 & 0.45 \\
0.001 & 0.67 & 2 & 0.89 & 0.78 \\
0.001 & 1.00 & 10 & 0.40 & 0.26 \\
0.001 & 1.00 & 5 & 0.65 & 0.48 \\
0.001 & 1.00 & 2 & 0.94 & 0.85 \\
0.002 & 0.33 & 10 & 0.58 & 0.41 \\
0.002 & 0.33 & 5 & 0.78 & 0.64 \\
0.002 & 0.33 & 2 & 0.93 & 0.85 \\
0.002 & 0.67 & 10 & 0.63 & 0.48 \\
0.002 & 0.67 & 5 & 0.86 & 0.73 \\
0.002 & 0.67 & 2 & 0.98 & 0.96 \\
0.002 & 1.00 & 10 & 0.63 & 0.48 \\
0.002 & 1.00 & 5 & 0.88 & 0.76 \\
0.002 & 1.0 & 2 & 1.00 & 0.98 \\
0.003 & 0.33 & 10 & 0.73 & 0.58 \\
0.003 & 0.33 & 5 & 0.90 & 0.80 \\
0.003 & 0.33 & 2 & 0.98 & 0.94 \\
0.003 & 0.67 & 10 & 0.78 & 0.63 \\
0.003 & 0.67 & 5 & 0.95 & 0.89 \\
0.003 & 0.67 & 2 & 1.00 & 0.99 \\
0.003 & 1.00 & 10 & 0.80 & 0.66 \\
0.003 & 1.00 & 5 & 0.96 & 0.91 \\
0.003 & 1.00 & 2 & 1.00 & 1.00 \\
\hline
\end{tabular}

$\mathbf{T}$ The significance level at which the test was conducted is given by $\boldsymbol{\alpha}$. 
Model 3.53 with Locale Effects $=0.50: 5$ sites, 1 treatment complement per site, and 3 treatments yielding a total of 15 ponds; 75,000 fish/pond; $1,125,000$ smolts.

\begin{tabular}{|c|c|c|c|c|}
\hline OCT Survival & Sampling Rate & School Size & Power for $\alpha=.10^{T}$ & Power for $\alpha=.05^{1}$ \\
\hline 0.001 & 0.33 & 10 & 0.34 & 0.22 \\
\hline 0.001 & 0.33 & 5 & 0.49 & 0.33 \\
\hline 0.001 & 0.33 & 2 & 0.65 & 0.49 \\
\hline 0.001 & 0.67 & 10 & 0.37 & 0.24 \\
\hline 0.001 & 0.67 & 5 & 0.57 & 0.41 \\
\hline 0.001 & 0.67 & 2 & 0.78 & 0.64 \\
\hline 0.001 & 1.00 & 10 & 0.38 & 0.24 \\
\hline 0.001 & 1.00 & 5 & 0.58 & 0.42 \\
\hline 0.001 & 1.00 & 2 & 0.85 & 0.71 \\
\hline 0.002 & 0.33 & 10 & 0.53 & 0.37 \\
\hline 0.002 & 0.33 & 5 & 0.70 & 0.54 \\
\hline 0.002 & 0.33 & 2 & 0.84 & 0.70 \\
\hline 0.002 & 0.67 & 10 & 0.57 & 0.40 \\
\hline 0.002 & 0.67 & 5 & 0.76 & 0.61 \\
\hline 0.002 & 0.67 & 2 & 0.92 & 0.81 \\
\hline 0.002 & 1.00 & 10 & 0.58 & 0.43 \\
\hline 0.002 & 1.00 & 5 & 0.79 & 0.64 \\
\hline 0.002 & 1.00 & 2 & 0.94 & 0.86 \\
\hline 0.003 & 0.33 & 10 & 0.65 & 0.49 \\
\hline 0.003 & 0.33 & 5 & 0.81 & 0.67 \\
\hline 0.003 & 0.33 & 2 & 0.91 & 0.80 \\
\hline 0.003 & 0.67 & 10 & 0.69 & 0.53 \\
\hline 0.003 & 0.67 & 5 & 0.86 & 0.73 \\
\hline 0.003 & 0.67 & 2 & 0.96 & 0.88 \\
\hline 0.003 & 1.00 & 10 & 0.70 & 0.55 \\
\hline 0.003 & 1.00 & 5 & 0.87 & 0.76 \\
\hline 0.003 & 1.00 & 2 & 0.97 & 0.91 \\
\hline
\end{tabular}

${ }^{\mathbf{T}}$ The significance level at which the test was conducted is given by $\boldsymbol{\alpha}$. 
Model 3.53 with Locale Effects $=0.25: 5$ sites, 1 treatment complement per site, and 3 treatments yielding a total of 15 ponds; 50,000 fish/pond; 750,000 smolts.

\begin{tabular}{|c|c|c|c|c|}
\hline OCT Survival & Sampling Rate & School Size & Power for $\alpha=.10^{I}$ & Power for $\alpha=.05^{1}$ \\
\hline 0.001 & 0.33 & 10 & 0.26 & 0.16 \\
\hline 0.001 & 0.33 & 5 & 0.39 & 0.26 \\
\hline 0.001 & 0.33 & 2 & 0.58 & 0.42 \\
\hline 0.001 & 0.67 & 10 & 0.29 & 0.17 \\
\hline 0.001 & 0.67 & 5 & 0.46 & 0.32 \\
\hline 0.001 & 0.67 & 2 & 0.75 & 0.61 \\
\hline 0.001 & 1.00 & 10 & 0.31 & 0.19 \\
\hline 0.001 & 1.00 & 5 & 0.51 & 0.35 \\
\hline 0.001 & 1.00 & 2 & 0.82 & 0.68 \\
\hline 0.002 & 0.33 & 10 & 0.44 & 0.30 \\
\hline 0.002 & 0.33 & 5 & 0.62 & 0.46 \\
\hline 0.002 & 0.33 & 2 & 0.82 & 0.68 \\
\hline 0.002 & 0.67 & 10 & 0.48 & 0.33 \\
\hline 0.002 & 0.67 & 5 & 0.72 & 0.57 \\
\hline 0.002 & 0.67 & 2 & 0.95 & 0.87 \\
\hline 0.002 & 1.00 & 10 & 0.49 & 0.34 \\
\hline 0.002 & 1.00 & 5 & 0.75 & 0.61 \\
\hline 0.002 & 1.00 & 2 & 0.97 & 0.92 \\
\hline 0.003 & 0.33 & 10 & 0.59 & 0.42 \\
\hline 0.003 & 0.33 & 5 & 0.79 & 0.65 \\
\hline 0.003 & 0.33 & 2 & 0.94 & 0.85 \\
\hline 0.003 & 0.67 & 10 & 0.62 & 0.46 \\
\hline 0.003 & 0.67 & 5 & 0.86 & 0.74 \\
\hline 0.003 & 0.67 & 2 & 0.99 & 0.95 \\
\hline 0.003 & 1.00 & 10 & 0.65 & 0.49 \\
\hline 0.003 & 1.00 & 5 & 0.88 & 0.78 \\
\hline 0.003 & 1.00 & 2 & 0.99 & 0.98 \\
\hline
\end{tabular}

The significance level at which the test was conducted is given by $\boldsymbol{\alpha}$. 
Model 3.53 with Locale Effects $=0.50: 5$ sites, 1 treatment complement per site, and 3 treatments yielding a total of 15 ponds; 50,000 fish/pond; 750,000 smolts.

\begin{tabular}{|c|c|c|c|c|}
\hline OCT Survival & Sampling Rate & School Size & Power for $\alpha=.10^{T}$ & Power for $\alpha=.05^{\top}$ \\
\hline 0.001 & 0.33 & 10 & 0.25 & 0.14 \\
\hline 0.001 & 0.33 & 5 & 0.37 & 0.24 \\
\hline 0.001 & 0.33 & 2 & 0.53 & 0.37 \\
\hline 0.001 & 0.67 & 10 & 0.29 & 0.17 \\
\hline 0.001 & 0.67 & 5 & 0.44 & 0.29 \\
\hline 0.001 & 0.67 & 2 & 0.67 & 0.51 \\
\hline 0.001 & 1.00 & 10 & 0.30 & 0.18 \\
\hline 0.001 & 1.00 & 5 & 0.45 & 0.30 \\
\hline 0.001 & 1.00 & 2 & 0.74 & 0.58 \\
\hline 0.002 & 0.33 & 10 & 0.41 & 0.28 \\
\hline 0.002 & 0.33 & 5 & 0.56 & 0.41 \\
\hline 0.002 & 0.33 & 2 & 0.73 & 0.58 \\
\hline 0.002 & 0.67 & 10 & 0.46 & 0.31 \\
\hline 0.002 & 0.67 & 5 & 0.64 & 0.49 \\
\hline 0.002 & 0.67 & 2 & 0.85 & 0.72 \\
\hline 0.002 & 1.00 & 10 & 0.44 & 0.30 \\
\hline 0.002 & 1.00 & 5 & 0.65 & 0.49 \\
\hline 0.002 & 1.00 & 2 & 0.89 & 0.78 \\
\hline 0.003 & 0.33 & 10 & 0.53 & 0.38 \\
\hline 0.003 & 0.33 & 5 & 0.68 & 0.52 \\
\hline 0.003 & 0.33 & 2 & 0.83 & 0.70 \\
\hline 0.003 & 0.67 & 10 & 0.57 & 0.41 \\
\hline 0.003 & 0.67 & 5 & 0.76 & 0.62 \\
\hline 0.003 & 0.67 & 2 & 0.91 & 0.82 \\
\hline 0.003 & 1.00 & 10 & 0.59 & 0.43 \\
\hline 0.003 & 1.00 & 5 & 0.79 & 0.64 \\
\hline 0.003 & 1.00 & 2 & 0.94 & 0.86 \\
\hline
\end{tabular}

The significance level at which the test was conducted is given by cc. 
Model 3.52 with Locale Effects $=0.25: 5$ sites, 1 treatment complement per site, and 2 treatments yielding a total of 10 ponds; 112,500 fish/pond; $1,125,000$ smolts.

\begin{tabular}{lcccc}
\hline OCT Survival & Sampling Rate & School Size & Power for $\boldsymbol{\alpha}=\mathbf{. 1 0}^{\mathbf{T}}$ & Power for $\boldsymbol{\alpha = . 0 5}^{\mathbf{1}}$ \\
\hline & & & & \\
0.001 & 0.33 & 10 & 0.54 & 0.37 \\
0.001 & 0.33 & 5 & 0.74 & 0.56 \\
0.001 & 0.33 & 2 & 0.89 & 0.76 \\
0.001 & 0.67 & 10 & 0.58 & 0.40 \\
0.001 & 0.67 & 5 & 0.80 & 0.63 \\
0.001 & 0.67 & 2 & 0.97 & 0.90 \\
0.001 & 1.00 & 10 & 0.60 & 0.41 \\
0.001 & 1 & 0 & 0.83 & 0.67 \\
0.001 & 1.00 & 2 & 0.99 & 0.94 \\
0.002 & 0.33 & 10 & 0.78 & 0.60 \\
0.002 & 0.33 & 5 & 0.93 & 0.81 \\
0.002 & 0.33 & 2 & 0.99 & 0.94 \\
0.002 & 0.67 & 10 & 0.82 & 0.64 \\
0.002 & 0.67 & 5 & 0.96 & 0.87 \\
0.002 & 0.67 & 2 & 1.00 & 0.99 \\
0.002 & 1.00 & 10 & 0.83 & 0.68 \\
0.002 & 1.00 & 5 & 0.97 & 0.90 \\
0.002 & 1.00 & 2 & 1.00 & 0.99 \\
0.003 & 0.33 & 10 & 0.89 & 0.76 \\
0.003 & 0.33 & 5 & 0.98 & 0.90 \\
0.003 & 0.33 & 2 & 1.00 & 0.98 \\
0.003 & 0.67 & 10 & 0.93 & 0.81 \\
0.003 & 0.67 & 5 & 0.99 & 0.95 \\
0.003 & 0.67 & 2 & 1.00 & 1.00 \\
0.003 & 1.00 & 10 & 0.93 & 0.81 \\
0.003 & 1.00 & 5 & 0.99 & 0.96 \\
0.003 & 1.00 & 2 & 1 & 1.00 \\
\hline
\end{tabular}

${ }^{T}$ The significance level at which the test was conducted is given by a. 
Model 3.52 with Locale Effects = 0.50: 5 sites, 1 treatment complement per site, and 2 treatments yielding a total of 10 ponds; 112,500 fish/pond; 1,125,000 smolts.

\begin{tabular}{lcccc}
\hline OCT Survival & Sampling Rate & School Size & Power for $\boldsymbol{\alpha}=\mathbf{. 1 0}^{\mathbf{T}}$ & ${\text { Power for } \boldsymbol{\alpha}=\mathbf{. 0 5}^{\mathbf{I}}}$ \\
\hline & & & & \\
0.001 & 0.33 & 10 & 0.50 & 0.34 \\
0.001 & 0.33 & 5 & 0.66 & 0.48 \\
0.001 & 0.33 & 2 & 0.82 & 0.65 \\
0.001 & 0.67 & 10 & 0.55 & 0.39 \\
0.001 & $\mathbf{0 . 6 7}$ & 5 & 0.74 & 0.55 \\
0.001 & 0.67 & 2 & 0.90 & 0.77 \\
0.001 & 1.00 & 10 & 0.57 & 0.39 \\
0.001 & 1.00 & 5 & 0.76 & 0.58 \\
0.001 & 1.00 & 2 & 0.93 & 0.81 \\
0.002 & 0.33 & 10 & 0.71 & 0.53 \\
$\mathbf{0 . 0 0 2}$ & 0.33 & 5 & 0.85 & 0.68 \\
0.002 & 0.33 & 2 & 0.92 & 0.79 \\
0.002 & 0.67 & 10 & 0.75 & 0.56 \\
0.002 & 0.67 & 5 & 0.88 & 0.74 \\
0.002 & 0.67 & 2 & 0.97 & 0.88 \\
0.002 & 1.00 & 10 & 0.76 & 0.58 \\
0.002 & 1.00 & 5 & 0.91 & 0.76 \\
0.002 & 1.00 & 2 & 0.98 & 0.91 \\
0.003 & 0.33 & 10 & 0.81 & 0.64 \\
0.003 & 0.33 & 5 & 0.91 & 0.78 \\
0.003 & 0.33 & 2 & 0.96 & 0.87 \\
0.003 & 0.67 & 10 & 0.84 & 0.69 \\
0.003 & 0.67 & 5 & 0.94 & 0.83 \\
0.003 & 0.67 & 2 & 0.98 & 0.92 \\
0.003 & 1.00 & 10 & 0.86 & 0.71 \\
0.003 & 1.00 & 5 & 0.95 & 0.84 \\
0.003 & 1.00 & 2 & 0.99 & 0.94 \\
\hline
\end{tabular}

The significance level at which the test was conducted is given by a. 
Model 3.52 with Locale Effects $=0.25$ : 5 sites, 1 treatment complement per site, and 2 treatments yielding a total of 10 ponds; 75,000 fish/pond; 750,000 smolts.

\begin{tabular}{|c|c|c|c|c|c|}
\hline OCT Survival & Sampling & Rate & School Size & Power for $\alpha=.10^{T}$ & Power for $\alpha=.05^{1}$ \\
\hline 0.001 & 0.33 & & 10 & 0.42 & 0.26 \\
\hline 0.001 & 0.33 & & 5 & 0.59 & 0.41 \\
\hline 0.001 & 0.33 & & 2 & 0.79 & 0.62 \\
\hline 0.001 & 0.67 & & 10 & 0.44 & 0.28 \\
\hline 0.001 & 0.67 & & 5 & 0.66 & 0.48 \\
\hline 0.001 & 0.67 & & 2 & 0.91 & 0.78 \\
\hline 0.001 & .00 & & 10 & 0.48 & 0.31 \\
\hline 0.001 & 1.00 & & 5 & 0.69 & 0.51 \\
\hline 0.001 & .00 & & 2 & 0.95 & 0.85 \\
\hline 0.002 & 0.33 & & 10 & 0.64 & 0.45 \\
\hline 0.002 & 0.33 & & 5 & 0.83 & 0.65 \\
\hline 0.002 & 0.33 & & 2 & 0.95 & 0.85 \\
\hline 0.002 & 0.67 & & 10 & 0.68 & 0.50 \\
\hline 0.002 & 0.67 & & 5 & 0.89 & 0.75 \\
\hline 0.002 & 0.67 & & 2 & 0.99 & 0.95 \\
\hline 0.002 & .00 & & 10 & 0.69 & 0.51 \\
\hline 0.002 & .00 & & 5 & 0.91 & 0.78 \\
\hline 0.002 & 1.00 & & 2 & 1.00 & 0.97 \\
\hline 0.003 & 0.33 & & 10 & 0.78 & 0.61 \\
\hline 0.003 & 0.33 & & 5 & 0.91 & 0.80 \\
\hline 0.003 & 0.33 & & 2 & 0.99 & 0.94 \\
\hline 0.003 & 0.67 & & 10 & 0.82 & 0.65 \\
\hline 0.003 & 0.67 & & 5 & 0.96 & 0.88 \\
\hline 0.003 & 0.67 & & 2 & 1.00 & 0.99 \\
\hline 0.003 &. $\mathrm{OC}$ & & 10 & 0.83 & 0.67 \\
\hline 0.003 & 1.00 & , & 5 & 0.97 & 0.90 \\
\hline 0.003 & $1 \quad .00$ & & 2 & 1.00 & 0.99 \\
\hline
\end{tabular}

The significance level at which the test was conducted is given by a. 
Model 3.52 with Locale Effects $=0.50: 5$ sites, 1 treatment complement per site, and 2 treatments yielding a total of 10 ponds; 75,000 fish/pond; 750,000 smolts.

\begin{tabular}{|c|c|c|c|c|}
\hline OCT Survival & Sampling Rate & School Size & Power for $\alpha=.10^{\prime}$ & Power for $\alpha=.05^{1}$ \\
\hline 0.001 & 0.33 & 10 & 0.40 & 0.26 \\
\hline 0.001 & 0.33 & 5 & 0.54 & 0.36 \\
\hline 0.001 & 0.33 & 2 & 0.70 & 0.52 \\
\hline 0.001 & 0.67 & 10 & 0.43 & 0.27 \\
\hline 0.001 & 0.67 & 5 & 0.61 & 0.43 \\
\hline 0.001 & 0.67 & 2 & 0.83 & 0.66 \\
\hline 0.001 & 1.00 & 10 & 0.44 & 0.28 \\
\hline 0.001 & 1.00 & 5 & 0.65 & 0.46 \\
\hline 0.001 & 1.00 & 2 & 0.86 & 0.71 \\
\hline 0.002 & 0.33 & 10 & 0.58 & 0.41 \\
\hline 0.002 & 0.33 & 5 & 0.73 & 0.56 \\
\hline 0.002 & 0.33 & 2 & 0.87 & 0.72 \\
\hline 0.002 & 0.67 & 10 & 0.63 & 0.45 \\
\hline 0.002 & 0.67 & 5 & 0.80 & 0.64 \\
\hline 0.002 & 0.67 & 2 & 0.94 & 0.82 \\
\hline 0.002 & 1.00 & 10 & 0.64 & 0.46 \\
\hline 0.002 & 1.00 & 5 & 0.82 & 0.66 \\
\hline 0.002 & 1.00 & 2 & 0.96 & 0.86 \\
\hline 0.003 & 0.33 & 10 & 0.71 & 0.53 \\
\hline 0.003 & 0.33 & 5 & 0.83 & 0.68 \\
\hline 0.003 & 0.33 & 2 & 0.93 & 0.81 \\
\hline 0.003 & 0.67 & 10 & 0.74 & 0.56 \\
\hline 0.003 & 0.67 & 5 & 0.88 & 0.74 \\
\hline 0.003 & 0.67 & 2 & 0.96 & 0.88 \\
\hline 0.003 & 1.00 & 10 & 0.75 & 0.57 \\
\hline 0.003 & 1.00 & 5 & 0.89 & 0.76 \\
\hline 0.003 & 1.00 & 2 & 0.97 & 0.90 \\
\hline
\end{tabular}

The significance level at which the test was conducted is given by a. 
Model 3.52 with Locale Effects $=0.25: 5$ sites, 1 treatment complement per site, and 2 treatments yielding a total of 10 ponds; 50,000 fish/pond; 500,000 smolts.

\begin{tabular}{ccccc}
\hline OCT Survival Sampling Rate & School Size & Power for $\boldsymbol{\alpha = . 1 \mathbf { 1 } ^ { \mathbf { 1 } }}$ & Power for $\boldsymbol{\alpha = . 0 5}^{\mathbf{1}}$ \\
\hline & & & & \\
0.001 & 0.33 & 10 & 0.31 & 0.18 \\
0.001 & 0.33 & 5 & 0.46 & 0.30 \\
0.001 & 0.33 & 2 & 0.63 & 0.44 \\
0.001 & 0.67 & 10 & 0.34 & 0.20 \\
0.001 & 0.67 & 5 & 0.52 & 0.35 \\
0.001 & 0.67 & 2 & 0.80 & 0.63 \\
0.001 & 1.00 & 10 & 0.35 & 0.21 \\
0.001 & 1.00 & 5 & 0.55 & 0.38 \\
0.001 & 1.00 & 2 & 0.85 & 0.71 \\
0.002 & 0.33 & 10 & 0.48 & 0.32 \\
0.002 & 0.33 & 5 & 0.70 & 0.51 \\
0.002 & 0.33 & 2 & 0.87 & 0.72 \\
0.002 & 0.67 & 10 & 0.54 & 0.36 \\
0.002 & 0.67 & 5 & 0.76 & 0.59 \\
0.002 & 0.67 & 2 & 0.96 & 0.87 \\
0.002 & 1.00 & 10 & 0.56 & 0.38 \\
0.002 & 1.00 & 5 & 0.80 & 0.62 \\
0.002 & 1.00 & 2 & 0.98 & 0.92 \\
0.003 & 0.33 & 10 & 0.64 & 0.45 \\
0.003 & 0.33 & 5 & 0.82 & 0.65 \\
0.003 & 0.33 & 2 & 0.95 & 0.84 \\
0.003 & 0.67 & 10 & 0.68 & 0.49 \\
0.003 & 0.67 & 5 & 0.88 & 0.74 \\
$\mathbf{0 . 0 0 3}$ & 0.67 & 2 & 0.99 & 0.95 \\
0.003 & 1.00 & 10 & 0.70 & 0.52 \\
0.003 & 1.00 & 5 & 0.91 & 0.78 \\
0.003 & 1.00 & 2 & 1.00 & 0.97 \\
\hline
\end{tabular}

The significance level at which the test was conducted is given by cx. 
Model 3.52 with Locale Effects $=0.50: 5$ sites, 1 treatment complement per site, and 2 treatments yielding a total of 10 ponds; 50,000 fish/pond; 500,000 smolts.

\begin{tabular}{|c|c|c|c|c|}
\hline OCT Survival & Sampling Rate & School Size & Power for $\alpha=.10^{1}$ & Power for $\alpha=.05^{1}$ \\
\hline 0.001 & 0.33 & 10 & 0.31 & 0.18 \\
\hline 0.001 & 0.33 & 5 & 0.42 & 0.26 \\
\hline 0.001 & 0.33 & 2 & 0.59 & 0.40 \\
\hline 0.001 & 0.67 & 10 & 0.32 & 0.18 \\
\hline 0.001 & 0.67 & 5 & 0.49 & 0.32 \\
\hline 0.001 & 0.67 & 2 & 0.72 & 0.54 \\
\hline 0.001 & 1.00 & 10 & 0.34 & 0.21 \\
\hline 0.001 & 1.00 & 5 & 0.52 & 0.35 \\
\hline 0.001 & 1.00 & 2 & 0.78 & 0.60 \\
\hline 0.002 & 0.33 & 10 & 0.47 & 0.31 \\
\hline 0.002 & 0.33 & 5 & 0.63 & 0.45 \\
\hline 0.002 & 0.33 & 2 & 0.78 & 0.60 \\
\hline 0.002 & 0.67 & 10 & 0.51 & 0.35 \\
\hline 0.002 & 0.67 & 5 & 0.69 & 0.51 \\
\hline 0.002 & 0.67 & 2 & 0.88 & 0.74 \\
\hline 0.002 & 1.00 & 10 & 0.54 & 0.36 \\
\hline 0.002 & 1.00 & 5 & 0.72 & 0.54 \\
\hline 0.002 & 1.00 & 2 & 0.91 & 0.78 \\
\hline 0.003 & 0.33 & 10 & 0.59 & 0.41 \\
\hline 0.003 & 0.33 & 5 & 0.74 & 0.56 \\
\hline 0.003 & 0.33 & 2 & 0.86 & 0.72 \\
\hline 0.003 & 0.67 & 10 & 0.62 & 0.44 \\
\hline 0.003 & 0.67 & 5 & 0.79 & 0.62 \\
\hline 0.003 & 0.67 & 2 & 0.93 & 0.81 \\
\hline 0.003 & 1.00 & 10 & 0.64 & 0.46 \\
\hline 0.003 & 1.00 & 5 & 0.83 & 0.65 \\
\hline 0.003 & 1.00 & 2 & $0: 95$ & 0.86 \\
\hline
\end{tabular}

The significance level at which the test was conducted is given by a. 
Model 3.33 with Locale Effects $=0.25: 3$ sites, 1 treatment complement per site, and 3 treatments yielding a total of 9 ponds; 75,000 fish/pond; 675,000 smolts.

\begin{tabular}{ccccc}
\hline OCT Survival Sampling Rate & School Size & Power for $\boldsymbol{\alpha = . 1 \mathbf { 1 } ^ { \mathbf { 1 } }}$ & ${\text { Power for } \boldsymbol{\alpha}=\mathbf{. 0 5}^{\mathbf{1}}}$ \\
\hline & & & & \\
0.001 & 0.33 & 10 & 0.22 & 0.12 \\
0.001 & 0.33 & 5 & 0.30 & 0.18 \\
0.001 & 0.33 & 2 & 0.43 & 0.26 \\
0.001 & 0.67 & 10 & 0.23 & 0.13 \\
0.001 & 0.67 & 5 & 0.36 & 0.21 \\
0.001 & 0.67 & 2 & 0.58 & 0.39 \\
0.001 & 1.00 & 10 & 0.25 & 0.14 \\
0.001 & 1.00 & 5 & 0.37 & 0.22 \\
0.001 & 1.00 & 2 & 0.65 & 0.46 \\
0.002 & 0.33 & 10 & 0.34 & 0.21 \\
0.002 & 0.33 & 5 & 0.47 & 0.31 \\
0.002 & 0.33 & 2 & 0.65 & 0.46 \\
0.002 & 0.67 & 10 & 0.37 & 0.22 \\
0.002 & 0.67 & 5 & 0.54 & 0.36 \\
0.002 & 0.67 & 2 & 0.80 & 0.61 \\
0.002 & 1.00 & 10 & 0.38 & 0.23 \\
0.002 & 1.00 & 5 & 0.59 & 0.39 \\
0.002 & 1.00 & 2 & 0.85 & 0.69 \\
0.003 & 0.33 & 10 & 0.43 & 0.26 \\
0.003 & 0.33 & 5 & 0.61 & 0.41 \\
0.003 & 0.33 & 2 & 0.79 & 0.60 \\
0.003 & 0.67 & 10 & 0.47 & 0.31 \\
0.003 & 0.67 & 5 & 0.69 & 0.49 \\
0.003 & 0.67 & 2 & 0.89 & 0.74 \\
0.003 & 1.00 & 10 & 0.48 & 0.31 \\
0.003 & 1.00 & 5 & 0.71 & 0.53 \\
0.003 & 1.00 & 2 & 0.93 & 0.81 \\
\hline
\end{tabular}

The significance level at which the test was conducted is given by a. 
Model 3.33 with Locale Effects $=0.50: 3$ sites, 1 treatment complement per site, and 3 treatments yielding a total of 9 ponds; 75,000 fish/pond; 675,000 smolts.

\begin{tabular}{ccccc}
\hline OCT Survival Sampling Rate & School Size & Power for $\boldsymbol{\alpha = . 1 0}$ & ${\text { Power for } \boldsymbol{\alpha}=\mathbf{. 0 5}^{\mathbf{1}}}^{\mathbf{1}}$ \\
\hline & & & & \\
0.001 & 0.33 & 10 & 0.21 & 0.12 \\
0.001 & 0.33 & 5 & 0.29 & 0.16 \\
0.001 & 0.33 & 2 & 0.38 & 0.23 \\
0.001 & 0.67 & $\mathbf{1 0}$ & 0.23 & 0.12 \\
0.001 & 0.67 & 5 & 0.33 & 0.19 \\
0.001 & 0.67 & 2 & 0.47 & 0.29 \\
0.001 & 1.00 & 10 & 0.23 & 0.13 \\
0.001 & 1.00 & 5 & 0.34 & 0.20 \\
0.001 & 1.00 & 2 & 0.53 & 0.35 \\
0.002 & 0.33 & 10 & 0.30 & 0.18 \\
0.002 & 0.33 & 5 & 0.42 & 0.25 \\
0.002 & 0.33 & 2 & $\mathbf{0 . 5 1}$ & 0.33 \\
0.002 & 0.67 & 10 & 0.33 & 0.20 \\
0.002 & 0.67 & 5 & 0.46 & 0.29 \\
0.002 & 0.67 & 2 & 0.62 & 0.43 \\
0.002 & 1.00 & 10 & 0.35 & 0.21 \\
0.002 & 1.00 & 5 & 0.47 & 0.30 \\
0.002 & 1.00 & 2 & 0.66 & 0.46 \\
0.003 & 0.33 & 10 & 0.39 & 0.23 \\
0.003 & 0.33 & 5 & 0.48 & 0.31 \\
0.003 & 0.33 & 2 & 0.60 & 0.41 \\
0.003 & 0.67 & 10 & 0.41 & 0.25 \\
0.003 & 0.67 & 5 & 0.54 & 0.35 \\
0.003 & 0.67 & 2 & 0.69 & 0.50 \\
0.003 & 1.00 & 10 & 0.43 & 0.26 \\
0.003 & 1.00 & 5 & 0.55 & 0.37 \\
$\mathbf{0 . 0 0 3}$ & 1.00 & 2 & 0.71 & $\mathbf{0 . 5 1}$ \\
\hline \\
\hline $\mathbf{T i n}$ & 5 & 5 &
\end{tabular}

The significance level at which the test was conducted is given by a. 
Model 3.33 with Locale Effects $=0.25: 3$ sites, 1 treatment complement per site, and 3 treatments yielding a total of 9 ponds; 50,000 fish/pond; 450,000 smolts.

\begin{tabular}{|c|c|c|c|c|}
\hline OCT Survival & Sampling Rate & School Size & Power for $\alpha=.10^{I}$ & Power for $\alpha=.05^{1}$ \\
\hline 0.001 & 0.33 & 10 & 0.19 & 0.10 \\
\hline 0.001 & 0.33 & 5 & 0.24 & 0.14 \\
\hline 0.001 & 0.33 & 2 & 0.33 & 0.20 \\
\hline 0.001 & 0.67 & 10 & 0.18 & 0.09 \\
\hline 0.001 & 0.67 & 5 & 0.27 & 0.15 \\
\hline 0.001 & 0.67 & 2 & 0.45 & 0.29 \\
\hline 0.001 & 1.00 & 10 & 0.19 & 0.10 \\
\hline 0.001 & 1.00 & 5 & 0.29 & 0.17 \\
\hline 0.001 & 1.00 & 2 & 0.53 & 0.34 \\
\hline 0.002 & 0.33 & 10 & 0.27 & 0.15 \\
\hline 0.002 & 0.33 & 5 & 0.37 & 0.22 \\
\hline 0.002 & 0.33 & 2 & 0.53 & 0.34 \\
\hline 0.002 & 0.67 & 10 & 0.29 & 0.17 \\
\hline 0.002 & 0.67 & 5 & 0.42 & 0.27 \\
\hline 0.002 & 0.67 & 2 & 0.69 & 0.49 \\
\hline 0.002 & 1.00 & 10 & 0.29 & 0.16 \\
\hline 0.002 & 1.00 & 5 & 0.45 & 0.29 \\
\hline 0.002 & 1.00 & 2 & 0.75 & 0.56 \\
\hline 0.003 & 0.33 & 10 & 0.33 & 0.20 \\
\hline 0.003 & 0.33 & 5 & 0.46 & 0.29 \\
\hline 0.003 & 0.33 & 2 & 0.66 & 0.45 \\
\hline 0.003 & 0.67 & 10 & 0.37 & 0.22 \\
\hline 0.003 & 0.67 & 5 & 0.55 & 0.37 \\
\hline 0.003 & 0.67 & 2 & 0.79 & 0.61 \\
\hline 0.003 & 1.00 & 10 & 0.38 & 0.23 \\
\hline 0.003 & 1.00 & 5 & 0.57 & 0.38 \\
\hline 0.003 & 1.00 & 2 & 0.86 & 0.69 \\
\hline
\end{tabular}

$\mathbf{T}$ The significance level at which the test was conducted is given by $\boldsymbol{\alpha}$. 
Model 3.33 with Locale Effects $=0.50: 3$ sites, 1 treatment complement per site, and 3 treatments yielding a total of 9 ponds; 50,000 fish/pond; 450,000 smolts.

\begin{tabular}{lcccc}
\hline OCT Survival Sampling Rate & School Size & Power for $\boldsymbol{\alpha = . 1 0}$ & ${\text { Power for } \boldsymbol{\alpha}=\mathbf{. 0 5}^{\mathbf{T}}}^{\mathbf{1}}$ \\
\hline & & & & \\
0.001 & 0.33 & 10 & 0.17 & 0.09 \\
0.001 & 0.33 & 5 & 0.22 & 0.13 \\
0.001 & 0.33 & 2 & 0.30 & 0.18 \\
0.001 & 0.67 & 10 & 0.17 & 0.09 \\
0.001 & 0.67 & 5 & 0.26 & 0.15 \\
0.001 & 0.67 & 2 & 0.40 & 0.25 \\
0.001 & 1.00 & 10 & 0.18 & 0.09 \\
0.001 & 1.00 & 5 & 0.26 & 0.15 \\
0.001 & 1.00 & 2 & 0.44 & 0.27 \\
0.002 & 0.33 & 10 & 0.25 & 0.14 \\
$\mathbf{0 . 0 0 2}$ & 0.33 & 5 & 0.33 & 0.19 \\
0.002 & 0.33 & 2 & 0.44 & 0.27 \\
0.002 & 0.67 & 10 & 0.26 & 0.14 \\
0.002 & 0.67 & 5 & 0.38 & 0.23 \\
0.002 & 0.67 & 2 & 0.53 & 0.35 \\
0.002 & 1.00 & 10 & 0.27 & 0.15 \\
0.002 & 1.00 & 5 & 0.38 & 0.24 \\
0.002 & 1.00 & 2 & 0.58 & 0.39 \\
0.003 & 0.33 & 10 & 0.30 & 0.18 \\
0.003 & 0.33 & 5 & 0.41 & 0.25 \\
0.003 & 0.33 & 2 & 0.51 & 0.33 \\
0.003 & 0.67 & 10 & 0.32 & 0.19 \\
0.003 & 0.67 & 5 & 0.46 & 0.29 \\
0.003 & 0.67 & 2 & 0.62 & 0.43 \\
0.003 & 1.00 & 10 & 0.34 & 0.21 \\
0.003 & 1.00 & 5 & 0.47 & 0.29 \\
0.003 & 1.00 & 2 & 0.65 & 0.46 \\
\hline
\end{tabular}

The significance level at which the test was conducted is given by a. 
Model 3.32 with Locale Effects $=0.25: 3$ sites, 1 treatment complement per site, and 2 treatments yielding a total of 6 ponds; 187,500 fish/pond; 1,125,000 smolts.

\begin{tabular}{lcccc}
\hline OCT Survival Sampling Rate & School Size & Power for $\boldsymbol{\alpha = . 1 0}$ & Power for $\boldsymbol{\alpha = . 0 5}$ \\
\hline & & & & \\
0.001 & 0.33 & 10 & 0.39 & 0.23 \\
0.001 & 0.33 & 5 & 0.55 & 0.32 \\
0.001 & 0.33 & 2 & 0.70 & 0.45 \\
0.001 & 0.67 & 10 & 0.43 & 0.25 \\
0.001 & 0.67 & 5 & 0.61 & 0.38 \\
0.001 & 0.67 & 2 & 0.82 & 0.61 \\
0.001 & 1.00 & 10 & 0.45 & 0.26 \\
0.001 & 1.00 & 5 & 0.64 & 0.41 \\
0.001 & 1.00 & 2 & 0.87 & 0.64 \\
0.002 & 0.33 & 10 & 0.59 & 0.37 \\
0.002 & 0.33 & 5 & 0.75 & 0.50 \\
0.002 & 0.33 & 2 & 0.87 & 0.65 \\
0.002 & 0.67 & 10 & 0.62 & 0.39 \\
0.002 & 0.67 & 5 & 0.80 & 0.57 \\
0.002 & 0.67 & 2 & 0.93 & 0.76 \\
0.002 & 1.00 & 10 & 0.64 & 0.40 \\
0.002 & 1.00 & 5 & 0.83 & 0.58 \\
0.002 & 1.00 & 2 & 0.95 & 0.80 \\
0.003 & 0.33 & 10 & 0.70 & 0.46 \\
0.003 & 0.33 & 5 & 0.83 & 0.60 \\
0.003 & 0.33 & 2 & 0.93 & 0.74 \\
0.003 & 0.67 & 10 & 0.74 & 0.50 \\
0.003 & 0.67 & 5 & 0.88 & 0.66 \\
0.003 & 0.67 & 2 & 0.97 & 0.82 \\
0.003 & 1.00 & 10 & 0.76 & 0.52 \\
0.003 & 1.00 & 5 & 0.90 & 0.69 \\
0.003 & 1.00 & 2 & 0.98 & 0.85 \\
\hline
\end{tabular}

The significance level at which the test was conducted is given by a. 
Model 3.32 with Locale Effects $=0.50: 3$ sites, 1 treatment complement per site, and 2 treatments yielding a total of 6 ponds; 187,500 fish/pond; $1,125,000$ smolts.

\begin{tabular}{|c|c|c|c|c|}
\hline OCT Survival & Sampling Rate & School Size & Power for $\alpha=.10^{1}$ & Power for $\alpha=.05^{\top}$ \\
\hline 0.001 & 0.33 & 10 & 0.36 & 0.20 \\
\hline 0.001 & 0.33 & 5 & 0.47 & 0.28 \\
\hline 0.001 & 0.33 & 2 & 0.56 & 0.34 \\
\hline 0.001 & 0.67 & 10 & 0.39 & 0.22 \\
\hline 0.001 & 0.67 & 5 & 0.50 & 0.30 \\
\hline 0.001 & 0.67 & 2 & 0.63 & 0.39 \\
\hline 0.001 & 1.00 & 10 & 0.39 & 0.23 \\
\hline 0.001 & 1.00 & 5 & 0.53 & 0.32 \\
\hline 0.001 & 1.00 & 2 & 0.67 & 0.42 \\
\hline 0.002 & 0.33 & 10 & 0.49 & 0.29 \\
\hline 0.002 & 0.33 & 5 & 0.59 & 0.36 \\
\hline 0.002 & 0.33 & 2 & 0.66 & 0.41 \\
\hline 0.002 & 0.67 & 10 & 0.53 & 0.32 \\
\hline 0.002 & 0.67 & 5 & 0.62 & 0.39 \\
\hline 0.002 & 0.67 & 2 & 0.72 & 0.46 \\
\hline 0.002 & 1.00 & 10 & 0.54 & 0.33 \\
\hline 0.002 & 1.00 & 5 & 0.64 & 0.41 \\
\hline 0.002 & 1.00 & 2 & 0.74 & 0.48 \\
\hline 0.003 & 0.33 & 10 & 0.56 & 0.34 \\
\hline 0.003 & 0.33 & 5 & 0.64 & 0.41 \\
\hline 0.003 & 0.33 & 2 & 0.71 & 0.46 \\
\hline 0.003 & 0.67 & 10 & 0.59 & 0.37 \\
\hline 0.003 & 0.67 & 5 & 0.69 & 0.45 \\
\hline 0.003 & 0.67 & 2 & 0.75 & 0.50 \\
\hline 0.003 & 1.00 & 10 & 0.59 & 0.37 \\
\hline 0.003 & 1.00 & 5 & 0.69 & 0.45 \\
\hline 0.003 & 1.00 & 2 & 0.75 & 0.51 \\
\hline
\end{tabular}

The significance level at which the test was conducted is given by a. 
Model 3.32 with Locale Effects = 0.25: 3 sites, 1 treatment complement per site, and 2 treatments yielding a total of 6 ponds; 125,000 fish/pond; 750,000 smolts.

\begin{tabular}{lcccc}
\hline OCT Survival Sampling Rate & School Size & Power for $\boldsymbol{\alpha = . 1 0}$ & ${\text { Power for } \boldsymbol{\alpha}=\mathbf{. 0 5}^{\mathbf{1}}}^{\mathbf{T}}$ \\
\hline & & & & \\
0.001 & 0.33 & 10 & 0.32 & 0.17 \\
0.001 & 0.33 & 5 & 0.44 & 0.25 \\
$\mathbf{0 . 0 0 1}$ & 0.33 & 2 & 0.58 & 0.35 \\
0.001 & 0.67 & 10 & 0.35 & 0.20 \\
0.001 & 0.67 & 5 & 0.50 & 0.29 \\
0.001 & 0.67 & 2 & 0.74 & 0.49 \\
0.001 & 1.00 & 10 & 0.35 & 0.20 \\
0.001 & 1.00 & 5 & 0.52 & 0.31 \\
0.001 & 1.00 & 2 & 0.77 & $\mathbf{0 . 5 3}$ \\
0.002 & 0.33 & 10 & 0.48 & 0.27 \\
0.002 & 0.33 & 5 & 0.63 & 0.39 \\
0.002 & 0.33 & 2 & 0.78 & 0.53 \\
0.002 & 0.67 & 10 & 0.51 & 0.29 \\
0.002 & 0.67 & 5 & 0.70 & 0.46 \\
0.002 & 0.67 & 2 & 0.89 & 0.67 \\
0.002 & 1.00 & 10 & 0.52 & 0.31 \\
0.002 & 1.00 & 5 & 0.73 & 0.48 \\
0.002 & 1.00 & 2 & 0.92 & 0.72 \\
0.003 & 0.33 & 10 & 0.58 & 0.37 \\
0.003 & 0.33 & 5 & 0.73 & 0.49 \\
0.003 & 0.33 & 2 & 0.86 & 0.64 \\
0.003 & 0.67 & 10 & 0.62 & 0.40 \\
0.003 & 0.67 & 5 & 0.80 & 0.55 \\
0.003 & 0.67 & 2 & 0.94 & 0.75 \\
0.003 & 1.00 & 10 & 0.64 & 0.40 \\
0.003 & 1.00 & 5 & 0.83 & 0.59 \\
0.003 & 1.00 & 2 & 0.96 & 0.80 \\
\hline
\end{tabular}

The significance level at which the test was conducted is given by a. 
Model 3.32 with Locale Effects = 0.50: 3 sites, 1 treatment complement per site, and 2 treatments yielding a total of 6 ponds; 125,000 fish/pond; 750,000 smolts.

\begin{tabular}{lcccc}
\hline OCT Survival Sampling & Rate & School Size & Power for $\boldsymbol{\alpha = . \mathbf { 1 0 } ^ { \mathbf { 1 } }}$ & ${\text { Power for } \boldsymbol{\alpha}=\mathbf{. 0 5}^{\mathbf{1}}}$ \\
\hline & & & & \\
0.001 & 0.33 & 10 & 0.29 & 0.16 \\
0.001 & 0.33 & 5 & 0.40 & 0.23 \\
0.001 & 0.33 & 2 & 0.50 & 0.30 \\
0.001 & 0.67 & 10 & 0.32 & 0.17 \\
0.001 & 0.67 & 5 & 0.44 & 0.26 \\
0.001 & 0.67 & 2 & 0.57 & 0.34 \\
0.001 & 1.00 & 10 & 0.32 & 0.18 \\
0.001 & 1.00 & 5 & 0.46 & 0.27 \\
0.001 & 1.00 & 2 & 0.61 & 0.39 \\
0.002 & 0.33 & 10 & 0.42 & 0.24 \\
$\mathbf{0 . 0 0 2}$ & 0.33 & 5 & 0.52 & 0.31 \\
0.002 & 0.33 & 2 & 0.61 & 0.38 \\
0.002 & 0.67 & 10 & 0.46 & 0.27 \\
0.002 & 0.67 & 5 & 0.56 & 0.34 \\
0.002 & 0.67 & 2 & 0.67 & 0.42 \\
0.002 & 1.00 & 10 & 0.46 & 0.27 \\
0.002 & 1.00 & 5 & 0.58 & 0.36 \\
0.002 & 1.00 & 2 & 0.70 & 0.46 \\
0.003 & 0.33 & 10 & 0.50 & 0.29 \\
0.003 & 0.33 & 5 & 0.57 & 0.35 \\
0.003 & 0.33 & 2 & 0.67 & 0.43 \\
0.003 & 0.67 & 10 & 0.53 & 0.32 \\
0.003 & 0.67 & 5 & 0.63 & 0.40 \\
0.003 & 0.67 & 2 & 0.72 & 0.47 \\
0.003 & 1.00 & 10 & 0.52 & 0.32 \\
0.003 & 1.00 & 5 & 0.64 & 0.40 \\
0.003 & 1.00 & 2 & 0.74 & 0.49 \\
\hline
\end{tabular}

The significance level at which the test was conducted is given by $\boldsymbol{\alpha}$. 
Model 3.32 with Locale Effects $=0.25: 3$ sites, 1 treatment complement per site, and 2 treatments yielding a total of 6 ponds; 112,500 fish/pond; 675,000 smolts.

\begin{tabular}{ccccc}
\hline OCT Survival Sampling Rate & School Size & Power for $\boldsymbol{\alpha = . 1 0}$ & ${\text { Power for } \boldsymbol{\alpha}=\mathbf{. 0 5}^{\mathbf{T}}}^{\mathbf{T}}$ \\
\hline & & & & \\
0.001 & 0.33 & 10 & 0.30 & 0.16 \\
0.001 & 0.33 & 5 & 0.41 & 0.24 \\
0.001 & 0.33 & 2 & 0.56 & 0.34 \\
0.001 & 0.67 & 10 & 0.33 & 0.19 \\
0.001 & 0.67 & 5 & 0.47 & 0.28 \\
0.001 & 0.67 & 2 & 0.70 & 0.45 \\
0.001 & 1.00 & 10 & 0.34 & 0.19 \\
0.001 & 1.00 & 5 & 0.50 & 0.30 \\
0.001 & 1.00 & 2 & 0.75 & 0.51 \\
0.002 & 0.33 & 10 & 0.45 & 0.27 \\
0.002 & 0.33 & 5 & 0.60 & 0.37 \\
0.002 & 0.33 & 2 & 0.75 & 0.51 \\
0.002 & 0.67 & 10 & 0.49 & 0.29 \\
0.002 & 0.67 & 5 & 0.66 & 0.42 \\
0.002 & 0.67 & 2 & 0.87 & 0.64 \\
0.002 & 1.00 & 10 & 0.50 & 0.30 \\
0.002 & 1.00 & 5 & 0.70 & 0.44 \\
0.002 & 1.00 & 2 & 0.90 & 0.69 \\
0.003 & 0.33 & 10 & 0.56 & 0.34 \\
0.003 & 0.33 & 5 & 0.71 & 0.47 \\
0.003 & 0.33 & 2 & 0.85 & 0.61 \\
0.003 & 0.67 & 10 & 0.59 & 0.38 \\
0.003 & 0.67 & 5 & 0.77 & 0.53 \\
0.003 & 0.67 & 2 & 0.93 & 0.73 \\
0.003 & 1.00 & 10 & 0.61 & 0.39 \\
0.003 & 1.00 & 5 & 0.80 & 0.56 \\
0.003 & 1.00 & 2 & 0.94 & 0.77 \\
\hline
\end{tabular}

The significance level at which the test was conducted is given by $\dot{\alpha}$. 
Model 3.32 with Locale Effects $=0.50: 3$ sites, 1 treatment complement per site, and 2 treatments yielding a total of 6 ponds; 112,500 fish/pond; 675,000 smolts.

\begin{tabular}{|c|c|c|c|c|}
\hline OCT Survival & Sampling Rate & School Size & Power for $a=.10$ & Power for $\alpha=.05^{1}$ \\
\hline 0.001 & 0.33 & 10 & 0.28 & 0.15 \\
\hline 0.001 & 0.33 & 5 & 0.38 & 0.22 \\
\hline 0.001 & 0.33 & 2 & 0.47 & 0.27 \\
\hline 0.001 & 0.67 & 10 & 0.30 & 0.16 \\
\hline 0.001 & 0.67 & 5 & 0.41 & 0.24 \\
\hline 0.001 & 0.67 & 2 & 0.57 & 0.34 \\
\hline 0.001 & 1.00 & 10 & 0.31 & 0.17 \\
\hline 0.001 & 1.00 & 5 & 0.43 & 0.25 \\
\hline 0.001 & 1.00 & 2 & 0.60 & 0.38 \\
\hline 0.002 & 0.33 & 10 & 0.39 & 0.22 \\
\hline 0.002 & 0.33 & 5 & 0.50 & 0.29 \\
\hline 0.002 & 0.33 & 2 & 0.59 & 0.36 \\
\hline 0.002 & 0.67 & 10 & 0.43 & 0.25 \\
\hline 0.002 & 0.67 & 5 & 0.56 & 0.35 \\
\hline 0.002 & 0.67 & 2 & 0.65 & 0.41 \\
\hline 0.002 & 1.00 & 10 & 0.43 & 0.25 \\
\hline 0.002 & 1.00 & 5 & 0.57 & 0.35 \\
\hline $\begin{array}{lllll}0 & . & 0 & 0 & 2\end{array}$ & 1.00 & 2 & 0.69 & 0.44 \\
\hline 0.003 & 0.33 & 10 & 0.48 & 0.28 \\
\hline 0.003 & 0.33 & 5 & 0.56 & 0.34 \\
\hline 0.003 & 0.33 & 2 & 0.66 & 0.42 \\
\hline 0.003 & 0.67 & 10 & 0.50 & 0.29 \\
\hline 0.003 & 0.67 & 5 & 0.61 & 0.38 \\
\hline 0.003 & 0.67 & 2 & 0.71 & 0.46 \\
\hline 0.003 & 1.00 & 10 & 0.51 & 0.30 \\
\hline 0.003 & 1.00 & 5 & 0.62 & 0.40 \\
\hline 0.003 & 1.00 & 2 & 0.73 & 0.49 \\
\hline
\end{tabular}

The significance level at which the test was conducted is given by a. 
Model 3.32 with Locale Effects $=0.25: 3$ sites, 1 treatment complement per site, and 2 treatments yielding a total of 6 ponds; 83,333 fish/pond; 500,000 smolts.

\begin{tabular}{|c|c|c|c|c|}
\hline OCT Survival & Sampling Rate & School Size & Power for $\alpha=.10^{T}$ & Power for $\alpha=.05^{1}$ \\
\hline 0.001 & 0.33 & 10 & 0.26 & 0.14 \\
\hline 0.001 & 0.33 & 5 & 0.34 & 0.19 \\
\hline 0.001 & 0.33 & 2 & 0.48 & 0.28 \\
\hline 0.001 & 0.67 & 10 & 0.28 & 0.15 \\
\hline 0.001 & 0.67 & 5 & 0.40 & 0.23 \\
\hline 0.001 & 0.67 & 2 & 0.60 & 0.39 \\
\hline 0.001 & 1.00 & 10 & 0.28 & 0.15 \\
\hline 0.001 & 1.00 & 5 & 0.42 & 0.24 \\
\hline 0.001 & 1.00 & 2 & 0.67 & 0.43 \\
\hline 0.002 & 0.33 & 10 & 0.37 & 0.21 \\
\hline 0.002 & 0.33 & 5 & 0.52 & 0.30 \\
\hline 0.002 & 0.33 & 2 & 0.67 & 0.44 \\
\hline 0.002 & 0.67 & 10 & 0.40 & 0.23 \\
\hline 0.002 & 0.67 & 5 & 0.58 & 0.35 \\
\hline 0.002 & 0.67 & 2 & 0.80 & 0.56 \\
\hline 0.002 & 1.00 & 10 & 0.42 & 0.25 \\
\hline 0.002 & 1.00 & 5 & 0.61 & 0.37 \\
\hline $\begin{array}{lllll}0 & . & 0 & 0 & 2\end{array}$ & 1.00 & 2 & 0.85 & 0.61 \\
\hline 0.003 & 0.33 & 10 & 0.48 & 0.28 \\
\hline 0.003 & 0.33 & 5 & 0.62 & 0.40 \\
\hline 0.003 & 0.33 & 2 & 0.78 & 0.54 \\
\hline 0.003 & 0.67 & 10 & 0.50 & 0.30 \\
\hline 0.003 & 0.67 & 5 & 0.69 & 0.45 \\
\hline 0.003 & 0.67 & 2 & 0.88 & 0.66 \\
\hline 0.003 & 1.00 & 10 & 0.54 & 0.33 \\
\hline 0.003 & 1.00 & 5 & 0.72 & 0.49 \\
\hline 0.003 & 1.00 & 2 & 0.91 & 0.71 \\
\hline
\end{tabular}

The significance level at which the test was conducted is given by $\boldsymbol{\alpha}$. 
Model 3.32 with Locale Effects $=0.50: 3$ sites, 1 treatment complement per site, and 2 treatments yielding a total of 6 ponds; 83,333 fish/pond; 500,000 smolts.

\begin{tabular}{|c|c|c|c|c|}
\hline OCT Survival & Sampling Rate & School Size & Power for $\alpha=.10^{1}$ & Power for $\alpha=.05^{1}$ \\
\hline 0.001 & 0.33 & 10 & 0.24 & 0.13 \\
\hline 0.001 & 0.33 & 5 & 0.32 & 0.17 \\
\hline 0.001 & 0.33 & 2 & 0.41 & 0.24 \\
\hline 0.001 & 0.67 & 10 & 0.27 & 0.15 \\
\hline 0.001 & 0.67 & 5 & 0.37 & 0.20 \\
\hline 0.001 & 0.67 & 2 & 0.51 & 0.29 \\
\hline 0.001 & 1.00 & 10 & 0.26 & 0.14 \\
\hline 0.001 & 1.00 & 5 & 0.38 & 0.22 \\
\hline 0.001 & 1.00 & 2 & 0.54 & 0.34 \\
\hline 0.002 & 0.33 & 10 & 0.35 & 0.19 \\
\hline 0.002 & 0.33 & 5 & 0.44 & 0.26 \\
\hline 0.002 & 0.33 & 2 & 0.54 & 0.33 \\
\hline 0.002 & 0.67 & 10 & 0.37 & 0.21 \\
\hline 0.002 & 0.67 & 5 & 0.49 & 0.29 \\
\hline 0.002 & 0.67 & 2 & 0.62 & 0.38 \\
\hline 0.002 & 1.00 & 10 & 0.38 & 0.21 \\
\hline 0.002 & 1.00 & 5 & 0.50 & 0.29 \\
\hline 0.002 & 1.00 & 2 & 0.65 & 0.41 \\
\hline 0.003 & 0.33 & 10 & 0.42 & 0.24 \\
\hline 0.003 & 0.33 & 5 & 0.52 & 0.30 \\
\hline 0.003 & 0.33 & 2 & 0.61 & 0.38 \\
\hline 0.003 & 0.67 & 10 & 0.44 & 0.25 \\
\hline 0.003 & 0.67 & 5 & 0.57 & 0.35 \\
\hline 0.003 & 0.67 & 2 & 0.68 & 0.44 \\
\hline 0.003 & 1.00 & 10 & 0.46 & 0.26 \\
\hline 0.003 & 1.00 & 5 & 0.58 & 0.36 \\
\hline 0.003 & 1.00 & 2 & 0.70 & 0.46 \\
\hline
\end{tabular}

The significance level at which the test was conducted is given by $\mathbf{a}$. 